\title{
CUTTING FORCE MODELING AND OPTIMIZATION IN 3D PLANE SURFACE MACHINING
}

\author{
by \\ Ning Su \\ Faculty of Engineering Science \\ Department of Mechanical \& Materials Engineering
}

\begin{abstract}
Submitted in partial fulfilment
of the requirements for the degree of

Master of Engineering Science
\end{abstract}

Faculty of Graduate Studies

The University of Western Ontario

London, Ontario

April, 1999

(C) Ning Su 1999 
National Library of Canada

Acquisitions and Bibliographic Services

395 Welfington Street Ottawa ON KIA ON4 Canada
Bibliothèque nationale du Canada

Acquisitions et services bibliographiques

395. rue Wellington Ottawa ON K1A ONA Canada
The author has granted a nonexclusive licence allowing the National Library of Canada to reproduce, loan, distribute or sell copies of this thesis in microform, paper or electronic formats.

The author retains ownership of the copyright in this thesis. Neither the thesis nor substantial extracts from it may be printed or otherwise reproduced without the author's permission.
L'auteur a accordé une licence non exclusive permettant à la Bibliothèque nationale du Canada de reproduire, prêter, distribuer ou vendre des copies de cette thèse sous la forme de microfiche/film, de reproduction sur papier ou sur format électronique.

L'auteur conserve la propriété du droit d'auteur qui protège cette thèse. $\mathrm{Ni}$ la thèse ni des extraits substantiels de celle-ci ne doivent être imprimés ou autrement reproduits sans son autorisation. 


\begin{abstract}
The prediction and optimization of cutting forces in the finish machining of $3 \mathrm{D}$ plane surface using ball-end milling are presented in this thesis. The cutting force model is developed based on the mechanistic modeling approach. The objective is to accurately model the cutting forces for non-horizontal and cross-feed cutter movements in 3D finishing ball-end milling. Main features of the model include: (I) a robust cut geometry identification method to establish the complicated engaged area on the cutter; (2) a generalized algorithm to determine the undeformed chip thickness for each engaged cutting edge element; and (3) a comprehensive empirical chip-force relationship to characterize non-horizontal cutting mechanics. Experimental results have shown that the present model gives excellent predictions of cutting forces in 3D ball-end milling.
\end{abstract}

Optimization of the cutting forces is used to determine both the tool path and the maximum feedrate in 3D plane surface finish machining. An integrated process planning method based on cutting force optimization for the concurrent optimization of tool path and feedrate for the finish machining of $3 \mathrm{D}$ plane surfaces using ball-end milling is presented. This method is based on the evaluation of machining errors caused by cutting forces and cutting system deflections. Optimum tool path and feedrate are established when the machining process is carried out at the highest possible efficiency and the resulting machining errors are maintained within the specified tolerance limits. The integrated optimization method determines the optimum cutter feed direction that corresponds to the optimum tool path and feedrate. Simulation results have indicated that the optimum cutter feed direction is often not unique but falls within an optimum range in 3D plane surface finishing machining. 


\section{ACKNOWLEDGEMENTS}

I would like to take this opportunity to thank my supervisor, Professor Hsi-Yung Feng, for his valuable guidance, encouragement, and assistance.

My sincere appreciation also goes to my fellow graduate students who provided me with valuable assistance and suggestions.

The financial support provided by the Natural Sciences and Engineering Research Council of Canada is gratefully acknowledged.

Last but not the least, I would like to thank my parents, Changsheng Su and Lianqing Qin, for their endless support and kind encouragement throughout my academic career. 


\section{TABLE OF CONTENTS}

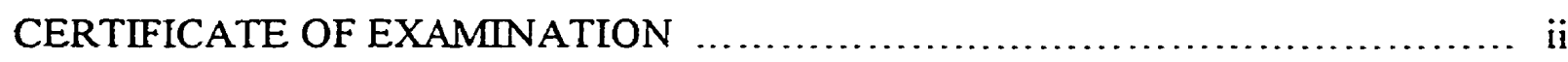

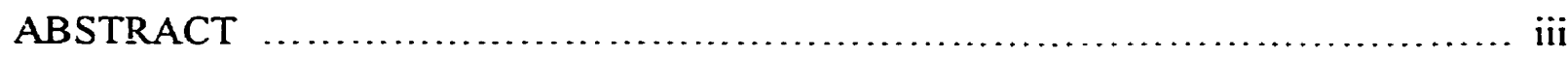

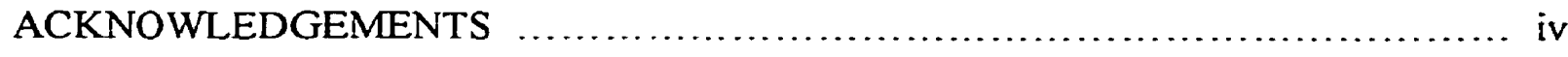

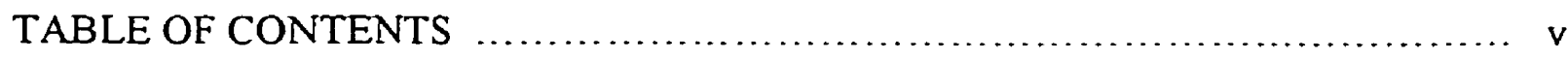

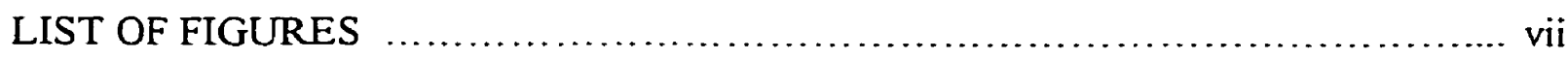

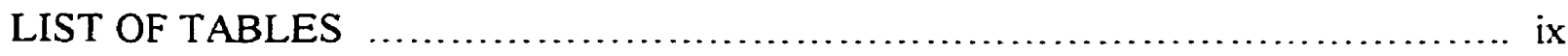

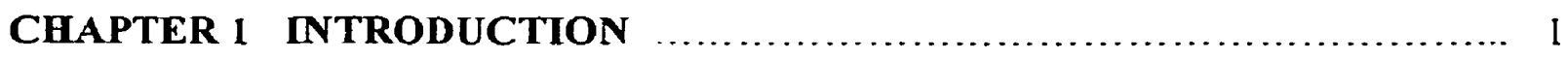

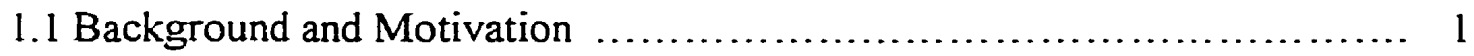

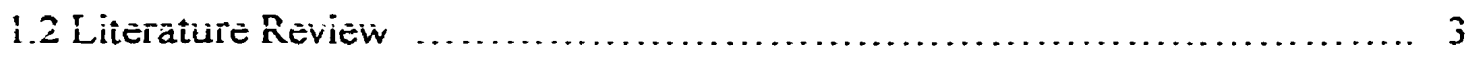

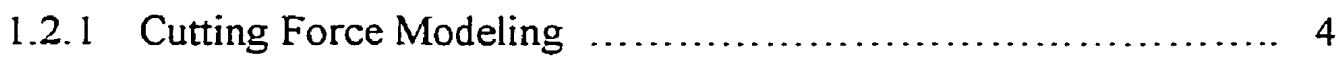

1.2.2 Process Planning for 3D Surface Machining …............. 6

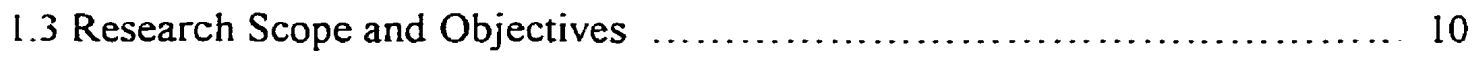

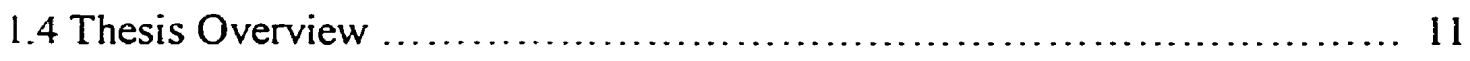

\section{CHAPTER 2 CUTTING FORCE MODELING FOR 3D BALL-END}

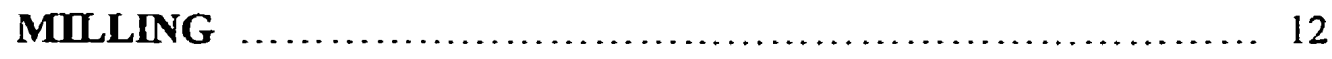

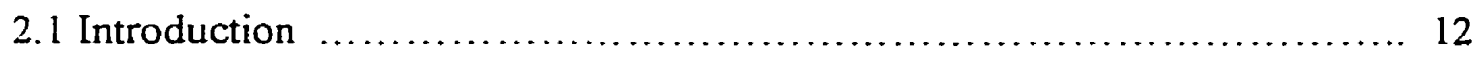

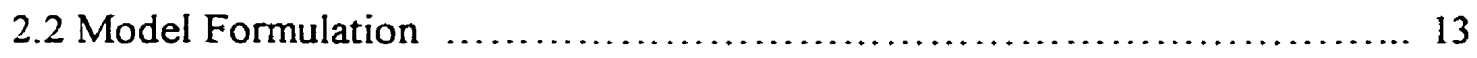

2.2.1 Cut Geometry .......................................... 16

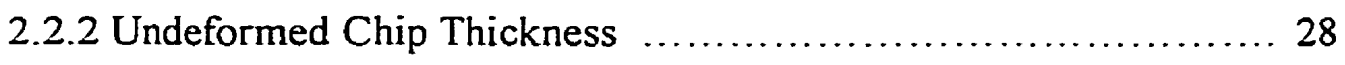

2.2.3 Empirical Chip-Force Relationships …................... 35 
2.3 Determination of Empirical Model Parameters ........................... 39

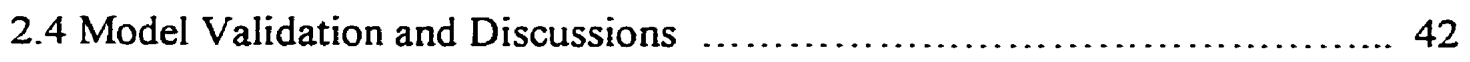

\section{CHAPTER 3 INTEGRATED PROCESS PLANNING BASED ON}

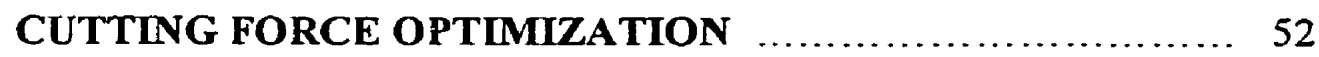

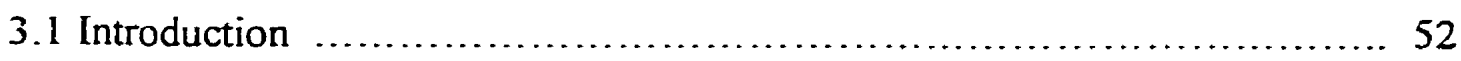

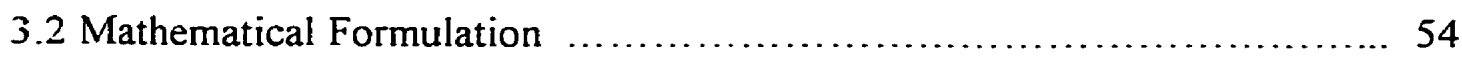

3.2.1 Feed Direction ............................................ 54

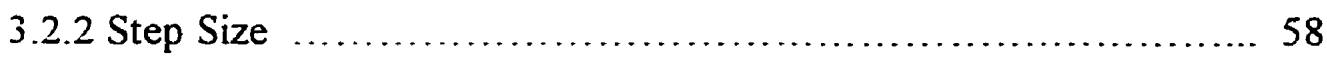

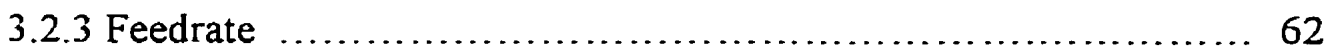

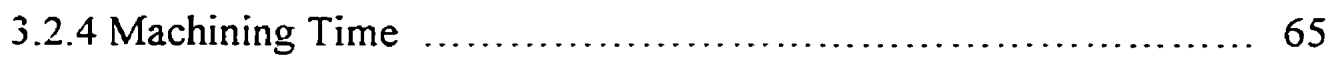

3.3 Simulation Results and Discussions ................................. 68

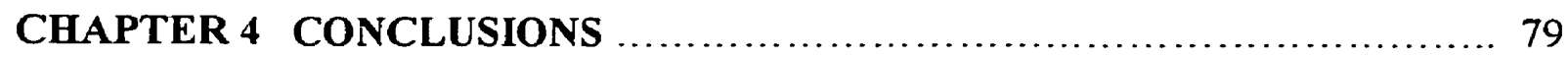

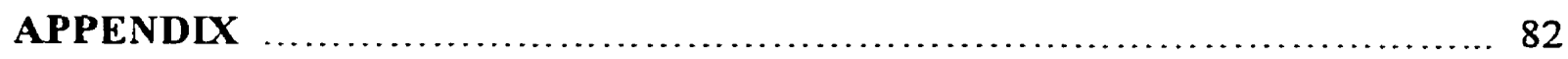

A. Determination of Cutter Contact Point $\mathrm{P}_{0}\left(X_{0}, Y_{0}, Z_{0}\right) \ldots \ldots \ldots \ldots \ldots \ldots \ldots . \ldots 2$

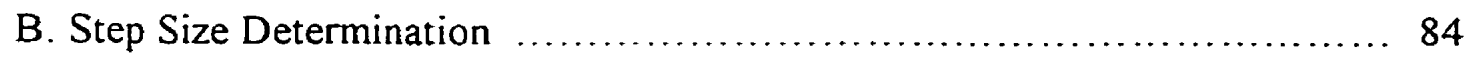

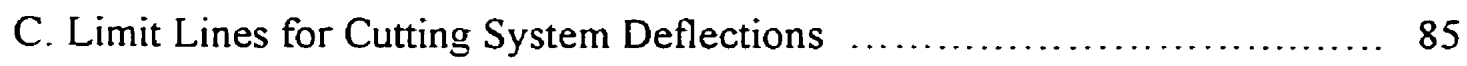

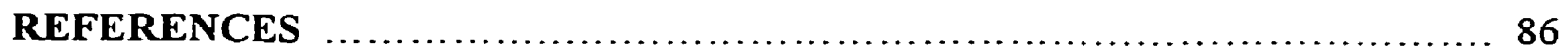

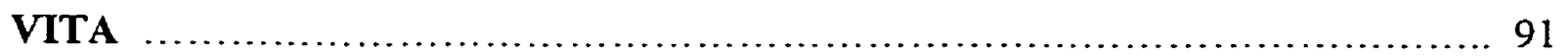




\section{LIST OF FIGURES}

2.1 A flow chart showing the cutting force calculation procedure

2.2 The Cartesian coordinate system used for the ball-end mill 17

2.3 Definitions of $\psi$ and $\phi$ 18

2.4 Sectional views of two special cases of cut geometry in $3 \mathrm{D}$ ball-end milling $\ldots \ldots 21$

2.5 Two forms of milling: (a) up milling and (b) down milling $\ldots \ldots \ldots \ldots \ldots \ldots \ldots . \ldots . \ldots 22$

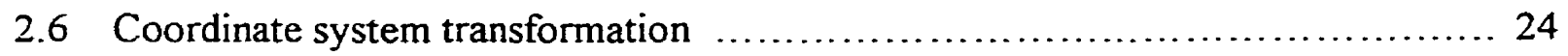

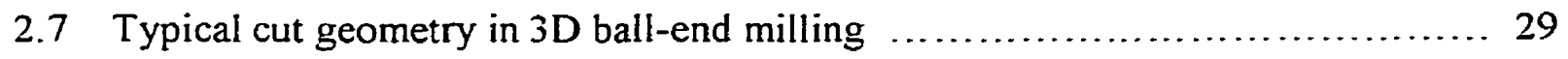

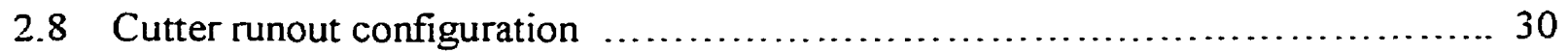

2.9 Undeformed chip thickness calculation geometry for 3D ball-end milling ....... 32

2.10 Cutting forces for $\psi=0^{\circ}, \phi=-15^{\circ}, s=-3.175 \mathrm{~mm}, f=0.0381 \mathrm{~mm} /$ tooth, and $d=6.35 \mathrm{~mm}$

2. Il The effect of cutter runout for $\psi=0^{\circ}, \phi=-15^{\circ}, s=-3.175 \mathrm{~mm}$, $f=0.0381 \mathrm{~mm} /$ tooth, and $d=6.35 \mathrm{~mm}$ 46

2.12 Cutting forces for $\psi=30^{\circ}, \phi=0^{\circ}, s=-3.175 \mathrm{~mm}, f=0.0381 \mathrm{~mm} /$ tooth, and $d=6.286 \mathrm{~mm}$

2.13 Cutting forces for $\psi=-30^{\circ}, \phi=15^{\circ}, s=-3.175 \mathrm{~mm}, f=0.0381 \mathrm{~mm} /$ tooth, and $d=6.286 \mathrm{~mm}$ 49

2.14 Cutting forces for $\psi=30^{\circ}, \phi=-15^{\circ}, s=-3.175 \mathrm{~mm}, f=0.0381 \mathrm{~mm} /$ tooth, and $d=6.286 \mathrm{~mm}$ 50

3.1 Machining time calculation procedure 55

3.2 Part coordinate system and cutter coordinate system 57 


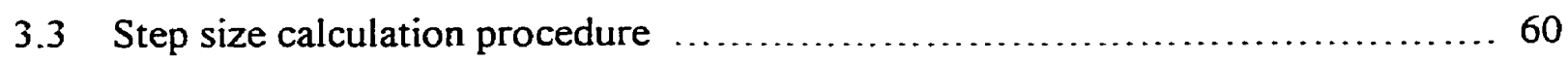

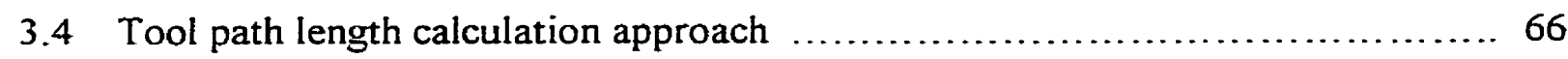

3.5 Variation of (a) step size and (b) total tool path length with $\alpha \ldots \ldots \ldots \ldots \ldots \ldots . .70$

3.6 Variation of (a) feed per tooth and (b) machining error with $\alpha \ldots \ldots \ldots \ldots \ldots . .72$

3.7 Trajectories of cutting system deflections at different $\alpha \ldots \ldots \ldots \ldots \ldots \ldots \ldots \ldots \ldots$

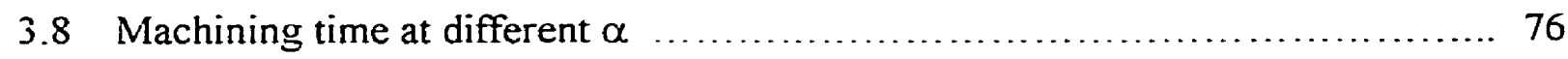

3.9 Machining time of plane surfaces at different inclinations $\ldots \ldots \ldots \ldots \ldots \ldots \ldots .78$

A. 1 Determination of cutter contact point in the cutter coordinate system $\ldots \ldots \ldots .82$

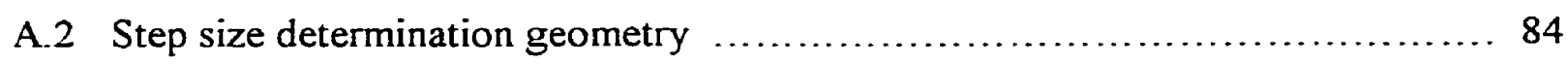




\section{LIST OF TABLES}

2.1 Values of the coefficients formulated in Eq. (2.31) for the two no-horizontal slot cuts

2.2 Detailed cutting conditions for model verification test cuts 43

2.3 Comparison of average prediction errors $5 I$ 


\section{CHAPTER 1}

\section{INTRODUCTION}

\subsection{Background and Motivation}

In modern manufacturing, products with 3D surfaces such as dies and molds in the automotive industry, and compressor and turbine blades in the aerospace industry, are widely used. These complex-shaped premium products are typically manufactured by Computer Numerical Control (CNC) machines using ball-end mills. Ball-end mills are used because they are easy to position with respect to the part surfaces and generate simple and short Numerical Control (NC) programs. Traditionally the majority of these machining operations have been carried out with experience-based approaches. The optimum cutting conditions such as feedrate, step size between adjacent tool paths, and depth of cut are determined after extensive shop floor tests. Very often, overly conservative cutting conditions are selected to ensure high quality of the machined product. This limits the process efficiency and leads to higher product cost. As more emphasis is placed on the quality of the products and the productivity of the machining process, it is necessary for the process planner to select the optimum cutting conditions on a rational and scientific base so as to reduce or eliminate the effort involved in the traditional trial and error method. As a result, mathematical models that can accurately characterize the performance of the particular machining processes need to be developed.

The cutting force acting on the cutter is one of the most important physical output variables that encapsulate important cutting action information. The characterisation of 
cutting forces is important for research and development into the modeling, optimization, monitoring, and control of milling processes. By virtue of their ease of measurement and their physical relevance, cutting forces often provide a key element to the understanding of the machining process. In 3D surface machining with ball-end mills cutting forces are modelled since they directly affect the product quality and the process efficiency. It is important that the cutting forces be maintained close to the optimum values during the machining processes. Excessive cutting forces cause large cutting system deflections and result in low product quality, while small cutting forces often indicate low machining efficiency. Therefore, reliable quantitative predictions of cutting forces and cutting force optimization in machining operations are essential for selecting optimal machining conditions and determining machined part geometrical errors.

Process efficiency and product quality are essential to the competitiveness of manufacturing industries. To make products within specified tolerance with the least time and the lowest cost is the ultimate goal of modern manufacturing. In the machining industry, high quality and cost effective machining can be achieved by the optimization of the machining process. Traditional experience-based process planning methods often generate less than optimal machining plan and tend to be conservative in the selection of cutting conditions. The conservative cutting conditions represent low machining efficiency and do not guarantee quality in machining parts with complex geometry. Outof-tolerance machined products are not uncommon in practice. As a result, it is very important to develop a process optimization method that is based on scientific knowledge of machining and is able to generate optimized plans to achieve highest machining efficiency and to ensure product quality. 
Determination of optimum tool path and feedrate has been the critical task in process planning for 3D surface machining. Current practice determines tool path and feedrate individually. Optimization of these two variables is accomplished sequentially and independently. This sequential approach limits further optimization of the machining process and causes the product to be made at a higher cost. Tool path and feedrate are in fact closely related with each other. Changes in either parameter result in changes of cutting forces. Therefore, optimization of cutting forces results in optimization of these two variables. With the developed cutting force model, a true integrated process planning method which is based on cutting force optimization for the concurrent determination of tool path and feedrate in 3D plane surface finishing machining with ball-end mills is presented in this work. Cutter feed direction and step size define the milling tool path for 3D surface machining. Both of these two parameters are optimized simultaneously with feedrate based on the calculation of cutting forces and the resulting machining errors.

\subsection{Literature Review}

Cutting force modeling and optimization in end milling have been receiving much attention for the last two decades. Lots of research work has been done on modeling of the milling processes. Various process models have been developed by different researchers from different points of view. Most of these models dealt with cutting forces in machining. Much work has also been carried out on developing practical process planning methods for 3D surface machining. The following sections give a review of the work done by other researchers in the past two decades. 


\subsubsection{Cutting Force Modeling}

Much work has been done in the past related to the modeling of the end milling processes. Comprehensive reviews on cutting force modeling for the milling processes have been presented (Smith and Tlusty, 1991; Ehmann et al., 1997). Cutting force modeling for flat-end milling has been the focus of many studies. In a series of work by Kline, DeVor et al. (DeVor et al., 1980; Kline et al., 1982a, b; Kline and DeVor, 1983), a mechanistic cutting force model for the flat-end milling process was developed and used to study problems associated with cutter runout, surface error generation, and machining process planning. Yellowley (1985) developed a force model which separated the cutting forces on the cutting edges into rake and flank face contributions. The cutting forces in these models were calculated with an assumption of a completely rigid machining system in the flat-end milling processes. The associated cutting system deflections had no feedback effect on the calculation of the cutting forces.

The first documented work which considered the complex chip geometry as a result of the cutting system deflection feedback was done by Sutherland and DeVor (1986) for the flat-end milling systems. Bayoumi et al. (1994a, b) presented and validated an analytic mechanistic cutting force model for milling operations. Cutting forces are calculated by integrating the pressure and the friction loads acting on the cutter surfaces represented by ruled surfaces. Budak et al. (1996) modelled the cutting forces using a unified cutting mechanics approach which relied on an experimentally determined orthogonal cutting data base. This method eliminated the need for the experimental calibration of each milling cutter geometry required in the mechanistic approach of cutting force prediction. Zheng et al. (1998) developed an explicit analytical cutting force 
model for flat-end milling in the cutter angle domain based on finite-series representations. The model formulation in this work led to a solution of force as an algebraic function of tool geometry, machining parameters, cutting configuration, and workpiece material properties. Melkote and Endres (1998) studied the importance of size effects on milling processes and presented a detailed mechanistic analysis that included size effects for slot milling operations. Zheng and Liang (1997) identified cutter axis tilt in flat end milling process via cutting force analysis. All the models mentioned above deal with cutting force prediction in flat-end milling processes. Cut geometry in flat-end mill is relatively simple and remains constant in the machining process.

Due to the complexity of the ball-end milling process, models for the prediction of cutting forces in ball-end milling were developed only recently. Yang and Park (190!) and Sim and Yang (1993) analyzed the cutting geometry of a special ball-end mill with plane rake faces, and, with the orthogonal machining data obtained from end turning tests, the cutting forces were predicted for rigid and flexible cutters. Feng and Menq (1994a, b) successfully employed the mechanistic approach to model the complicated ball-end milling process. A rigid system model was developed in their work which is applicable to rigid ball-end milling cutters with small length-to-diameter ratios. Common ball-end milling cutters are, however, flexible and characterised with large length-todiameter ratios. A flexible system model was developed to consider this important property of the cutting system (Feng and Menq, 1996). Yucesan and Altintas (1996) analyzed the ball-shaped helical geometry of the cutting edges on the ball-end mill. The cutting forces were calculated based on the pressure and the friction load on the rake and the clearance surfaces of the cutting edges. The pressure and friction coefficients are 
identified from a set of slot ball end milling tests at different feeds and axial depth of cuts, and were used to predict the cutting forces for various cutting conditions. More recently, Abrari and Elbestawi (1997) presented and verified a closed form formulation of cutting forces for both ball and flat end milling. The cutting forces were calculated using the linear combination of a set of force basis functions.

It should be noted that most of the studies described above dealt with relatively simple cut geometry and horizontal cutter movements. Though some claimed to be able to model cutting forces for $3 \mathrm{D}$ end milling, no experimental validation was given. Predicted cutting forces were only verified with simple horizontal cuts. The present work is aimed at modeling the cutting forces for $3 \mathrm{D}$ ball-end milling. The previous work by Feng and Menq (1906) will be extended to consider the complexities caused by nonhorizontal and cross-feed movements of the ball-end mill in the finishing machining of 3D surfaces.

\subsubsection{Process Planning for 3D Surface Machining}

Many previous studies examined the geometric aspects of milling tool path generation in the machining of 3D surfaces. Since the late 1980's there has been an enormous amount of work published on tool path generation from different points of view. Much work was focused on part geometry-related tool path generation in which the major concerns were the minimization of total tool path length and step size maximization. Dragomatz and Mann (1997) gave a review on the development of NC milling tool path generation since 1980s. Suh and Lee (1990) and Hwang (1992) presented a method to determine the tool paths by calculating, at each path, the smallest 
tool path interval (step size) and using it as a constant offset for the next tool path. The reason for their selecting the smallest interval as the offset distance is that this makes it easy to define the constant isoparametric offset as the next tool path, thereby satisfying the surface accuracy. However, one serious problem in this method is the un-controlled scallop height left on the part surface, which causes either surface roughness (if too large) or inefficient machining (if too small). A tool path planning method that kept the scallop height constant was presented by Suresh and Yang (1994). Their work led to a reduction of the cutter location (CL) data. Huang and Oliver (1992) described a non-constant parameter approach in tool path generation to solve the problem of eliminating unnecessary cutter movement and gouging in sculptured surface machining. In their approach step size is no longer constant and adjusted with the machined surface. A computationally intensive approach to determine an accurate true machining error was used in their work. Lin and Koren (1996) developed a method based on non-constant offset of the previous tool path to guarantee the cutter moving in an unmachined area of the part surface and without redundant machining. In this method step size varied according to the cutter radius and the local surface curvatures, and the scallop height was maintained constant on the machined surface. To avoid excessive scallop height left on sloped surfaces when constant step size is used, Marshall and Griffiths (1994) introduced a tool path generation method in which extra milling occurs wherever it is needed; i.e., when the surface is sloped. By this way the tool path and the resulting machining time are dramatically reduced. Veeramani and Gau (1998) divided the machined surface into small patches and minimized the machining time by arranging the sequence of their machining order. 
Besides total tool path length and step size, tool interference is another important topic in tool path generation. Hwang (1992) developed an interference-free tool-path generation method for 3D surface machining with ball-end mills. This work was later extended to the machining of sculptured surface using flat and filleted endmills by Hwang and Chang (1998).

Many process planning methods that involve tool path planning and feedrate optimization have also been developed. Dong et al. (1993) focused their work on tool path and cutting condition optimization in sculptured surface rough machining. The tool path is optimized by using a contour map cutting method to avoid an unnecessary cut. The cutting condition parameters are optimized by taking into account both geometryrelated parameters and process parameters. Park et al. (1093) dealt with cutting condition optimization in the machining of 3D sculptured surface by studying the cut geometry of the cutter. Boogert et al. (1996) considered the effect of cutting forces in their planning of $2 \frac{1}{2 D}$ tool paths for prismatic parts. Even though cutting forces are taken into account in their method, the method is mainly used to determine the cutting conditions for a preselected tool path. The geometrical tool path calculation and cutting condition determination are separated.

It should be noted that the optimization of tool path and cutting conditions in the above studies was carried out independently and based on a sequential approach. It is assumed that the optimal feed direction is already known or selected with experiences. The optimal cutting conditions are then determined based on this preset feed direction. Process planning in these methods is a sequential procedure. In addition, because the cutting system is assumed to be completely rigid, cutting system deflection induced by 
cutting forces is ignored. The geometry of the machined part is considered as the determining factor in tool path generation. In fact, cutting forces should also be considered since they cause inevitable cutting system deflection that often results in significant machining errors.

A recent work by Lim and Menq (1997) described a first attempt toward the development of an integrated machining process planning method. This method determined cutter feed direction and feedrate simultaneously at discrete points on a part surface. The step size of adjacent tool paths at these locations is assumed known and independent of the optimization process. This preset step size resulted in varying scallop height for different cutter feed direction in $3 \mathrm{D}$ surface machining. As a result, the milling tool path is only partially optimized. The advantage of constant scallop height machining to reduce redundancy and maximize efficiency wâs not considered.

For a particular $3 \mathrm{D}$ surface, the plane orientation relative to the cutter changes at different cutter feed directions. This leads to different tool paths and cutting forces. Among these different feed directions, only those that give maximum feedrate and minimum machining errors are chosen as the practical machining directions. Cutting forces at these directions are optimized. The complicated interactions among the feed direction, the feedrate, the step size, the cutting forces, the resulting tool paths and machining errors make it difficult to include all these factors in process planning. To incorporate all these factors for optimal process planning is the main purpose of this work. The true integrated process optimization is achieved when the machining process is carried out at the highest possible feedrate and efficiency and the resulting machining 
errors caused by cutting forces and cutting system deflections are maintained within the specified tolerance limits.

\subsection{Research Scope and Objectives}

In the machining of a 3D surface, after the roughing cut, a semi-finish and finish cut are required to bring the accuracy of the machined surface within stringent tolerance. Since the surface dimensional errors are mainily caused by the machining inaccuracies associated with the finish pass, the present study is focused on the finishing milling process analyses. In practice, the tool paths in machining 3D surfaces are approximated by a series of line segments. It is then reasonable to approximate the $3 \mathrm{D}$ surface by a series 3D plane surface patches. The present work is focused on cutting force prediction and optimization for 3D plane surface machining. It represents an important step toward the true optimization of the finish machining of sculptured surface using ball-end mills.

This thesis work consists of two main parts: cutting force modeling and process planning based on cutting force optimization for 3D plane surface finish machining. These two parts are closely related. The objective of this work in the first part is to develop an accurate and practical cutting force model for ball-end milling in the finishing machining of 3D plane surfaces. This requires the model to be able to characterize the cutting mechanics of non-horizontal and cross-feed cutter movements that are typical in 3D ball-end milling. The objective of the second part is to develop an integrated process planning method based on the developed ball-end milling cutting force model for the three-axis finishing machining of $3 \mathrm{D}$ plane surfaces. The integrated process planning process is achieved by optimizing cutting forces. 


\subsection{Thesis Overview}

This thesis is focused on cutting force modeling and process planning based on cutting force optimization in 3D plane surface finishing machining with ball-end mills. Four chapters are written to document this work.

Chapter I provides the background information and review of milling process modeling and process planning in 3D surface machining.

Chapter 2 presents an improved mechanistic cutting force model for the ball-end milling process. A new cut geometry determination algorithm based on boundary limits has been developed to identify engaged cutting edge elements. A generalized method is used to establish the undeformed chip thickness for each engaged cutting element by considering the radial difference between tooth trajectories. An improved empirical chipforce relationship is developed to deal with non-horizontal cutter movements. The developed model is validated by experimental results.

An integrated method for process planning based on cutting force optimization for the finishing machining of 3D plane surfaces is presented in Chapter 3 . It considers both the part geometry and the cutting forces in process planning. It facilitates the determination of the most economical process plan for machining product with high quality. Simulation results are provided to demonstrate the feasibility of this new approach.

Concluding remarks and future work recommendations are described in Chapter 4. 


\section{CHAPTER 2}

\section{CUTTING FORCE MODELING FOR 3D BALL-END \\ MILLING}

\subsection{Introduction}

Cutting forces are very important to the determination of machining errors in the ball-end milling process. Machining errors of ball-end milled surfaces can be attributed to a number of sources such as cutting system deflections, geometric errors of the machine tools, thermal effects of the machining processes, vibration, etc. Among them, the cutting system deflection caused by cutting forces is identified as the most significant in $3 D$ finishing ball-end milling. The cutting force, that is one of the output variables, is directly influenced by any change taking place in machining. In ball-end milling, cutting forces are generated by complicated interactions between the workpiece and the helical cutting edges. The variables that affect cutting forces include feedrate, radial and axial depth of cut, cutting speed, workpiece and cutting tool material, and cutting tool geometry.

The basic strategy to develop the present cutting force model is to partition the ball-end mill into a series of small disc-like elements along the cutter axis. The undeformed chip geometry, which is central to the prediction of cutting forces, is established by identifying the cutting edge elements actively engaged in cutting for a given cutter orientation and determining the undeformed chip thickness for each engaged element. The elemental cutting force components for these elements are calculated from the empirical chip-force relationships for the particular workpiece/cutter combination. 
The instantaneous cutting forces on the ball-end mill are then obtained by summing the contributions of all the engaged cutting edge elements. The cutting system deflection is taken as the immediate response of the cutting force; i.e., the system inertia and the cutting process damping are assumed to have no effect on the resulting deflection. The compliance of the workpiece and the difference between the machine tool structure compliance in different directions are assumed negligible. Since end milling processes are prone to the condition of chatter, the cutting conditions in the present work are selected as suggested in the machining data handbooks such that the cutting operations are smooth and no noticeable chatter is observed. The effects of chatter on the machining process are therefore reduced to the least and not taken into account in the present model.

\subsection{Mode! Formulation}

Accurate process models are essential to achieve optimum machining operations. Typically, there are three kinds of machining process modeling approaches: analytical, experimental, and mechanistic. It is easy to distinguish these models as their names imply. In analytical models, mathematical methods are employed to analyze the machining processes and explicit analytical equations are derived. The advantage of using analytical models is that it is more accurate. Nonetheless, as the machining system becomes very complicated, difficulties arise in deriving explicit equations for this complicated system. In experimental models, a lot of experiments need to be performed to determine the empirical parameters and empirical expressions for the machining system are obtained based on the empirical parameters. The difficulty of deriving complicated mathematical expressions for the complicated machining systems is eliminated when using experimental models. Yet, the large number of empirically 
determined parameters makes the expressions of a machining system cumbersome and impractical for many applications. The mechanistic approach is a recent development. It is rooted in both the analytical and the empirical modeling approaches and employs computer simulation techniques. It is important to note that generally a combination of these methods is needed to obtain a working model since existing knowledge is insufficient to afford the superiority of any particular approach over the others. The present work on cutting force modeling for $3 \mathrm{D}$ ball-end milling is based on the mechanistic modeling approach.

Figure 2.1 shows the cutting force determination procedure in $3 \mathrm{D}$ ball-end milling. Components essential to the determination of cutting forces include: the cut


empirical chip-force relationships. The first two components form undeformed chip geometry on the ball-end mill. It refers to the geometry of the material that is to be removed by the cutter at the particular moment. The empirical chip-force relationships relate the cutting forces to the undeformed chip geometry. In a flexible cutting system, system deflections caused by cutting forces redistribute the undeformed chip thickness for each engaged cutting element. This effect is shown in the figure as a feedback from the cutting forces to the undeformed chip thickness. The complexity and the methods to establish these components for 3D ball-end milling will be discussed in detail in the following sections. 


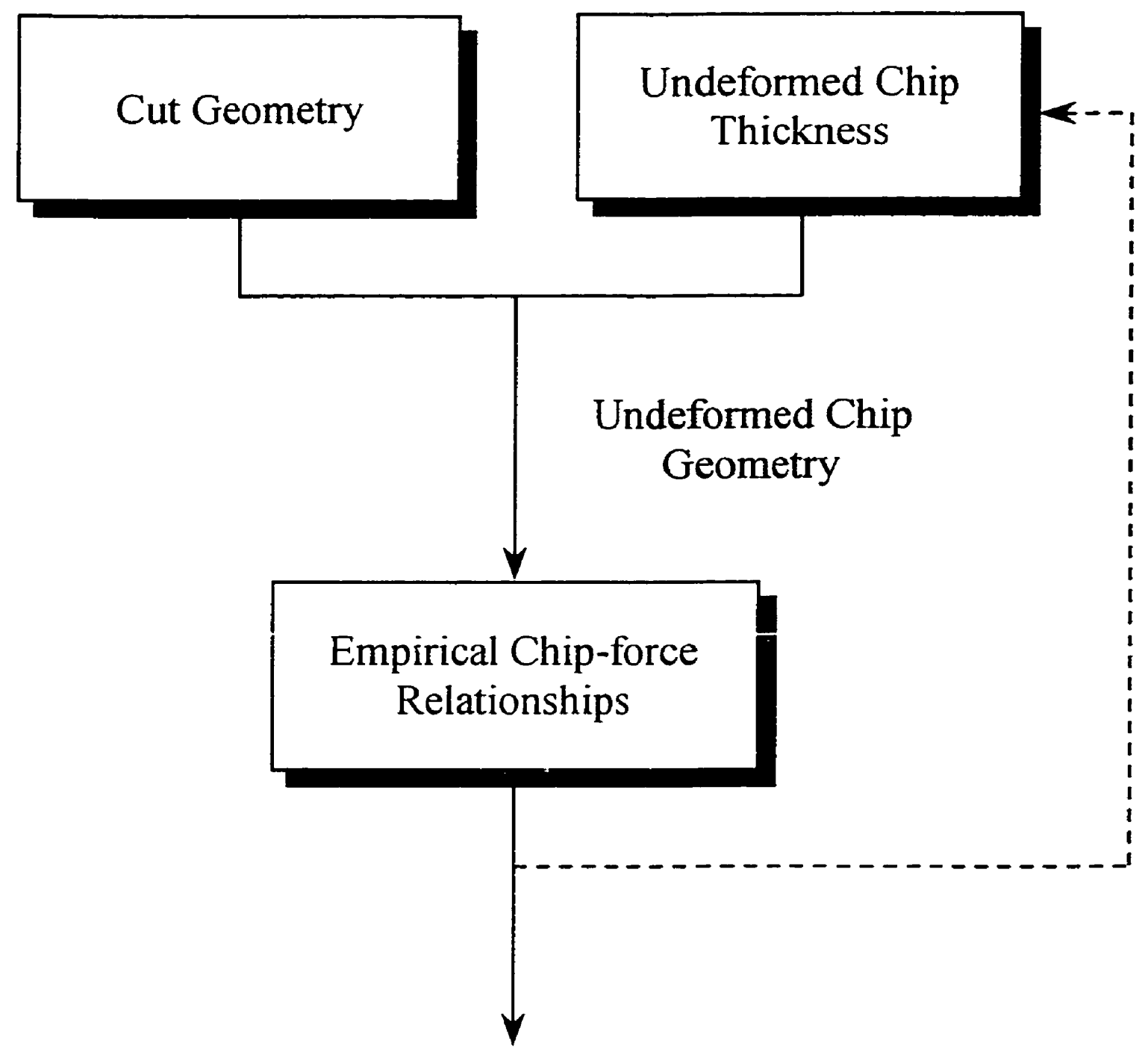

Cutting Forces

Figure 2.1 A flow chart showing the cutting force calculation procedure. 


\subsection{Cut Geometry}

Cut geometry is a very important parameter in the analysis of ball-end milling mechanics. It represents the surface geometry generated by the cutter over one tooth period and also represents the engaged area on the cutter. Cut geometry is very complicated in 3D ball-end milling due to the non-horizontal and cross-feed cutter movements. A cutting edge element is considered engaged if it is within the cut geometry. As the cutter rotates, a cutting edge element can be engaged constantly, or become engaged and then disengaged, or be not engaged at all. Cut geometry is best established using a comprehensive solid modeling approach. A preliminary generic solid modeler based simulation system has recently been developed and demonstrated experimentally for horizontal ball-cnd milling (El Mounayti ot al., 1998). Solid modeling techniques require large computing power for accurate simulations. A less computing intensive but robust cut geometry identification method was developed in the present work. This method utilizes boundary limits of the cutter-part engagement geometry to establish the cut geometry and identify the engaged cutting elements for $3 \mathrm{D}$ ball-end milling.

The complex motion of the ball-end mill in the finish machining of 3D sculptured surfaces results in cut geometry that is continuously changing. Since the linear feed movement of the cutter is often much smaller than the rotational movement, cut geometry at any cutter location can be approximated as if the cutter is machining a small $3 \mathrm{D}$ plane surface patch. The small plane surface is tangent to both the ball surface of the cutter and the 3D sculptured surface at the cutter contact point with the surface (surface generation point of the cutter). Figure 2.2 shows the Cartesian coordinate system and the two 


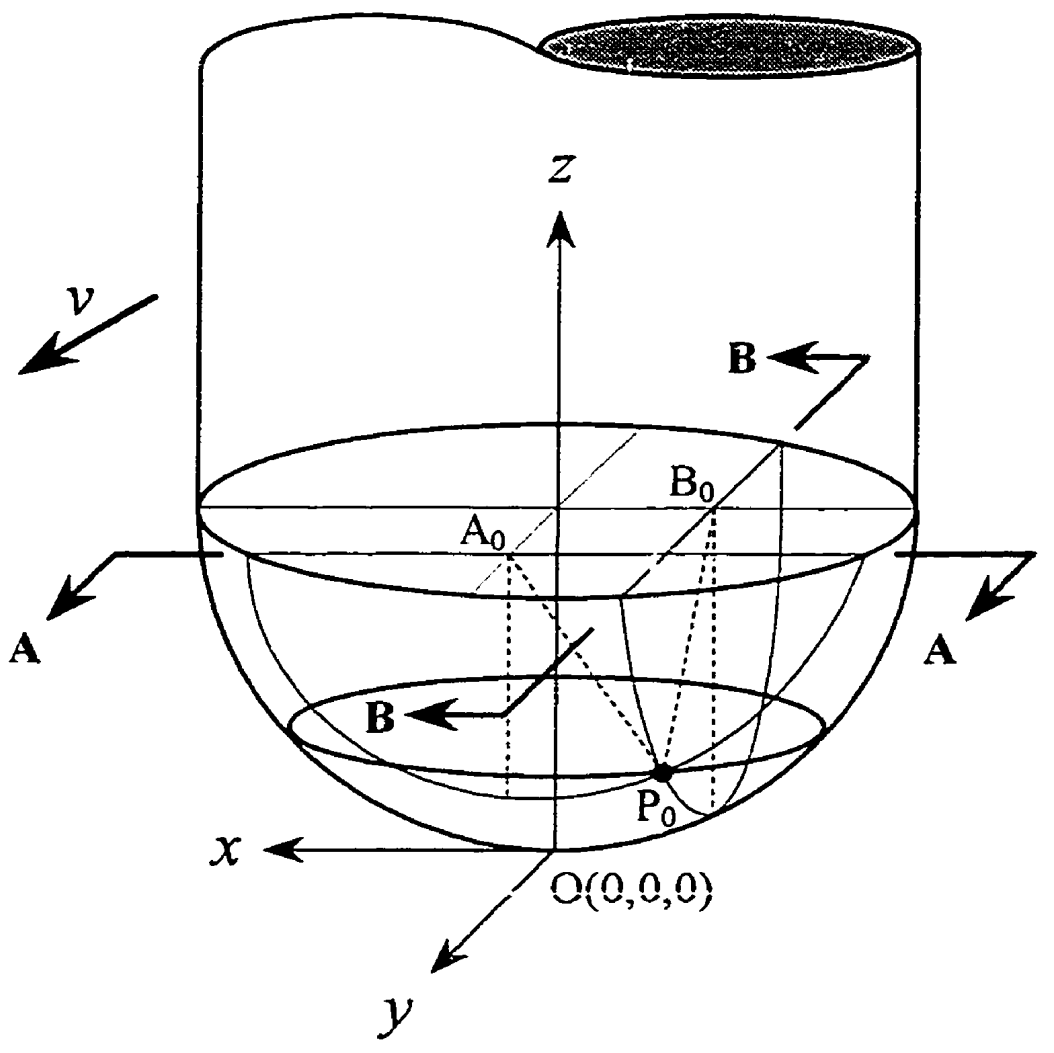

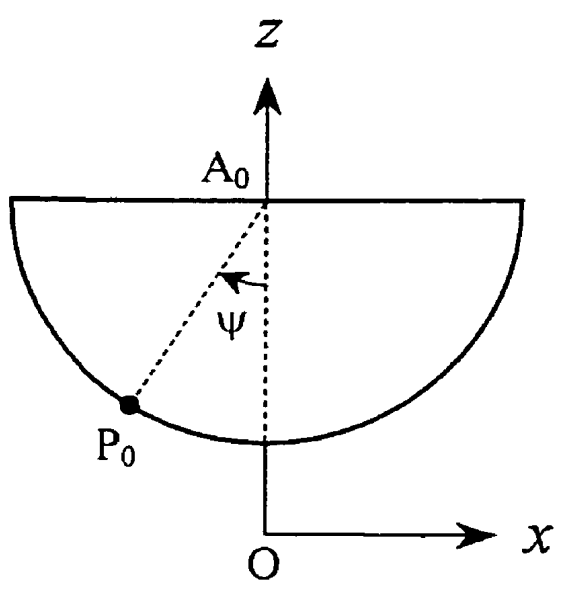

A-A section: : view ( $x z$ plane)

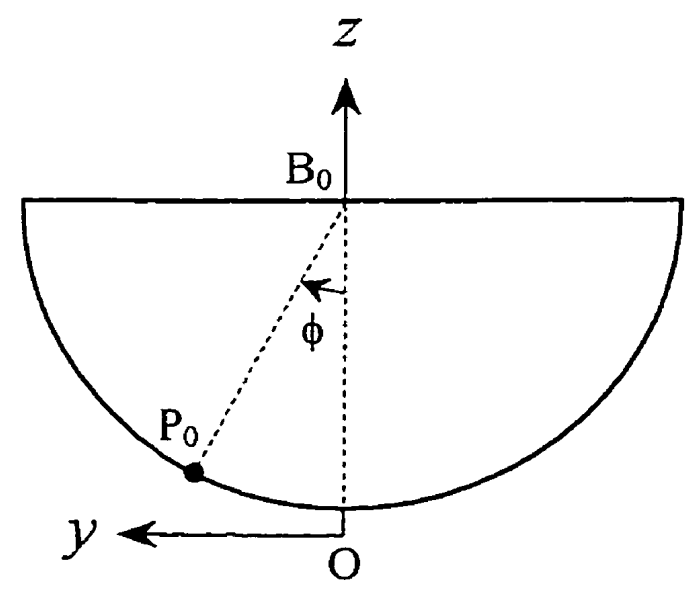

B-B sectional view ( $y z$ plane)

Figure 2.2 The Cartesian coordinate system used for the ball-end mill. 
angular coordinates, $\psi$ and $\phi$, that are used to characterize the instantaneous cut geometry. The Cartesian coordinate system is established by setting (1) the tip at the free end of the ball-end mill as the origin; (2) the cutter axis as the $z$ axis; and (3) the plane defined by the cutter feed direction and the cutter axis as the $x z$ plane. The cross-section of the ball part of the ball-end mill in the $y z$ plane is a half circle. The angle $\psi$ is the angle swept by the half circle until it reaches the surface generation point $\mathrm{P}_{0}$ about an axis that passes through $(0,0, R)$ and is parallel to the $y$ axis ( $R$ is the nominal radius of the cutter). The angle $\phi$ is defined in a similar way and by sweeping the half circle in the $x z$ plane about an axis parallel to the $x$ axis. Definitions of $\psi$ and $\phi$ can also be seen in Figure 2.2. It should be noted that the radii of the semi-circles in Figure 2.3 are generally not equal to the nominal radius of the ball-end mill. The figure shows the cross-sections of the cutter intersected by a plane parallel to $x z$ plane and a plane parallel to $y z$ plane passing the surface generation points $P_{0}$.
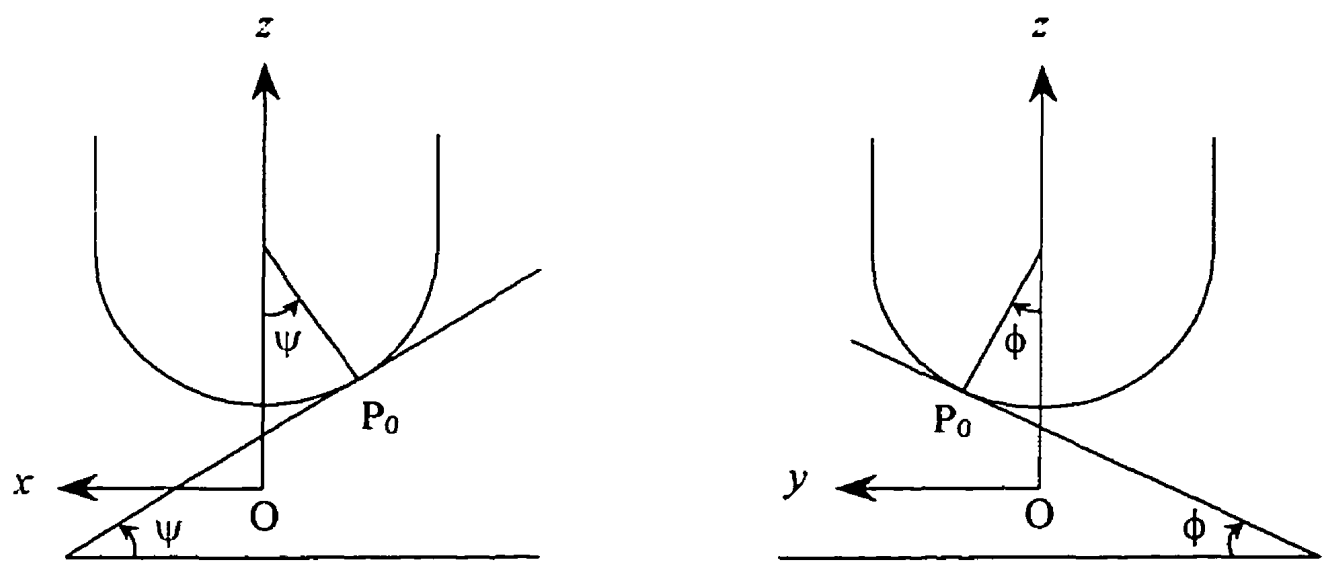

Figure 2.3 Definitions of $\psi$ and $\phi$. 
Using the Cartesian coordinate system of the ball-end mill, the mathematical equation for any point at the ball part of the cutter can be expressed as:

$$
x^{2}+y^{2}+(z-R)^{2}=R^{2}
$$

For the surface generation point $\mathrm{P}_{0}\left(x_{0}, y_{0}, z_{0}\right)$ on the ball part of the cutter, it can be seen from Figure 2.2 that

$$
\begin{aligned}
& \frac{-x_{0}}{R-z_{0}}=\tan \psi \\
& \frac{y_{0}}{R-z_{0}}=\tan \phi
\end{aligned}
$$

Substitution of Eqs. (2.2) and (2.3) into Eq. (2.1) yields:

$$
z_{0}=R\left(1-\frac{1}{\sqrt{1+\tan ^{2} \psi+\tan ^{2} \phi}}\right)
$$

By substituting Eq. (2.4) into Eq. (2.2) and Eq. (2.3), the coordinate values of the surface generation point $\mathrm{P}_{0}$ can be obtained

$$
\begin{aligned}
& x_{0}=\frac{-R \tan \psi}{\sqrt{1+\tan ^{2} \psi+\tan ^{2} \phi}} \\
& y_{0}=\frac{R \tan \phi}{\sqrt{1+\tan ^{2} \psi+\tan ^{2} \phi}} \\
& z_{0}=R\left(1-\frac{1}{\sqrt{1+\tan ^{2} \psi+\tan ^{2} \phi}}\right)
\end{aligned}
$$


According to the definition of $\psi$, when the cutter goes up in the feed direction, the value of $\psi$ is negative. When the cutter goes down, the value of $\psi$ is positive.

Three geometric elements have been identified as the main factors that determine cut geometry and control cutter engagement in 3D finishing ball-end milling: the part surface preceding the current process (the semi-finished part surface), the slot surface left by the adjacent finishing tool path, and the non-horizontal cutter feed direction. These geometric elements define the boundary limits of the cutter-part engagement geometry. Sectional views of two special cases of cut geometry in $3 \mathrm{D}$ ball-end milling are shown in Figure 2.4: $\phi=0$ (upper) and $\psi=0$ (lower). In this figure, $v$ is the non-horizontal feedrate, $f$ the feed per tooth, $d$ the depth of cut, and $s$ the step size.

There are two forms of milling to machine the workpiece: up milling and down milling, illustrated in Figure 2.5. In up milling, also called conventional milling, the direction of motion of the cutter teeth is opposite to the feed direction of the workpiece when the teeth cut into the work. It is milling "against the feed". In down milling, also called climb milling, the motion direction of the cutter teeth is the same as the feed direction of the workpiece when the teeth cut into the work. It is milling "with the feed" (Groover, 1996). According to the definition of the coordinate system in the present model, for up milling the step size is in the $+y$ direction, while for down milling the step size is in the $-y$ direction.

It is evident from Figure 2.4 that the semi-finished part surface represents one of the boundary limits. The semi-finished surface geometry is generated by the semifinishing process and can be complicated. It is simplified in the present work as an offset 

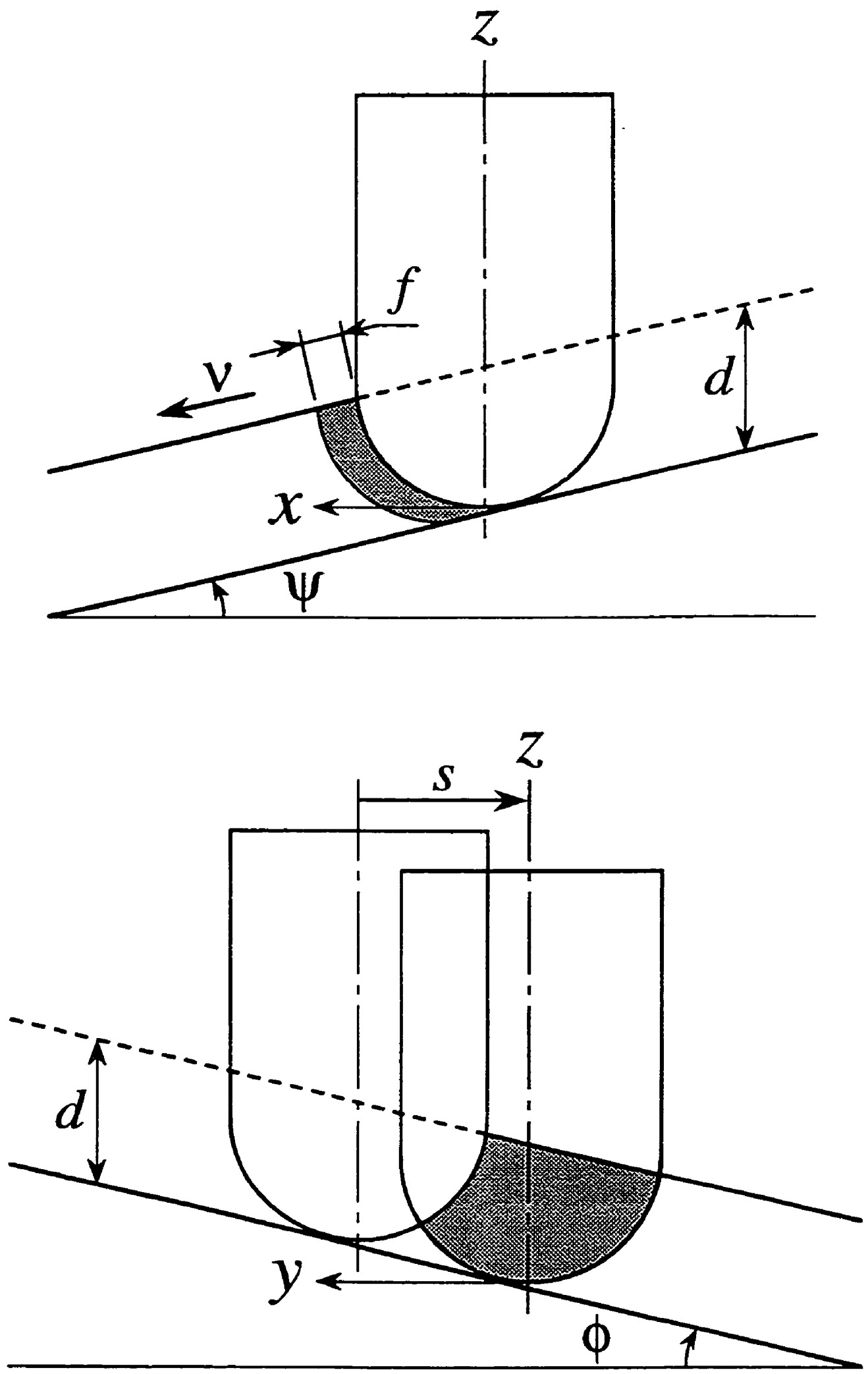

Figure 2.4 Sectional views of two special cases of cut geometry in 3D ball-end milling. 


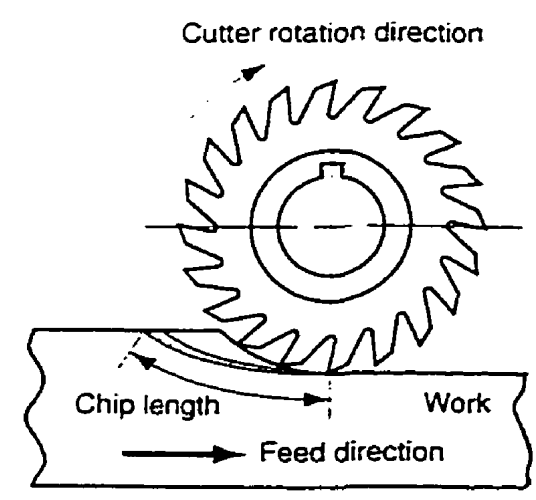

(a)

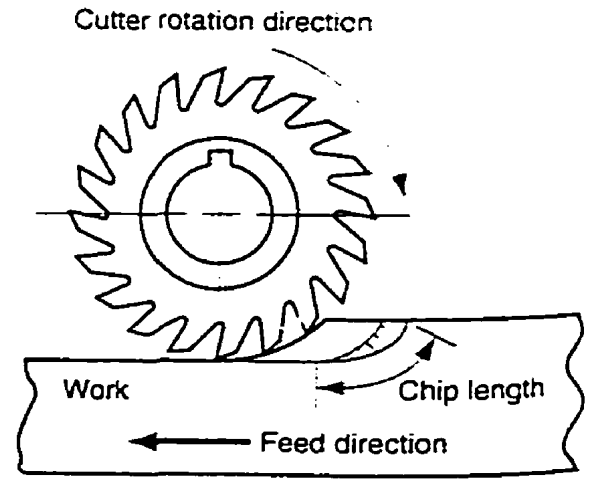

(b)

Figure 2.5 Two forms of milling: (a) up milling and (b) down milling (Groover, 1996).

surface to the finished surface with a uniform vertical offset $d$. This vertical offset is in fact the axial depth of cut used in the current model. The semi-finished part surface is expressed in the cutter coordinate system as:

$$
x \tan \psi-y \tan \phi+z=-R\left(\sqrt{1+\tan ^{2} \psi+\tan ^{2} \phi}-1\right)+d
$$

Let $z_{p}$ donate the $z$ coordinate value of any point on this surface. $z_{p}$ can be expressed as:

$$
z_{p}=-x \tan \psi+y \tan \phi-R\left(\sqrt{1+\tan ^{2} \psi+\tan ^{2} \phi}-1\right)+d
$$

It is clear that cutting elements below this simplified surface can be engaged in cutting, while cutting elements above this surface do not participate in cutting. This condition for any cutting element at $z$ can be given as follows:

If $z \leq z_{p}$, the cutting element can be engaged in cutting; 
If $z>z_{p}$, the cutting element is not engaged in cutting.

The adjacent slot surface in finish ball-end milling represents another boundary limit. In order to ensure the quality of the machined surface, the step size is usually very small such that the scallop height is within the specified requirement. Due to the small step size in the cross feed direction, part of the cutter falls inside the adjacent machined slot (as shown in Figure 2.4) when the cutter is machining the current slot. Cutting elements within this adjacent machined slot are not engaged in cutting because the materials within this area have been removed in the previous tool path. While cutting elements outside this slot can be participating in cutting. When the cutter moves nonhorizontally, the cross-section of the machined slot intersected by planes parallel to $y z$ piane becomes an eiiipse rather than a semi-circie. Diñricuities arise in determining this boundary limit when the current $x y z$ coordinate system is used. It is noted that in the plane normal to the cutter feed direction, the cross-section of the slot is a semi-circle. Therefore, to simplify the derivation, coordinate transformations are carried out to obtain this boundary limit. The coordinate transformation procedure is illustrated in Figure 2.6. The steps for the coordinate transformation are as follows:

l) Translation

Translation is made in the $y z$ plane from the current coordinate system $x y z$ to the coordinate system $x^{\prime} y^{\prime} z^{\prime}$ on the previous adjacent slot surface. The new coordinates $\left(x^{\prime}, y^{\prime}, z^{\prime}\right)$ in term of $(x, y, z)$ are: 

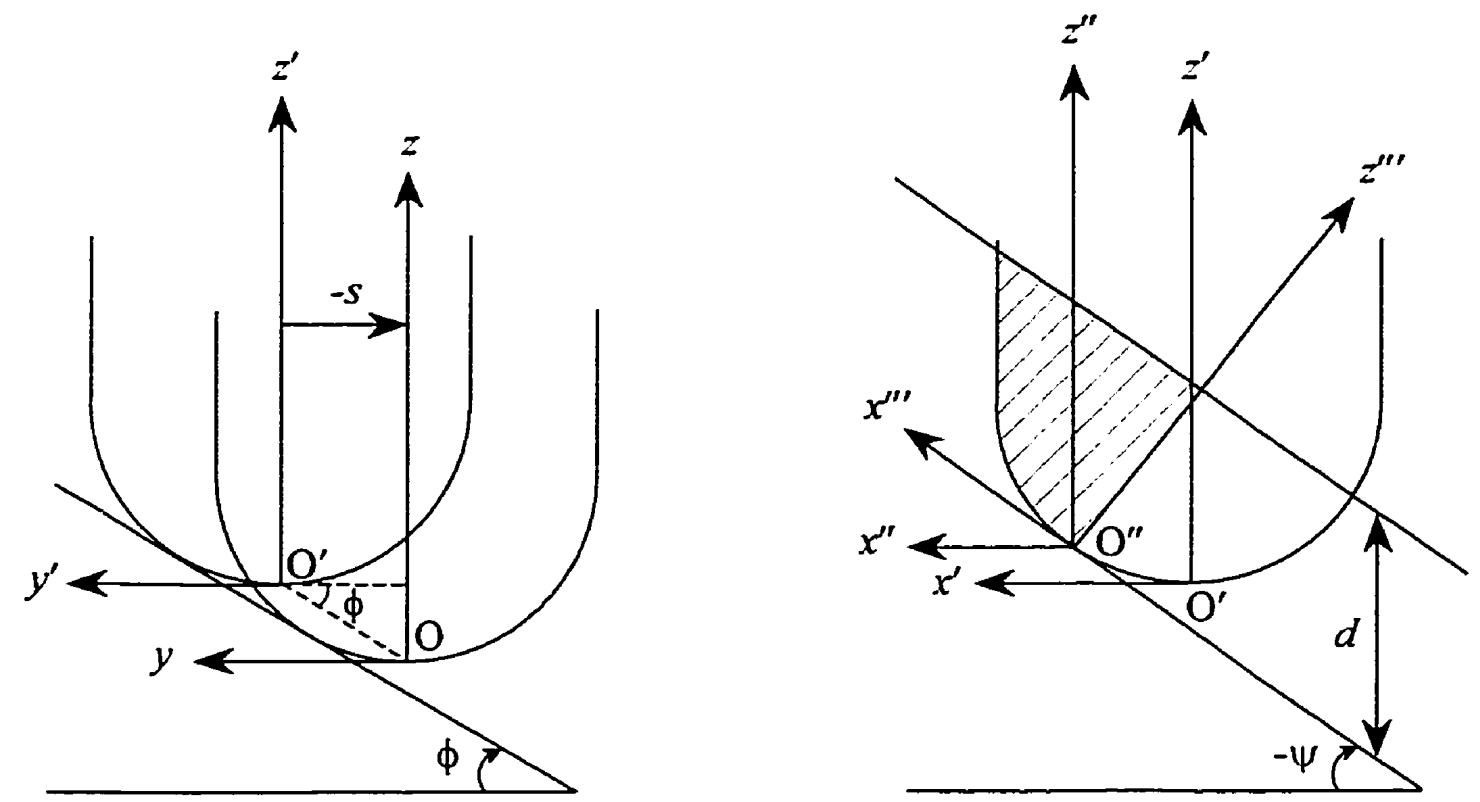

Figure 2.6 Coordinate system transformation.

$$
\left[\begin{array}{l}
x^{\prime} \\
y^{\prime} \\
z^{\prime}
\end{array}\right]=\left[\begin{array}{c}
x \\
y+s \\
z+s \tan \phi
\end{array}\right]
$$

where the down milling step size is negative (in the $-y$ direction) and has a magnitude of $-s$.

2) Translation

Translation of coordinate system from $x^{\prime} y^{\prime} z^{\prime}$ to $x^{\prime \prime} y^{\prime \prime} z^{\prime \prime}$ is made in the $x^{\prime} z^{\prime}$ plane. The origin of the coordinate system is translated from $\mathrm{O}^{\prime}$ to $\mathrm{O}^{\prime \prime} . \mathrm{O}^{\prime \prime}$ is a point on the cutter surface in the $x^{\prime} z^{\prime}$ plane whose tangent is in the same direction as the cutter feed direction. The coordinates $\left(x^{\prime \prime}, y^{\prime \prime}, z^{\prime \prime}\right)$ in terms of $(x, y, z)$ are: 


$$
\begin{aligned}
{\left[\begin{array}{c}
x^{\prime \prime} \\
y^{\prime \prime} \\
z^{\prime \prime}
\end{array}\right] } & =\left[\begin{array}{c}
x^{\prime}+R \sin \psi \\
y^{\prime} \\
z^{\prime}-(R-R \cos \psi)
\end{array}\right] \\
& =\left[\begin{array}{c}
x+R \sin \psi \\
y+s \\
z+s \tan \phi-(R-R \cos \psi)
\end{array}\right]
\end{aligned}
$$

\section{3) Rotation}

Rotation of coordinate system $x^{\prime \prime} y^{\prime \prime} z^{\prime \prime}$ with respect to $y^{\prime \prime}$ axis by $-\psi$ results in coordinate system $x^{\prime \prime \prime} y^{\prime \prime \prime} z^{\prime \prime \prime}$.

$$
\begin{aligned}
{\left[\begin{array}{l}
x^{\prime \prime \prime} \\
y^{\prime \prime \prime} \\
z^{\prime \prime \prime}
\end{array}\right] } & =\left[\begin{array}{ccc}
\cos \psi & 0 & -\sin \psi \\
0 & 1 & 0 \\
\sin \psi & 0 & \cos \psi
\end{array}\right]\left[\begin{array}{l}
x^{\prime \prime} \\
y^{\prime \prime} \\
z^{\prime \prime}
\end{array}\right] \\
& =\left[\begin{array}{c}
x \cos \psi-z \sin \psi-s \sin \psi \tan \phi+R \sin \psi \\
y+s \\
x \sin \psi+z \cos \psi+s \tan \phi \cos \psi-R \cos \psi+R
\end{array}\right]
\end{aligned}
$$

In the $y^{\prime \prime \prime} z^{\prime \prime \prime}$ plane, the cross section of the previous slot surface is circular. The slot surface boundary limit can then be expressed as:

$$
\begin{array}{ll}
y^{\prime \prime \prime}+\left(z^{\prime \prime \prime}-R\right)^{2}=R^{2} & \text { if } z^{\prime \prime \prime} \leq R \text { (ball part of the slot surface) } \\
y^{\prime \prime \prime}= \pm R & \text { if } z^{\prime \prime \prime}>R \text { (cylindrical part of the slot surface) }
\end{array}
$$

where $y^{\prime \prime \prime}$ and $z^{\prime \prime \prime}$ can be obtained from Eq. (2.10). If cutting elements are inside the boundary limits defined in Eq. (2.11) they are not engaged in cutting. For any cutting 
element at $\left(x^{\prime \prime \prime}, y^{\prime \prime \prime}, z^{\prime \prime}\right)$, the engagement with respect to the adjacent slot surface can be determined in the ball part and the cylindrical part of the cutter separately:

a) when $z^{\prime \prime \prime} \leq R$ (the ball part of the slot surface)

If $y^{\prime \prime \prime 2}+\left(z^{\prime \prime \prime}-R\right)^{2} \leq R^{2}$, the cutting element is inside the previous adjacent slot surface. It is not engaged in cutting.

If $y^{\prime \prime \prime 2}+\left(z^{\prime \prime \prime}-R\right)^{2}>R^{2}$, the cutting element is outside the previous adjacent slot surface. It can be participating in cutting.

b) when $z^{\prime \prime \prime}>R$ (the cylindrical part of the slot surface)

If $\left|y^{\prime \prime}\right| \leq K$, the cutting eiement is inside the previous adjacent siot surface. it is noi engaged in cutting.

If $\left|y^{\prime \prime \prime}\right|>R$, the cutting element is outside the previous adjacent slot surface. It can be participating in cutting.

The non-horizontal feed direction of the cutter results in the third boundary limit:

$$
\begin{array}{ll}
x=(z-R) \tan \psi & \text { if } z \leq R \text { (ball part of the cutter) } \\
x=0 & \text { if } z>R \text { (cylindrical part of cutter) }
\end{array}
$$

In the cylindrical part of the cutter, this boundary limit is the $y z$ plane. The cross-section of the ball part of the ball-end mill in the $y z$ plane is a half circle. The boundary limit set by the non-horizontal feed direction in the ball part of the cutter is obtained by sweeping 
this half circle to an angle $\psi$ until it reaches the surface generation point $\mathrm{P}_{0}$ about an axis that passes through $(0,0, R)$ and is parallel to the $y$ axis. The half circle plane at this position is the boundary limit for the ball part of the cutter set by the non-horizontal cutter feed direction. For both the ball part and cylindrical part of the ball-end mill, cutting elements in front of these two planes (in the $x$ direction) can be engaged in cutting, while the rest of the cutter is not engaged in cutting. In Figure 2.6, cutting elements within the shaded area can be participating in cutting. The mathematical expression for this boundary limit can be expressed as:

a) when $z \leq R$ (the ball part of the cutter)

If $x \geq(z-R) \tan \psi$, the cutting element is in front of the non-horizontal feed direction boundary limit. It can be participating in cutting.

If $x<(z-R) \tan \psi$, the cutting element is not engaged in cutting.

b) when $z>R$ (the cylindrical part of the cutter)

If $x \geq 0$, the cutting element is in front of the $y z$ plane (in the $x$ direction). It can be participating in cutting.

If $x<0$, the cutting element is not engaged in cutting.

Each of these three boundary limits slices off the unengaged cutting elements from the cutter. These boundary limits then enclose an area on the cutter surface that represents the cut geometry. This area includes cutting elements that satisfy all the engagement requirements simultaneously. Typical cut geometry in $3 \mathrm{D}$ ball-end milling is 
depicted in Figure 2.7. In this figure, the darker area is the cut geometry. It is very complicated and used to identify the engaged cutting elements on the ball-end mill.

\subsubsection{Undeformed Chip Thickness}

Undeformed chip thickness is the radial distance between the path the current cutting edge element is generating and the machined surface left in the immediate previous cutter revolution at the same angular position. A generalized algorithm is employed in the present work to determine the undeformed chip thickness for each engaged cutting element in 3D ball-end milling. It is evident that the path of a milling tooth is trochoidal. Due to the fact that the cutting speed is much larger than the table feed rate, the tooth path can be approximated by a circular curve. All the calculations related to undeformed chip thickness are based on this assumption. Factors considered in establishing the cutting element trajectory include cutter runout, cutting system deflection, and non-horizontal cutter feed motion.

Cutter runout in machining refers to the state of tool cutting points rotating about an axis different from geometrical axis of the cutter. It is an inevitable condition in the milling processes resulting from errors in holding the cutter in the spindle and has been examined in the form of an offset, a tilt or a combination of both of the cutter axis from the spindle axis. Figure 2.8 depicts a possible configuration of a ball-end mill and a spindle. In the lower half of the figure, a cross-section of the ball-end mill at $z$ is shown. $\rho(z)$ is the cutter axis offset from the spindle axis and $\lambda(z)$ is the locating angle that indicates the direction of the offset at $z$. If the machining system is completely rigid, the presence of cutter runout tends to make cutting forces quite asymmetric in comparison to 

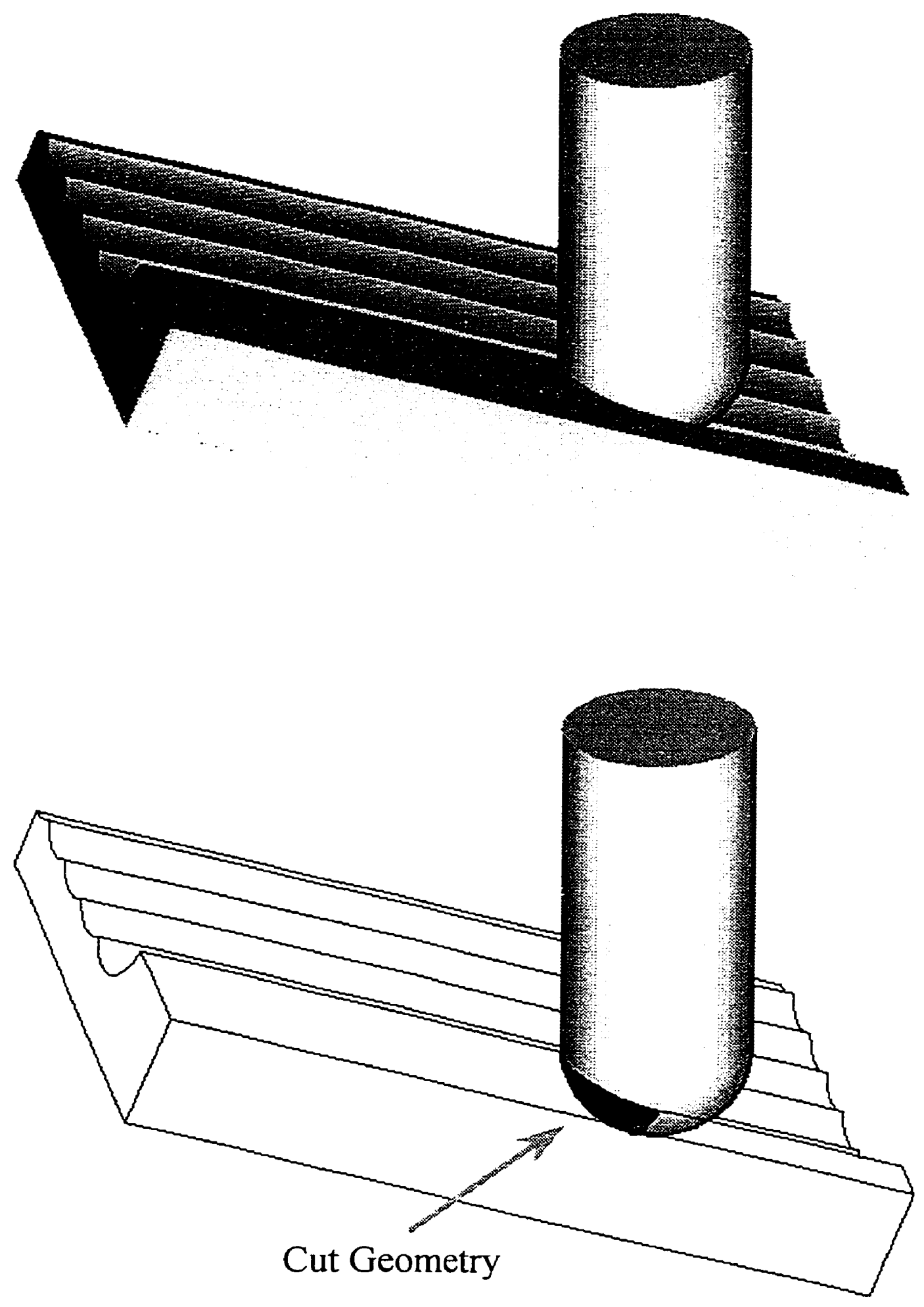

Figure 2.7 Typical cut geometry in 3D ball-end milling. 

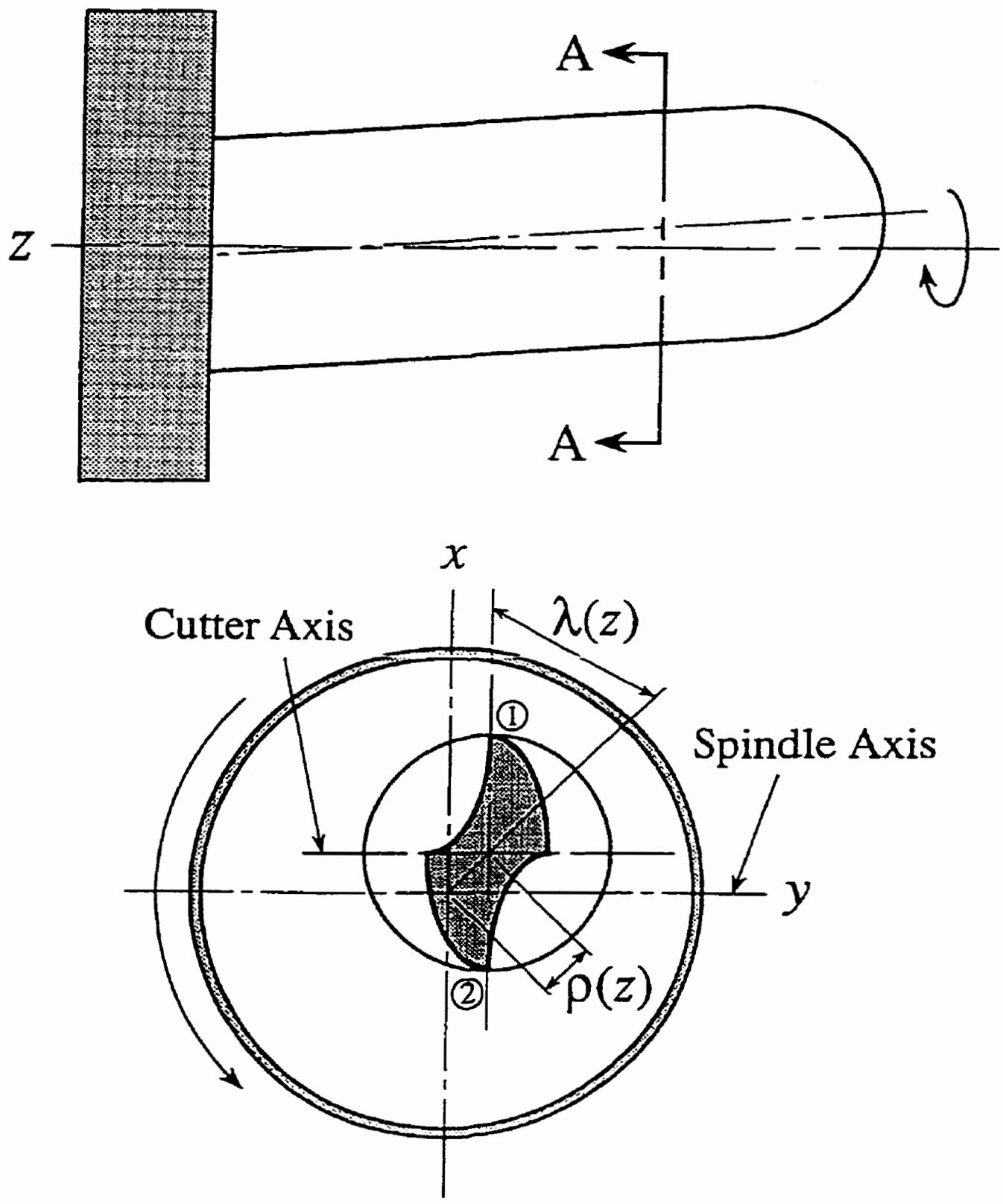

Section AA

Figure 2.8 Cutter runout configuration (Feng and Menq, 1994a). 
those without runout. Cutter runout causes the chip load to vary between cutting teeth over the rotation of a multi-tooth cutter. It is obvious that with cutter runout, the chip loads of some cutting teeth become larger while the chip loads of some other cutting teeth become smaller or even zero. This varying chip load will alter cutting forces and result in asymmetric cutting forces. Cutting system deflection is typical for slender ball-end mills. Cutting system deflections temper the effect of runout and reduce peak cutting forces. The combined effect of cutter runout and cutting system deflection is to redistribute the ideal symmetric undeformed chip thickness distribution for the multipie cutting edges. It often results in a machined surface that is not necessarily generated by the immediate previous cutting edge in the last cutter revolution. Non-horizontal feed motion of the cutter further complicates the analysis with feed components in the axial as well as the horizontal directions.

The present undeformed chip thickness determination algorithm is based on the analysis of trajectories of an engaged cutting element and the corresponding cutting element on each cutting edge in the immediate previous cutter revolution at the same angular position. Because of the existence of cutter runout and cutting system deflection caused by cutting forces, the surface left in the previous revolution may or may not be generated by the immediate previous tooth. It may be generated by any tooth of the cutter in the immediate previous cutter revolution. The generalized chip thickness determination algorithm is to first determine the possible chip thickness candidates and then identify the correct undeformed chip thickness. The detailed procedure is depicted in Figure 2.9. In this figure, the cutting element under consideration is on the $i$ th cutting edge, at a distance $z$ from the cutter free end, and at an angular position $\theta_{i}(\theta, z)$ with respect to the $y$ axis, 


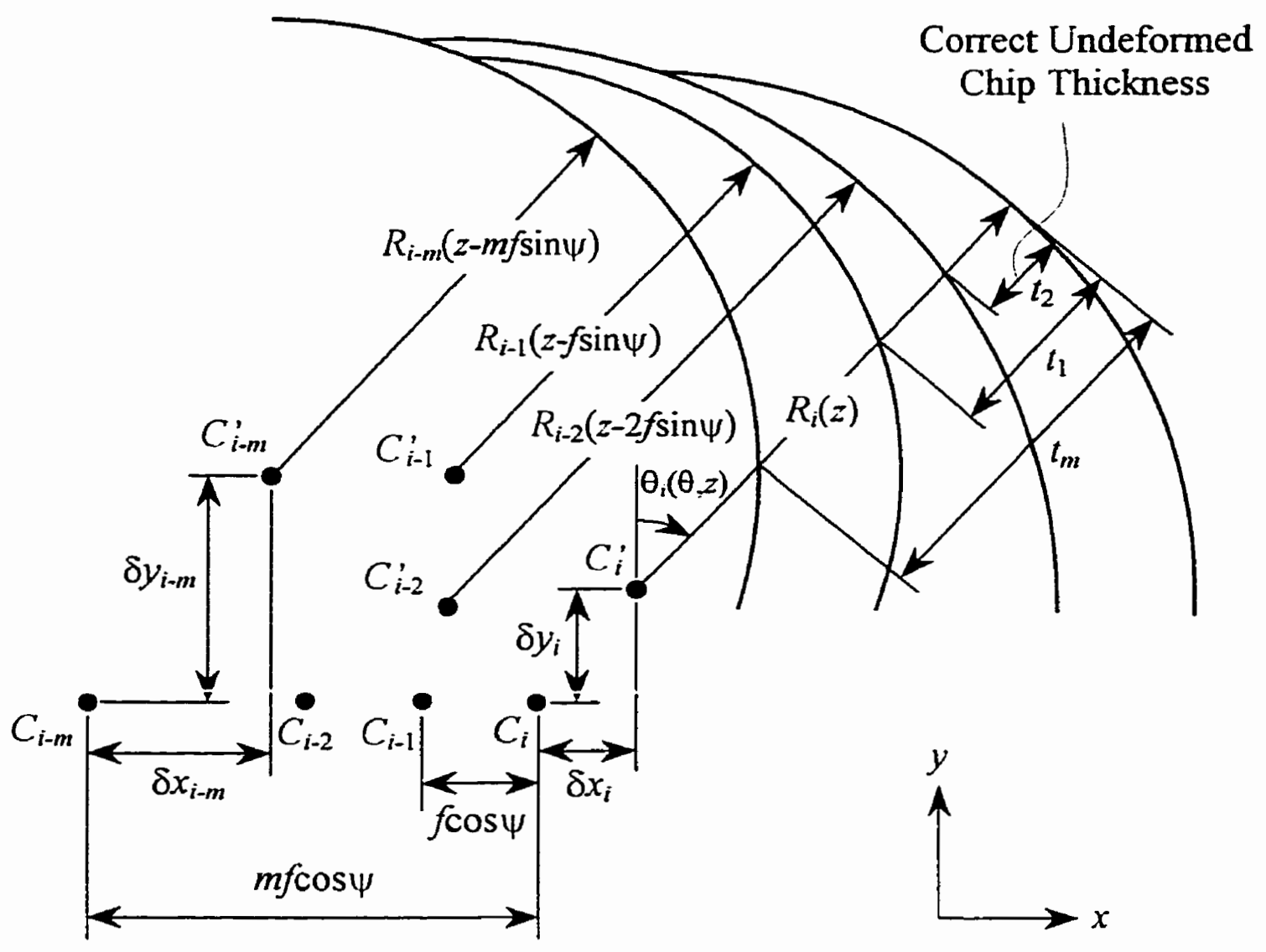

Figure 2.9 Undeformed chip thickness calculation geometry for $3 \mathrm{D}$ ball-end milling. 
where $\theta$ represents the angular orientation of the cutter. $C_{i}, C_{i-1}, C_{i-2}$, and $C_{i-m}$ are the ideal rotational centers (undeflected spindle centers) of the current cutting element and the corresponding cutting elements on the immediate previous, the second previous, and the $m$ th previous cutting edges. Cutting system deflections caused by the cutting forces shift the ideal rotational centers to the deflected centers, $C^{\prime}{ }_{1}, C_{1-1}^{\prime}, C^{\prime}{ }_{i-2}$, and $C^{\prime}{ }_{i-m}$. $\delta x^{\prime} s$ and $\delta y^{\prime} s$ indicate cutting system deflections in the $x$ and the $y$ directions. $R_{i}(z)$ represents the cutting radius of the cutting element, which is often different from the ideal cutter radius due to cutter runout. The non-horizontal cutter feed motion results in feed components in both the $x$ and the $z$ directions. The $x$ component advances the ideal spindle center by $f \cos \psi$ in one tooth period. The $z$ component causes cutting radius changes for the corresponding cutting elements on the multiple cutting edges.

Based on the above descriptions, trajectories of the cutting elements shown in Figure 2.9 can be formulated as

Trajectory $=$ Spindle center position + Cutter deflection + Cutting radius

If the ideal spindle center $C_{l}$ is specified as the reference zero, the radial position of the current cutting element, $T_{i}(\theta, z)$, at the angular position $\theta_{i}(\theta, z)$ can be expressed as

$$
T_{i}(\theta, z)=\left[\delta x_{i} \sin \theta_{i}(\theta, z)+\delta y_{i} \cos \theta_{i}(\theta, z)\right]+R_{i}(z)
$$

where

$$
R_{i}(z)=R(z)+\rho(z) \cos \left[\lambda(z)-(i-1) \frac{2 \pi}{N}\right]
$$




$$
\theta_{i}(\theta, z)=\theta-\frac{z}{R} \tan \beta-(i-1) \frac{2 \pi}{N}
$$

In Eq. (2.14), $R(z)$ is the ideal cutter radius at $z . R(z)$ changes with $z$ in the ball part of the cutter and remains uniform in the cylindrical part of the cutter:

$$
\begin{array}{ll}
R(z)=\sqrt{2 R z-z^{2}} & 0 \leq z \leq R \text { (ball part of the cutter) } \\
R(z)=R & z>R \text { (cylindrical part of the cutter) }
\end{array}
$$

$N$ is number of cutting edges of the cutter, $\rho(z)$ and $\lambda(z)$ are parameters characterizing the cutter runout (Feng and Menq, 1994a), $\beta$ is the helix angle of the cutter, and $\theta$ is the angular position of tooth number I (arbitrarily selected) at the cutter free end $(z=0)$.

The radial position of the corresponding cutting element on the $m$ th previous cutting edge in the last cutter revolution at the same angular position is given by

$$
\begin{aligned}
T_{i-m}(\theta, z)= & -m f \cos \psi \sin \theta_{i}(\theta, z)+\left[\delta x_{i-m} \sin \theta_{i}(\theta, z)+\delta y_{i-m} \cos \theta_{i}(\theta, z)\right]+ \\
& R_{t-m}(z-m f \sin \psi)
\end{aligned}
$$

The radial position difference between the current cutting element and the corresponding cutting element on the $m$ th previous cutting edge at the same angular position forms an undeformed chip thickness candidate. This candidate, $t_{m}$, is obtained by subtracting Eq. (2.16) from Eq. (2.13):

$$
t_{m}=T_{1}-T_{t-m}
$$


For a ball-end mill of $N$ cutting edges, $N$ undeformed chip thickness candidates can be obtained using Eq. (2.17). The correct undeformed chip thickness is the smallest positive one of the $N$ candidates ( $t_{2}$ in Figure 2.9). If all of the $N$ candidates are negative, the undeformed chip thickness is zero. This indicates that the current cutting element is not cutting any material at this particular angular position due to the combined effect of cutter runout and cutting system deflections.

It should be noted that, for cutting elements close to the cutter free end, the corresponding cutting element on the previous $m$ th cutting edge does not always exist. This occurs when the ball-end mill is feeding with a negative $z$ component and $R_{i-m}(z-m f \sin \psi)=0$ (or $z-m f \sin \psi \leq 0$ ). In this situation, the undeformed chip thickness candidate is given by

$$
\iota_{m}=T_{t}
$$

\subsubsection{Empirical Chip-Force Relationships}

Having established the undeformed chip geometry for a given cutter orientation from the cut geometry and the undeformed chip thickness determination procedure, the instantaneous cutting force is readily obtained using the empirical chip-force relationships. Empirical chip-force relationships in metal cutting are established based on extensive experimental studies. They relate the cutting forces to the undeformed chip geometry. Researchers have used different but similar empirical relationships to model cutting mechanics in the multi-toothed milling processes. The empirical chip-force relationships employed in the previous work by Feng and Menq (1994a) were 


$$
\begin{aligned}
& d F_{T_{i}}=K_{T}(z) d z\left[t_{i}(\theta, z)\right]^{m_{T}} \\
& d F_{R i}=K_{R}(z) d z\left[t_{i}(\theta, z)\right]^{m_{R}}
\end{aligned}
$$

where $d F_{T i}$ and $d F_{R i}$ are the differential tangential and radial cutting force components, $d z$ the axial depth of cut, and $t_{i}(\theta, z)$ the undeformed chip thickness of the cutting element at $\theta_{i}(\theta, z) . K_{T}(z)$ and $K_{R}(z)$ characterize the cutting mechanics of the differential cutting elements at $z$. In Eqs. (2.19) and (2.20), size effect in metal cutting (Nakayama and Tamura, 1968) is explicitly considered. The size effect is the effect of undeformed chip thickness on the unit horsepower and specific energy values needed for the machining processes. As undeformed chip thickness $t_{i}(\theta, z)$ is reduced, power and energy requirements to machine the same undeformed chip area increase. This relationship is referred to as the size effect (Groover, 1996). In Eqs. (2.19) and (2.20), the model parameters $m_{T}$ and $m_{R}$, which basically characterize the size effect of machining the workpiece material, are assumed to be constant for a particular material. For most metallic materials, $m_{T}$ and $m_{R}$ are both greater than 0 and less than 1 (i.e., $0<m_{T}<1$ and $\left.0<m_{R}<\mathrm{I}\right)$. The importance of including size effect in modelling slot milling operations has recently been demonstrated (Melkote and Endres, 1998).

The empirical parameters $K_{T}(z), K_{R}(z), m_{T}$, and $m_{R}$ were obtained from a set of horizontal slot cuts. Verification experiments have shown that Eqs. (2.19) and (2.20) provide reliable cutting force predictions for horizontal cuts (Feng and Menq, 1996). Nonetheless, for non-horizontal cuts typical in 3D ball-end milling, the empirical chipforce relationships are likely to be insufficient. To achieve accurate cutting force 
prediction in non-horizontal ball-end milling, non-horizontal cutting mechanics should be considered. Ideal chip-force relationships considering the cutter feed angle $\psi$ would be:

$$
\begin{aligned}
& d F_{T_{t}}=K_{T}(\psi, z) d z\left[t_{i}(\theta, z)\right]^{m_{T}} \\
& d F_{R i}=K_{R}(\psi, z) d z\left[t_{i}(\theta, z)\right]^{m_{R}}
\end{aligned}
$$

The cutting mechanics parameters $K_{T}$ and $K_{R}$ are expressed as functions of $\psi$ as well as $z$ in order to deal with the chip flow direction changes in non-horizontal cuts. The exact functional forms of $K_{\tau}(\psi, z)$ and $K_{R}(\psi, z)$ can be quite complex and it will require extensive experimental tests to determine the empirical coefficients. The amount of the experimental test cuts can be dramatically reduced if the effects of the variables $\psi$ and $z$ on the cutting mechanics are independent with each other such that $K_{T}(\psi, z)$ and $K_{R}(\psi, z)$ can be expressed as

$$
\begin{aligned}
& K_{T}(\psi, z)=K_{T . \psi}(\psi) K_{T_{. z}}(z) \\
& K_{R}(\psi, z)=K_{R_{. \psi}}(\psi) K_{R_{. z}}(z)
\end{aligned}
$$

Equations (2.23) and (2.24) are in fact reasonable approximations to $K_{T}(\psi, z)$ and $K_{R}(\psi, z)$. The correlation between the effects of $\psi$ and $z$ on the cutting mechanics is minor in that the former is process-based (characterized by the cutter feed direction of the ball-end milling process) while the latter is cutter-based (characterized by the cutting edge design of the ball-end milling cutter). Introducing Eqs. (2.23) and (2.24) to Eqs. (2.21) and (2.22) results in 


$$
\begin{aligned}
& d F_{T_{i}}=K_{T_{.} \psi}(\psi) K_{T_{i}=}(z) d z\left[t_{i}(\theta, z)\right]^{m_{T}} \\
& d F_{R_{i}}=K_{R_{.} \psi}(\psi) K_{R_{i}=}(z) d z\left[l_{i}(\theta, z)\right]^{m_{R}}
\end{aligned}
$$

The main advantage of Eqs. (2.25) and (2.26) can be observed from a comparison with Eqs. (2.19) and (2.20), the empirical chip-force relationships used previously. $K_{T, \psi}(\psi)$ and $K_{R, \psi}(\psi)$ are the newly introduced terms to characterize non-horizontal cutting mechanics in $3 \mathrm{D}$ ball-end milling. The rest of the formulation is the same. As a result, the experimental procedure to determine the empirical model parameters is greatly simplified as will be described in the following section.

\section{2.+ Cutting Force Calculation}

In the mathematical procedure to calculate the cutting forces, an iterative procedure is employed to obtain equilibrium chip geometry and cutting forces. Since the deflection-dependent chip geometry can only be established if the cutting forces are known at any $\theta$ over the last full cutter revolution, for any $\theta$, initial values are first assumed for the cutting forces the model is intended to predict. Once the cutting forces are assumed, the resulting chip geometry can be obtained. With this obtained chip geometry, the new cutting forces are calculated. The cutting force information is updated by comparing the calculated cutting forces with the initially guessed cutting forces, and this iterative procedure continues until the difference between the guessed cutting forces and the caiculated cutting forces is within specified convergence criteria. 


\subsection{Determination of Empirical Model Parameters}

Empirical model parameters in Eqs. (2.25) and (2.26) need to be determined in order to use the present model to calculate cutting forces in $3 \mathrm{D}$ ball-end milling. The empirical parameters $K_{T .=}(z), K_{R_{. z}}(z), m_{T}$, and $m_{R}$ can be obtained from horizontal slot cuts with $K_{T, \psi}(0)=1$ and $K_{R, \psi}(0)=1$ using the same model building procedure described before (Feng and Menq, 1994a). The values of $K_{T \cdot \psi}(\psi)$ and $K_{R . \psi}(\psi)$ for $\psi \neq 0$ are determined from measured average cutting forces of non-horizontal slot cuts based on the mathematical procedure shown below.

To sbtain the cutting forces acting on the ball-end mill at any instant, the eiementai tangentiai and radiai cutting forces are resoived into the $x, y$ directions and summed over all the engaged differential cutting edges. The summation (integration) is done numerically along the $z$-axis to yield the instantaneous forces in the $x, y$ directions:

$$
\begin{aligned}
F_{x}=\int_{0}^{d} & \left\{\sum_{i=1}^{N} K_{T . \psi}(\psi) K_{T . z}(z)\left[t_{i}(\theta, z)\right]^{m_{T}}\left[-\cos \theta_{i}(\theta, z)\right]\right. \\
& \left.+K_{R . \psi}(\psi) K_{R . z}(z)\left[t_{i}(\theta, z)\right]^{m_{R}}\left[-\sin \theta_{i}(\theta, z)\right]\right\} d z \\
F_{y}=\int_{0}^{d} & \left\{\sum_{i=1}^{N} K_{T . \psi}(\psi) K_{T . z}(z)\left[t_{i}(\theta, z)\right]^{m_{T}}\left[\sin \theta_{i}(\theta, z)\right]\right. \\
& \left.+K_{R . \psi}(\psi) K_{R . z}(z)\left[t_{i}(\theta, z)\right]^{m_{R}}\left[-\cos \theta_{i}(\theta, z)\right]\right\} d z
\end{aligned}
$$

From Eqs. (2.27) and (2.28) the average cutting forces in the $x$ and $y$ directions of a ballend mill cutting with a feed angle $\psi$ can be expressed as 


$$
\begin{aligned}
& \overline{F_{x}}=K_{T . \psi}(\psi) a_{0}+K_{R . \psi}(\psi) a_{1} \\
& \overline{F_{y}}=K_{T . \psi}(\psi) c_{0}+K_{R . \psi}(\psi) c_{1}
\end{aligned}
$$

where

$$
\begin{aligned}
& a_{0}=\frac{1}{2 \pi} \int_{0}^{2 \pi} \int_{0}^{d}\left\{\sum_{i=1}^{N} K_{T . z}(z)\left[t_{i}(\theta, z)\right]^{m_{T}}\left[-\cos \theta_{i}(\theta, z)\right]\right\} d z d \theta \\
& a_{1}=\frac{1}{2 \pi} \int_{0}^{2 \pi} \int_{0}^{d}\left\{\sum_{i=1}^{N} K_{R_{.} z}(z)\left[t_{i}(\theta, z)\right]^{m_{R}}\left[-\sin \theta_{i}(\theta, z)\right]\right\} d z d \theta \\
& c_{0}=\frac{1}{2 \pi} \int_{0}^{2 \pi} \int_{0}^{d}\left\{\sum_{i=1}^{N} K_{T . z}(z)\left[t_{i}(\theta, z)\right]^{m_{T}}\left[\sin \theta_{i}(\theta, z)\right]\right\} d z d \theta \\
& c_{1}=\frac{1}{2 \pi} \int_{0}^{2 \pi} \int_{0}^{d}\left\{\sum_{i=1}^{N} K_{R, z}(z)\left[t_{i}(\theta, z)\right]^{m_{R}}\left[-\cos \theta_{i}(\theta, z)\right]\right\} d z d \theta
\end{aligned}
$$

When cutting system deflection is not considered, for the particular case of slot cut machining, the variation of the undeformed chip thickness over a full cutter revolution is symmetric to the $x$ axis for each differential cutting edge element. Because of the antisymmetry of the cosine function to the same axis, the tangential and radial model parameters are decoupled and can be determined independently (as shown by Feng and Menq, 1994a). Under this situation $a_{0}$ and $c_{1}$ are equal to zero. Due to the consideration of cutting system deflection in the determination of undeformed chip thickness, the variation of the undeformed chip thickness over a full cutter revolution is no longer symmetric to the $x$ axis. The tangential and radial parameters in Eqs. (2.29) and (2.30) are 
not decoupled any more. So, to obtain $K_{T . \psi}$ and $K_{R . \psi}$, numerical integration has to be carried out for each item formulated in Eq. (2.31). The coefficients $a_{0}, a_{1}, c_{0}$, and $c_{1}$ are calculated using the empirical parameters $K_{T, z}(z), K_{R, z}(z), m_{T}$, and $m_{R}$ determined previously. These coefficients are then used in Eqs. (2.29) and (2.30) with the measured $\overline{F_{x}}$ and $\overline{F_{y}}$ to solve for the values of $K_{T \cdot \psi}$ and $K_{R \cdot \psi}$ for the particular $\psi$.

Two non-horizontal slot cuts were carried out using the same ball-end mill and workpiece material as in the previous work (Feng and Menq, 1994a). The detailed cutting conditions were $\psi= \pm 30^{\circ}, \phi=0^{\circ}, d=6.35 \mathrm{~mm}$, and $v=45.72 \mathrm{~mm} / \mathrm{min}(f=$ $0.0381 \mathrm{~mm} /$ tooth). Slot cuts were used since they resulted in symmetric undeformed chip geometry with respect to the $x$ axis in one cutter revolution for the rigid bal!-end milling system and nearly symmetric undeformed chip geometry for the flexible system. The resulting values of the coefficients formulated in Eq. (2.31) are shown in Table 2.1. As expected, the values of $a_{0}$ and $c_{1}$ are negligibly small compared with those of $a_{1}$ and $c_{0}$. This indicates that $K_{T . \psi}(\psi)$ and $K_{R . \psi}(\psi)$ are in effect decoupled in Eqs. (2.29) and (2.30) and can be determined independently.

This procedure has generated two sets of values for $K_{T \cdot \psi}(\psi)$ and $K_{R . \psi}(\psi)$ : $K_{T . \psi}=0.97, K_{R . \psi}=1.16$, for $\psi=30^{\circ} ;$ and $K_{T . \psi}=1.09, K_{R . \psi}=1.06$, for $\psi=-30^{\circ}$. These values represent the effect of the chip flow direction changes in non-horizontal cuts on the cutting mechanics. They are used to calculate cutting forces in 3D ball-end milling with $\psi= \pm 30^{\circ}$. Values of $K_{T . \psi}$ and $K_{R, \psi}$ for different $\psi$ can be obtained using this 
procedure. Empirical functional expressions will be developed when sufficient data become available.

Table 2. I Values of the coefficients formulated in Eq. (2.31) for the two non-horizontal slot cuts.

\begin{tabular}{ccccc}
\hline$\psi$ & $a_{0}$ & $a_{1}$ & $c_{0}$ & $c_{1}$ \\
\hline$-30^{\circ}$ & 0.06 & -188.48 & 308.39 & 0.05 \\
$+30^{\circ}$ & -2.78 & -114.11 & 359.78 & 0.15 \\
\hline
\end{tabular}

\subsection{Model Validation and Discussions}

The present model has been validated by comparing the predicted and the measured cutting forces in 3D ball-end milling. The measured cutting forces were obtained from a set of steady state non-horizontal and cross-feed cuts of a ball-end mill. The workpiece material used was SAE 1018 cold-rolled steel. Union Butterfield M42 Cobalt HSS ball-end mills with $12.7 \mathrm{~mm}$ diameter, 2 flutes and $35^{\circ}$ helix angle were used as the cutting tools in the experiments. The detailed experimental setup has been illustrated in the previous work (Feng and Menq, 1994a). Predicted cutting forces were calculated using the current model and the previously developed flexible system model (Feng and Menq, 1996). The test conditions of the experiments comprised of down milling cross-feed cuts and horizontal and non-horizontal cuts. Cross-feed cuts and nonhorizontal cuts were tested because they illustrated more closely the actual action of a ball-end mill used in 3-axis milling. Cross-feed cuts are required to generate satisfactory 
surface finish on the machined surface. Non-horizontal cuts are indispensable if a 3-axis NC machine is used to generate a $3 \mathrm{D}$ sculptured surface. The detailed cutting conditions of the tests are listed in Table 2.2.

Table 2.2 Detailed cutting conditions for model verification test cuts.

\begin{tabular}{ccccccc}
\hline $\begin{array}{c}\text { Test } \\
\text { No. }\end{array}$ & $\begin{array}{c}\text { Milling } \\
\text { Type }\end{array}$ & $\begin{array}{c}\text { Feed per tooth } \\
(\mathrm{mm} / \text { tooth })\end{array}$ & $\begin{array}{c}\text { Depth of Cut } \\
(\mathrm{mm})\end{array}$ & $\begin{array}{c}\text { Step Size } \\
(\mathrm{mm})\end{array}$ & $\begin{array}{c}\psi \\
(\mathrm{deg})\end{array}$ & $\begin{array}{c}\phi \\
\text { (deg.) }\end{array}$ \\
\hline 1 & down & $0.038 \mathrm{l}$ & 6.350 & -3.175 & 0 & -15 \\
2 & down & 0.0381 & 6.286 & -3.175 & +30 & 0 \\
3 & down & 0.0381 & 6.286 & -3.175 & -30 & +15 \\
4 & down & 0.0381 & 6.286 & -3.175 & +30 & -15 \\
\hline
\end{tabular}

First, a horizontal cut is carried out to show the ability of the present model in predicting cutting forces for horizontal cuts. Figure 2.10 (test No. 1) shows cutting force predictions of a horizontal down milling cut with a downward $15^{\circ}$ cross-feed. As pointed out before, the previous model (Feng and Menq, 1996) gives excellent predictions of cutting forces in horizontal cuts. Modifications are made in the current model to deal with non-horizontal cuts. The applicability of both the previous and the current models in horizontal cuts can be seen in the figure. In the current model, horizontal cuts can be treated as special cases in which $\psi=0^{\circ}$. Therefore, cutting force predictions for horizontal cuts in the current model should be as good as those in the previous model. In Figure 2.10, the heavier lines represent the current predicted cutting forces, while the thinner lines represent the previous predicted cutting forces. It can be seen that these two lines overlap each other. As expected the predicted cutting forces in the current model are 

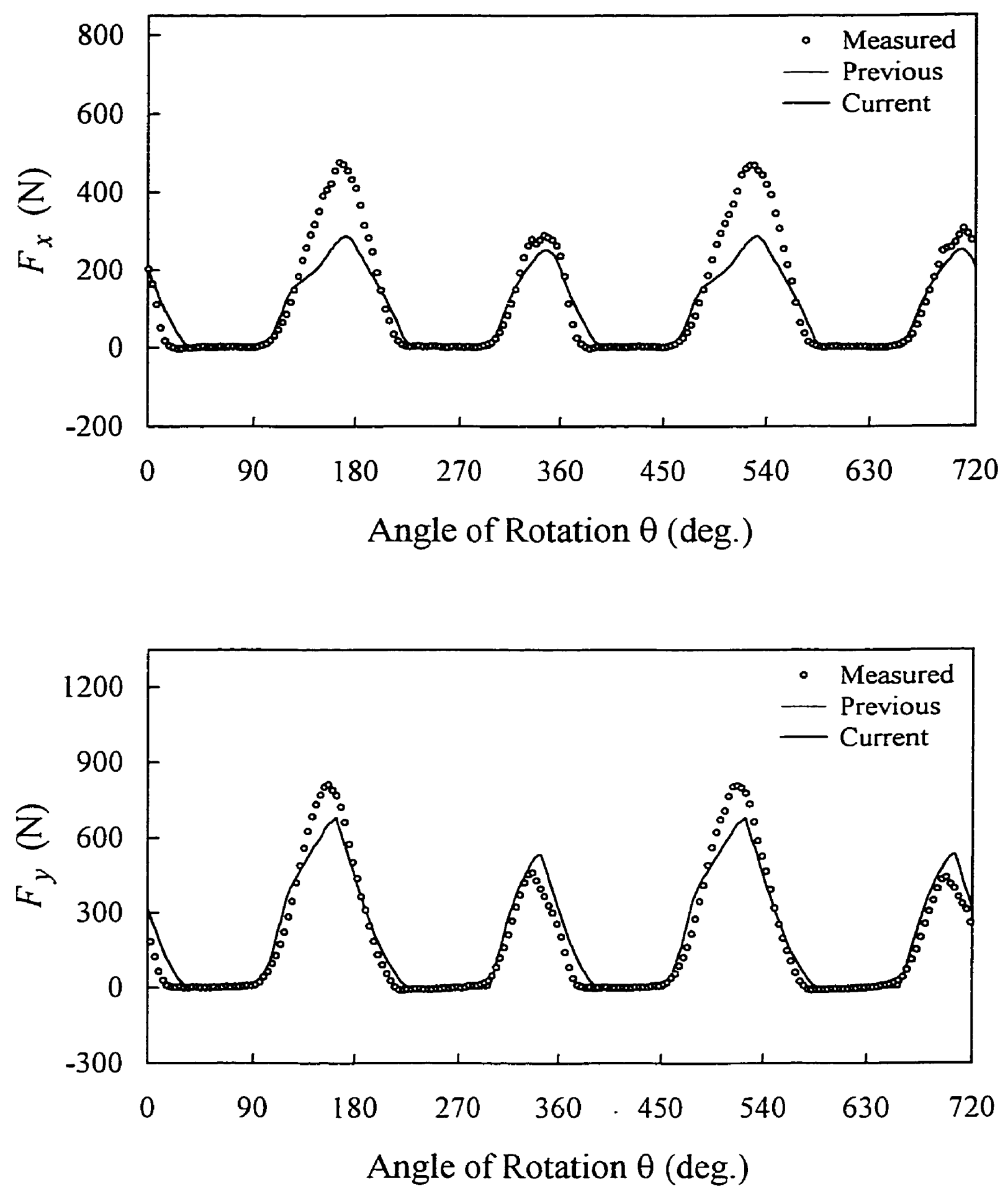

Figure 2.10 Cutting forces for $\psi=0^{\circ}, \phi=-15^{\circ}, s=-3.175 \mathrm{~mm}, f=0.0381 \mathrm{~mm} / \mathrm{tooth}$, and $d=6.35 \mathrm{~mm}$. 
exactly the same as those in the previous model and in good agreement with the measured cutting forces.

Test No. $l$ is also used to show the effect of cutter runout on cutting forces. Figure 2.11 is the comparison of predicted cutting forces with cutter runout and without runout using the current model. The thicker lines represent the predicted cutting forces with cutter runout while the thinner lines represent the predicted cutting forces without cutter runout. When cutter runout is not taken into account, the predicted cutting forces are symmetric. The peak force in the $x$ direction at $\theta=170^{\circ}$ is equal to that at $\theta=350^{\circ}$. Due to the presence of cutter runout, chip load on one tooth is larger than that on the other such that the cutting forces become asymmetric. In one cutter revolution $\left(\theta=0^{\circ}-360^{\circ}\right)$, the peak force at $\bar{\theta}=i 70^{\circ}$ becomes higher than that without cutter runout. On the other hand, the other peak force at $\theta=350^{\circ}$ is lower than the corresponding one without cutter runout. The same observation is also made for cutting forces in the $y$ direction. In practice, cutter runout is inevitable. To reflect the real characteristic of the milling processes, it is important to include cutter runout when modeling cutting forces. It has been shown in Figure 2.11 that the inclusion of cutter runout in the cutting force model gives better cutting force predictions.

Figure 2.12 (test No. 2) shows the predicted results of a non-horizontal cross feed cut carried out to show the suitability of predicting instantaneous cutting forces using coefficients obtained from measured average cutting forces of slot cuts. In the current model the newly introduced model parameters $K_{T . \psi}(\psi)$ and $K_{R, \psi}(\psi)$ are established from measured average cutting forces of non-horizontal slot cuts. The step size in test No. 

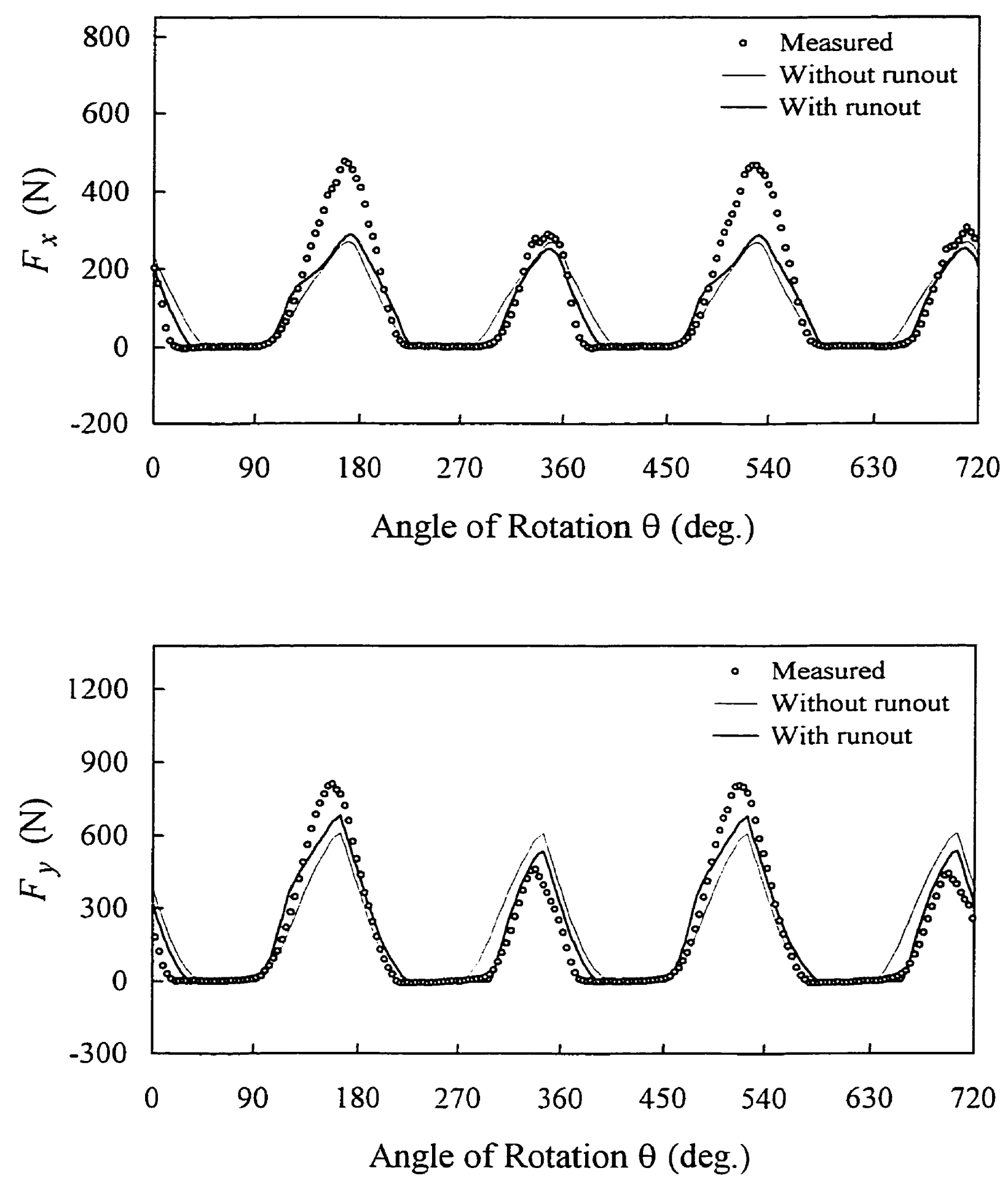

Figure 2.11 The effect of cutter runout for $\psi=0^{\circ}, \phi=-15^{\circ}, s=-3.175 \mathrm{~mm}$, $f=0.0381 \mathrm{~mm} /$ tooth, and $d=6.35 \mathrm{~mm}$. 

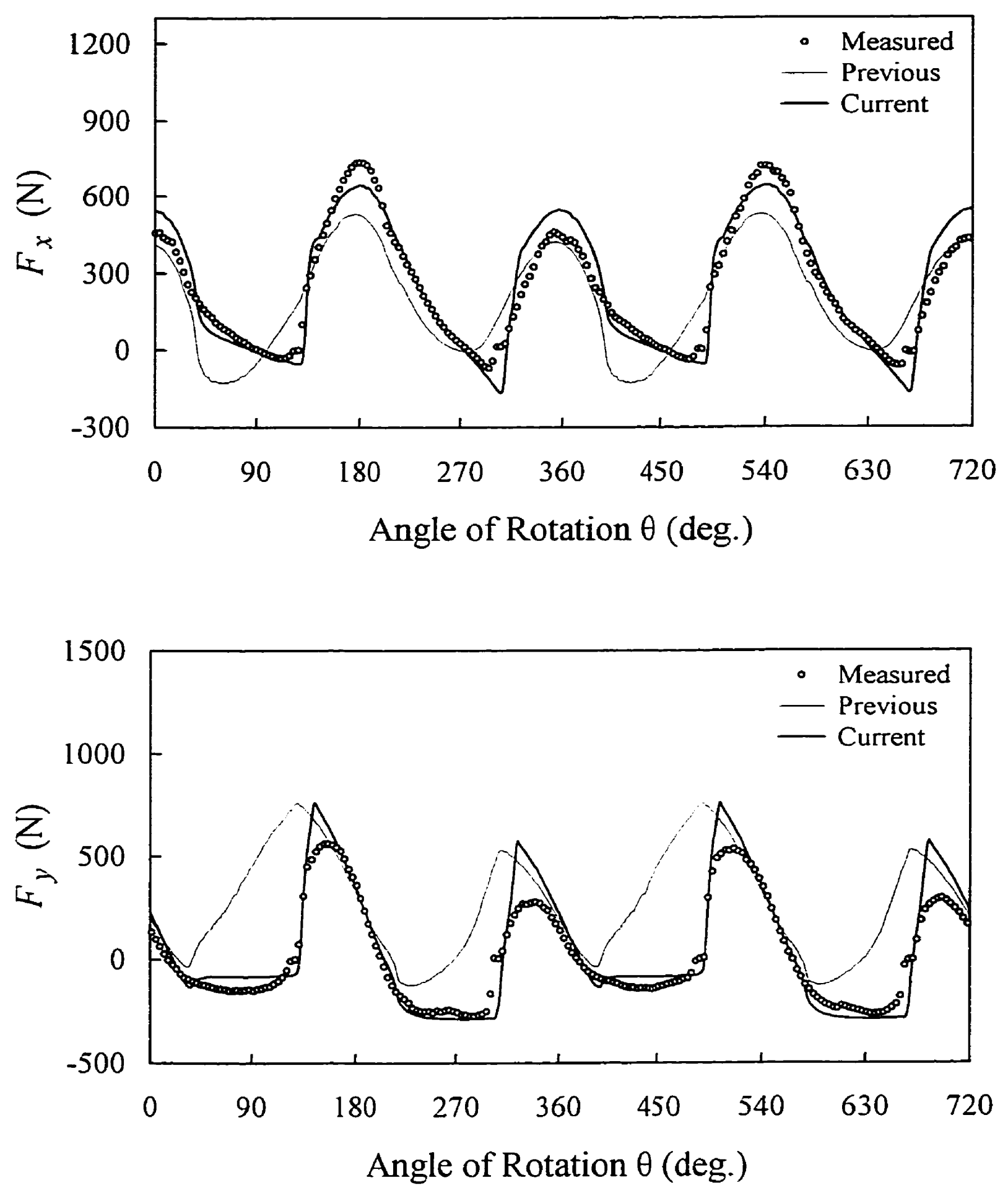

Figure 2.12 Cutting forces for $\psi=30^{\circ}, \phi=0^{\circ}, s=-3.175 \mathrm{~mm}, f=0.0381 \mathrm{~mm} / \mathrm{tooth}$, and $d=6.286 \mathrm{~mm}$. 
2 is $1 / 4$ of the cutter diameter. It is shown that the predicted results in the previous model are not even close to the measured one, especially for the $y$ cutting forces. Remarkable improvements can be found in instantaneous cutting force predictions in the current model. These results have shown that coefficients obtained from average cutting forces of slot cuts are suitable in predicting instantaneous cutting forces.

Figures 2.13 (test No. 3) and 2.14 (test No. 4) show two other cutting force comparisons. Figure 2.13 represents a 3D ball-end milling cut where the cutter feeds upward at an angle of $30^{\circ}$ and cross-feeds in the $-y$ direction (down milling) at an upward angle of $15^{\circ}$ and with a step size equal to $1 / 4$ of the cutter diameter. Figure 2.14 is for a cut with a downward $30^{\circ}$ feed and a downward $15^{\circ}$ cross-feed.

It can been seen from Figure 2.13 that the current predicted results are similar to the previous ones. Both predictions are in good agreement with the measured results. Some improvements of the present model are observed for the relatively small $x$ forces. The asymmetric cutting force waveforms of the two cutting edges are evident and this results from the combined effect of cutter runout and cutting system deflections. Figure 2.14 shows the significant improvement of the present model compared with the previous one. The previous predicted cutting forces only follow the general trend of the measured forces. Prediction inconsistency is seen to exceed $700 \mathrm{~N}$ in some areas. The present model provides excellent cutting force predictions. It accurately predicts fine details of the measured force signals. The onset of cutter engagement is shown as turning points in the cutting force waveforms in Figure 2.14. The measured $x$ force signal shows a turning point around $\theta=150^{\circ}$. The present predicted value is almost identical to the measured 

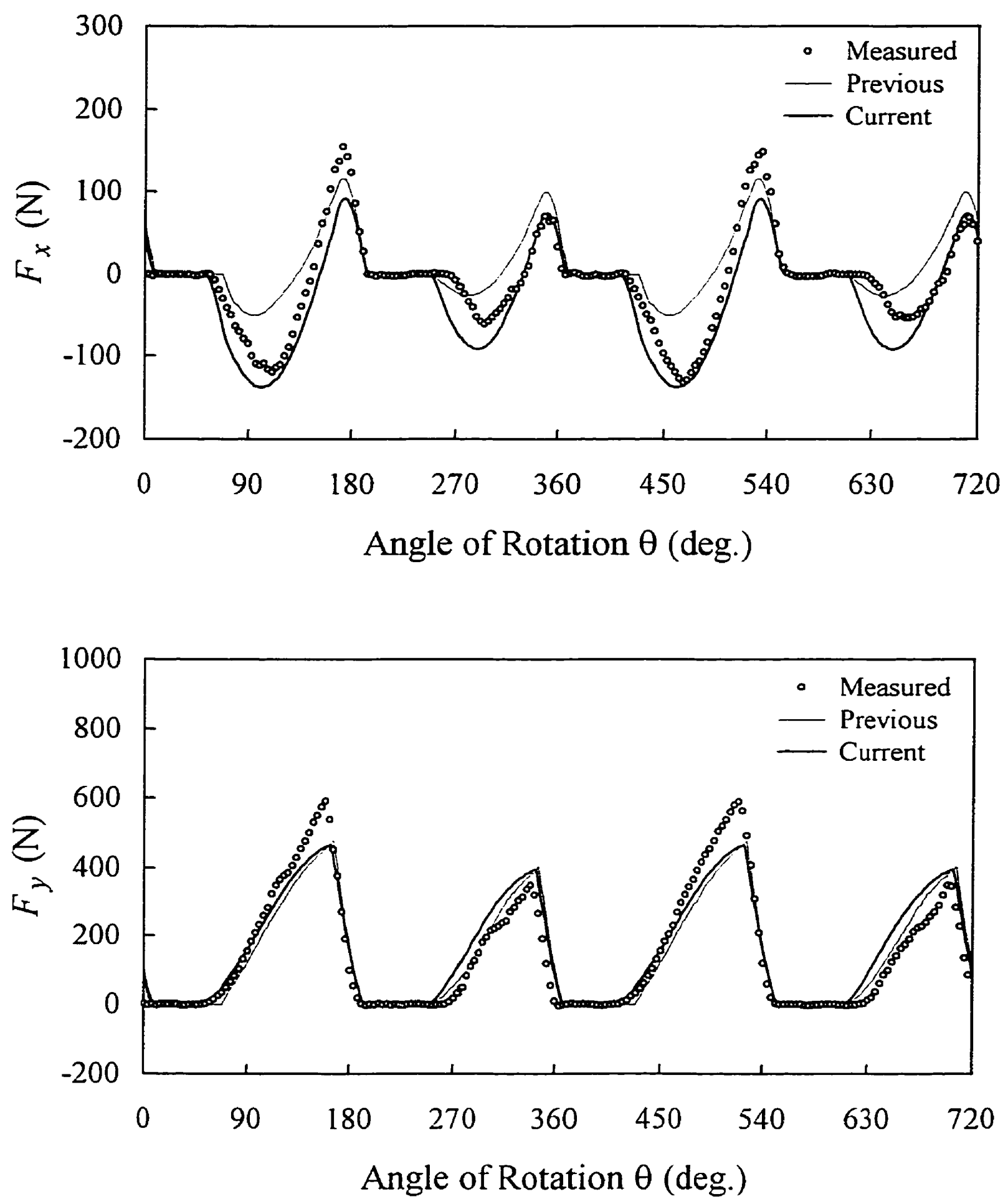

Figure 2.13 Cutting forces for $\psi=-30^{\circ}, \phi=15^{\circ}, s=-3.175 \mathrm{~mm}, f=0.0381 \mathrm{~mm} / \mathrm{tooth}$, and $d=6.286 \mathrm{~mm}$. 

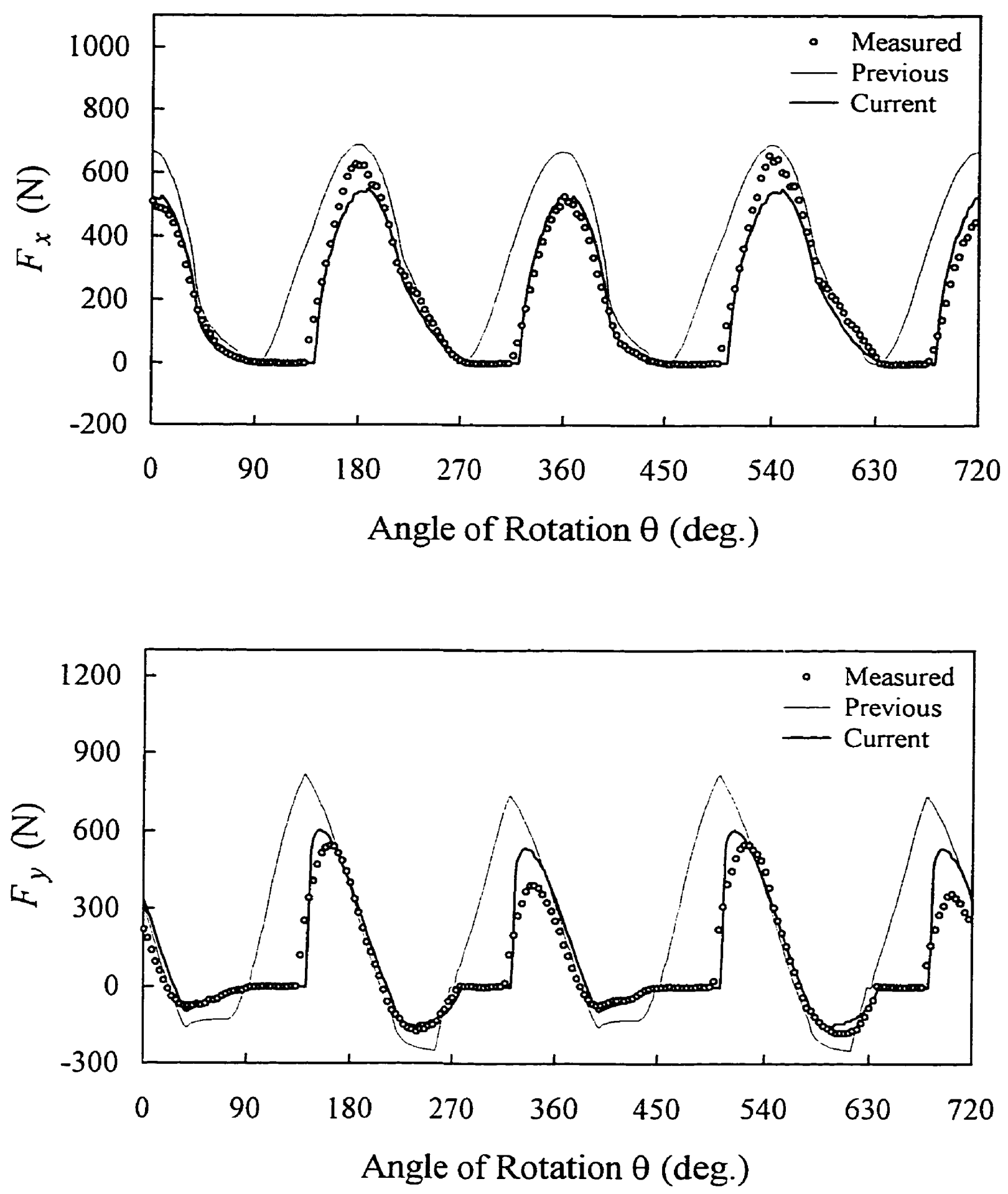

Figure 2.14 Cutting forces for $\psi=30^{\circ}, \phi=-15^{\circ}, s=-3.175 \mathrm{~mm}, f=0.0381 \mathrm{~mm} / \mathrm{tooth}$, and $d=6.286 \mathrm{~mm}$. 
one while the previous model predicts a turning point around $\theta=90^{\circ}$. Similar observations can be made for the $y$ cutting forces.

Table 2.3 Comparison of Average Prediction Errors

\begin{tabular}{ccccc}
\hline $\begin{array}{c}\text { Test } \\
\text { No. }\end{array}$ & $\begin{array}{c}\text { Average Prediction Errors } \\
\text { in Previous Model (N) }\end{array}$ & $\begin{array}{c}\text { Average Prediction Errors } \\
\text { in Current Model }(\mathrm{N})\end{array}$ & $\begin{array}{c}\text { Improvements } \\
(\%)\end{array}$ \\
\hline \multirow{2}{*}{1} & $F_{x}$ & 42.67 & 42.67 & 0 \\
& $F_{y}$ & 60.53 & 60.53 & 0 \\
2 & $F_{x}$ & 109.06 & 63.58 & 41.7 \\
& $F_{y}$ & 270.37 & 61.02 & 77.4 \\
3 & $F_{x}$ & 24.15 & 20.50 & 15.1 \\
& $F_{y}$ & 34.82 & 35.53 & $0-$ \\
& $F_{x}$ & 122.42 & 23.96 & 80.4 \\
& $F_{y}$ & 178.68 & 38.34 & 78.5 \\
\hline
\end{tabular}

Table 2.3 shows the comparison of the average prediction errors for the previous model and the current model. It can be seen that the present model provides reliable cutting force predictions for 3D ball-end milling. This is attributed to accurate representations of the cut geometry, the undeformed chip thickness distribution, and the empirical chip-force relationships. This model is being used to develop optimization technologies for sculptured surface machining with ball-end mills. 


\section{CHAPTER 3}

\section{INTEGRATED PROCESS PLANNING BASED ON CUTTING FORCE OPTIMIZATION}

\subsection{Introduction}

Process planning is a manufacturing activity generating production information from design information. It is aimed at determining the most economical manufacturing process for producing a part with high quality. As cutting forces are directly related to the process efficiency and product quality, optimization of cutting forces in machining processses plays an important roit in process pianning. The optimum cutting forces shouid be maintained in the machining process so as to achieve the highest efficiency. Optimum process parameters such as maximum feedrate are selected based on the machining errors caused by cutting forces. Process planning in 3D surface machining using ball-end milling primarily involves two procedures: tool path determination and maximum feedrate selection. Tool path is directly related to the surface geometry and feedrate specifies the speed of the tool moving along the tool path. Tool path planning requires specifying cutter feed directions and step sizes between adjacent tool paths for the cutter to generate the product geometry. The allowable scallop height on the machined surface determines the maximum step size for each cutter feed direction. Feedrate selection directly affects machining errors caused by cutting forces and cutting system deflections in end milling. As cutter feed direction and step size change, cut geometry and the resulting cutting forces change. This leads to changes in maximum feedrate so that the 
resulting machining errors can be maintained within the specified tolerance limits. Optimization of the machining process is achieved when the machining time required to manufacture the product is minimum. The machining process planning procedure can thus be interpreted as a machining time minimization procedure subjected to the constraint of the product quality requirements.

Much work has been done in the past in the area of adaptive control of the milling processes. However, implementation of such on-line adaptive control systems in industrial settings is often very difficult. The process planning approach presented herein is an off-line optimization procedure. It is clear that in this off-line optimization procedure if the machined product quality can be predicted prior to actually cutting the surface, machining planning can be intelligentiy condiucted to achieve higher prodictivity and better product quality simultaneously. To achieve this, models to predict the cutting forces, tool deflections, and machining errors of the machining process are required. The cutting force model developed in Chapter 2 provides a valuable tool for this purpose. In the finishing machining of $3 \mathrm{D}$ plane surfaces, tool path determination and maximum feedrate selection are interrelated and interact with each other. Determination of one should not be independent of the other.

For a given $3 \mathrm{D}$ plane surface, there exist many machining process plans with which the part can be machined within tolerance requirements. Of all the possible machining process plans, only the one with the minimum time and relatively small machining errors is chosen as the optimal machining process plan in this new process planning approach. In search for such an optimal machining process, the maximum step 
size, the maximum feedrate, the total tool path length, the machining errors, and the resulting machining time need to be analyzed and compared.

\subsection{Mathematical Formulation}

Numerous process plans exist to machine a $3 \mathrm{D}$ plane surface using ball-end milling that are able to meet the scallop height and tolerance requirements. The optimum machining plan requires the least machining time. Figure 3.1 illustrates the components essential to the determination of machining time for the finishing machining of a 3D plane surface. It is evident that parallel tool paths will be used to generate the plane surface geometry. For a particular cutter feed direction, maximum step size between the parallel tool paths is determined from the scallop height requirement based on the cutter geometry and the plane surface orientation. Total tool path length can then be calculated from the given plane surface geometry and the established maximum step size. Maximum feedrate is determined from the tolerance requirement using the cutting force model described in Chapter 2. Machining time for the particular feed direction is readily available from the total tool path length and the maximum feedrate. The minimum machining time corresponds to the optimum feed direction. The corresponding tool path and feedrate then constitute the optimum process plan. The components involved in Figure 3.1 are described in more detail in the following sections.

\subsubsection{Feed Direction}

Feed direction represents the moving direction of the cutter along the tool path. It is a constant in the finishing machining of $3 \mathrm{D}$ plane surfaces due to parallel tool paths. Two Cartesian coordinate systems are used to specify the cutter feed direction: the part 


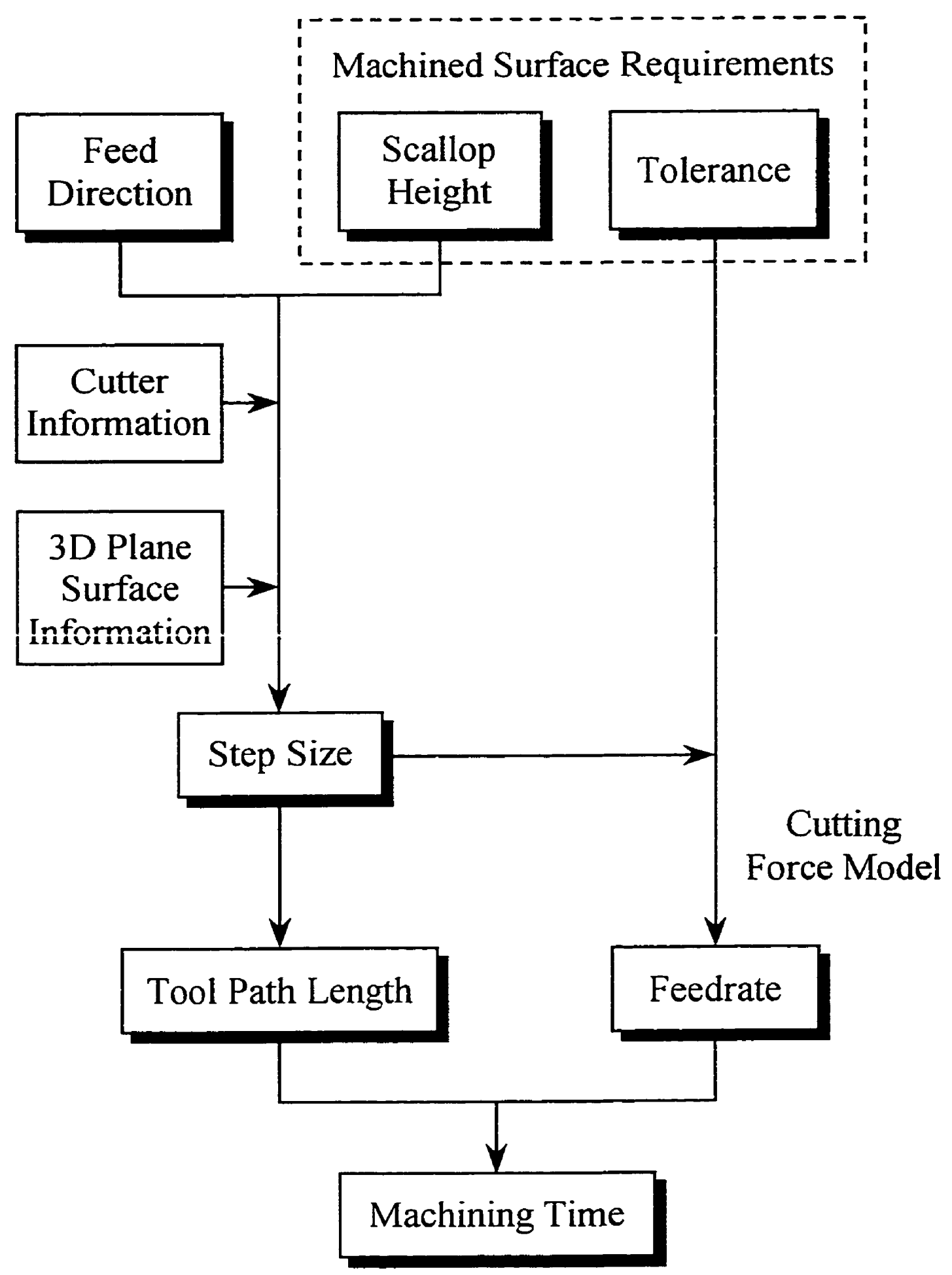

Figure 3.1 Machining time calculation procedure. 
coordinate system and the cutter coordinate system. The part coordinate system is used to define the geometry of the $3 \mathrm{D}$ plane surface. There is no restriction on the selection of the origin of the part coordinate system. It should be selected for the purpose of convenience. The cutter coordinate system is defined according to the cutter position and the feed direction. The detailed definition of the cutter coodinate system can be found in Section 2.2.1.

Figure 3.2 depicts these two coordinate systems. The coordinate system with the upper case letters $X Y Z$ is the part coordinate system. The one with the lower case letters $x y z$ is the cutter coordinate system. It is noted that the $z$ directions in both coordinate systems are the same. From the definition of the cutter coordinate system, it is clear that the $x$ axis is actually the feed direction projected on the $x$ plane. An important $2 D$ angle $\alpha$ in the $X Y$ plane in defining the cutter feed direction is introduced in this work. It represents the angular displacement between the cutter and the part coordinate systems. The range of $\alpha$ is $0^{\circ}$ to $360^{\circ}$. The definition of $\alpha$ is shown in Figure 3.2. In this figure, $\mathrm{P}_{0}$ is the cutter contact point with the surface (surface generation point). As the feed direction $(\alpha)$ changes, the ball-end mill follows different tool path to generate the plane surface. This results in changes in the cut geometry of the ball-end mill and thus changes in cutting forces, cutting system deflections, and the resulting machining errors. The coordinates of $\mathrm{P}_{0}$ in the cutter coordinate system are required to formulate the cut geometry. They vary with the feed direction. Let $\left(X_{0}, Y_{0}, Z_{0}\right)$ represent the coordinates of $P_{0}$ in the cutter coordinate system for $\alpha=0^{\circ}$ (the determination of $X_{0}, Y_{0}$, and $Z_{0}$ is described in detail in Appendix A). The coordinates of the cutter contact point $P_{0}\left(x_{0}, y_{0}\right.$, $z_{0}$ ) in the cutter coordinate system at any feed direction $\alpha$ can be expressed by 

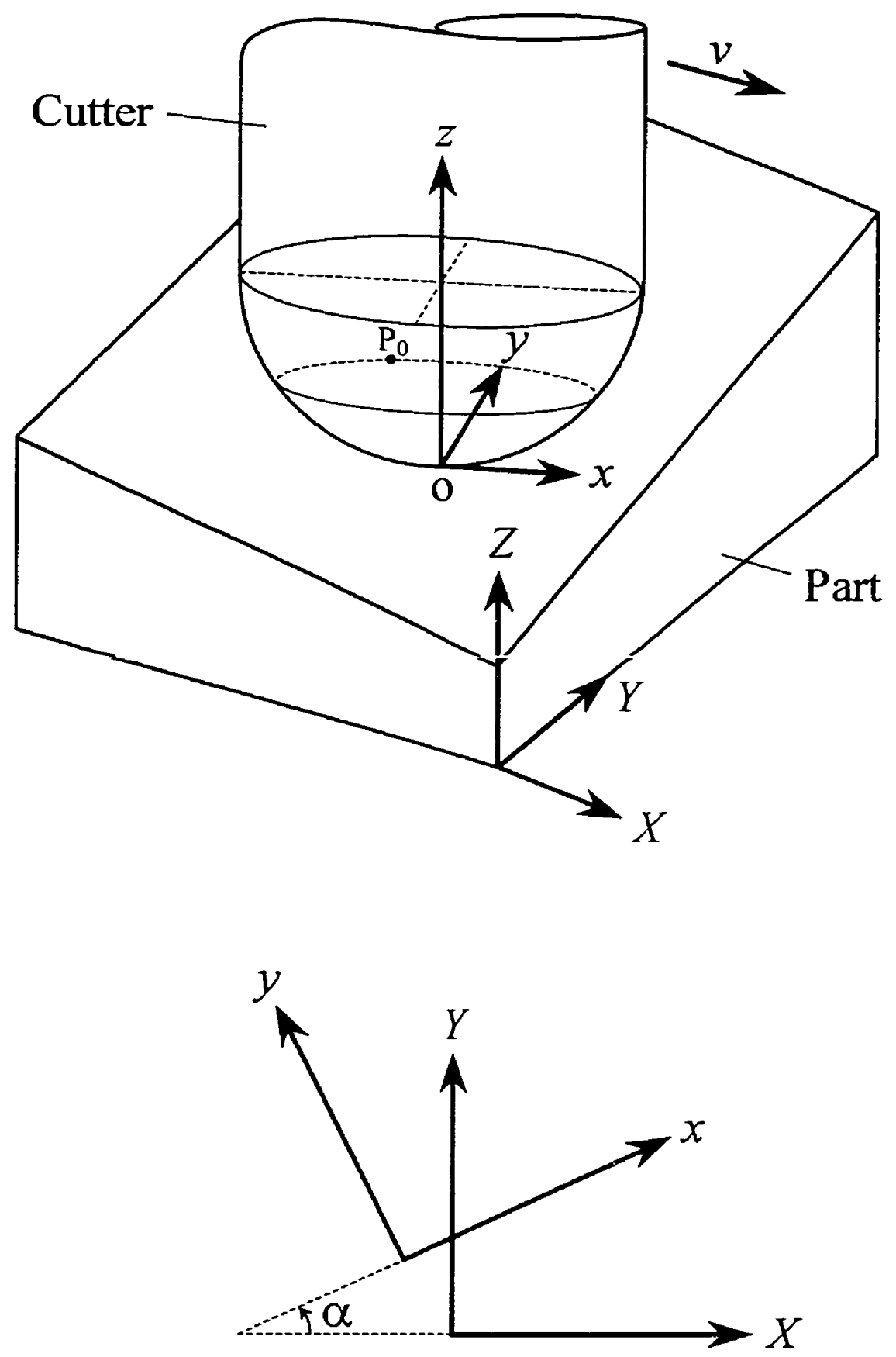

Figure 3.2 Part coordinate system and cutter coordinate system. 


$$
\left[\begin{array}{l}
x_{0} \\
y_{0} \\
z_{0}
\end{array}\right]=\left[\begin{array}{c}
X_{0} \cos \alpha+Y_{0} \sin \alpha \\
-X_{0} \sin \alpha+Y_{0} \cos \alpha \\
Z_{0}
\end{array}\right]
$$

As discussed in Section 2.2.1, the cut geometry is characterized by angles $\psi$ and $\phi$. It is evident that $\psi$ and $\phi$ change with respect to the cutter feed direction $(\alpha)$ as $x_{0}$ and $y_{0}$ change with $\alpha$. For one particular $\mathrm{P}_{0}$, the corresponding feed angle $\psi$ and cross feed angle $\phi$ at $\alpha$ are given by Eqs. (2.2) and (2.3) and re-written as

$$
\begin{aligned}
& \psi=\tan ^{-1}\left(-\frac{x_{0}}{R-z_{0}}\right) \\
& \phi=\tan ^{-1}\left(\frac{y_{0}}{R-z_{0}}\right)
\end{aligned}
$$

Changes in $\psi$ and $\phi$ result in changes in cut geometry, and therefore lead to changes in cutting forces.

\subsubsection{Step Size}

Step size represents the distance between two adjacent tool paths in the $y$ direction of the cutter coordinate system. It determines how far in the cross feed direction the cutter moves to machine the next tool path so that the machined scallop is smaller than the requirements. Changes in step size affect the cut geometry of the ball-end mill and the size of the scallop left on the machined surface. Step size is kept constant between the parallel tool paths in 3D plane surface machining to produce constant scallop height and to maximize efficiency. It is evident that maximum step size reduces the total tool path length for a specific cutter feed direction. Step size plays an important role in machining 
time calculation because it is not only related to the total tool path length but also related to the maximum feedrate. Changes of step size results in variations in the total tool path length and the maximum feedrate.

Given the scallop height requirement of a 3D plane surface, the maximum step size varies according to changes of $\psi$ and $\phi$. Step size for a given scallop height is readily determined in the normal direction of the 3D plane surface. Figure 3.3 shows the step size calculation procedure. The $x y z$ coordinate system is the original cutter coordinate system. As the scallop height is measured in the surface normal direction, if the original cutter coordinate system is used, the step size calculation procedure will become very complicated. To reduce the difficulties in calculating step size, coordinate system

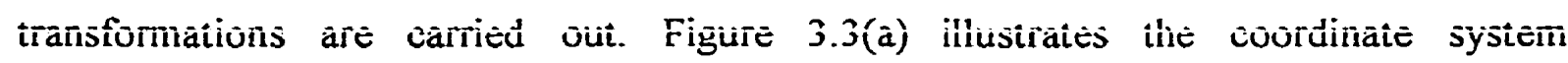
transformation procedures needed to calculate the step size:

First, the $x y z$ coordinate system is translated in the $x z$ plane to the point on the cutter whose tangent is at an angle of $\psi$ with the $x$ axis. The coordinate system is now $x^{\prime} y^{\prime} z^{\prime}$. The coordinates $\left(x_{0}, y_{0}, z_{0}\right)$ of $\mathrm{P}_{0}$ in the original cutter coordinate system now become $\left(x_{0}{ }^{\prime}, y_{0}{ }^{\prime}, z_{0}{ }^{\prime}\right)$ in the translated coordinate system $x^{\prime} y^{\prime} z^{\prime}$ :

$$
\left[\begin{array}{c}
x_{0}{ }^{\prime} \\
y_{0}{ }^{\prime} \\
z_{0}{ }^{\prime}
\end{array}\right]=\left[\begin{array}{c}
x_{0}+R \sin \psi \\
y_{0} \\
z_{0}-(R-R \cos \psi)
\end{array}\right]
$$

Second, rotation of an angle of $\psi$ is made about the $y^{\prime}$ axis and the coordinate system rotates from $x^{\prime} y^{\prime} z^{\prime}$ to $x^{\prime \prime} y^{\prime \prime} z^{\prime \prime}$. After the rotation the cross-section of the ball part of 


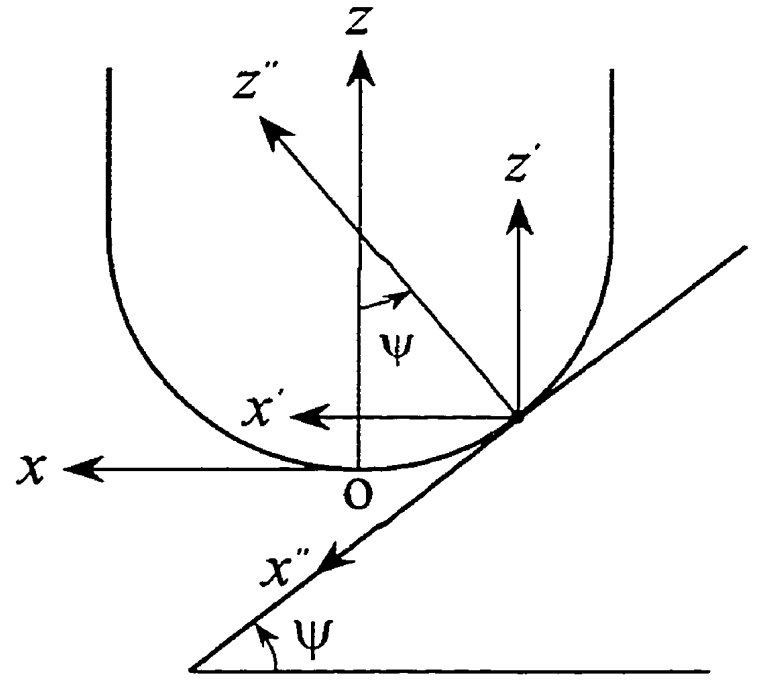

(a)

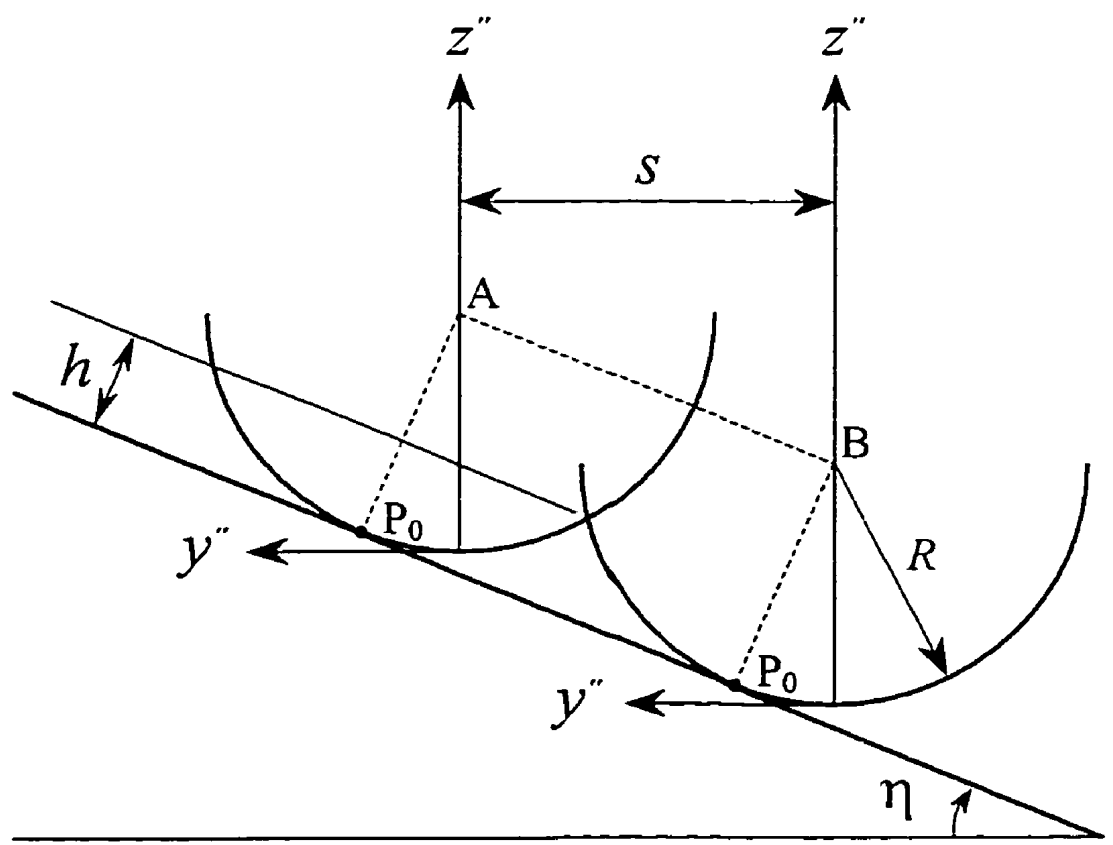

(b)

Figure 3.3 Step size calculation procedure. 
the cutter on $y^{\prime \prime} z^{\prime \prime}$ plane is a half circle. The coordinates of the cutter contact point $\mathrm{P}_{0}$ become $\left(x_{0}{ }^{\prime \prime}, y_{0}{ }^{\prime \prime}, z_{0}{ }^{\prime \prime}\right)$ :

$$
\left[\begin{array}{l}
x_{0}{ }^{\prime \prime} \\
y_{0}{ }^{\prime \prime} \\
z_{0}{ }^{\prime \prime}
\end{array}\right]=\left[\begin{array}{ccc}
\cos \psi & 0 & -\sin \psi \\
0 & 1 & 0 \\
\sin \psi & 0 & \cos \psi
\end{array}\right]\left[\begin{array}{c}
x_{0}{ }^{\prime} \\
y_{0}{ }^{\prime} \\
z_{0}{ }^{\prime}
\end{array}\right]
$$

It can been seen that after the coordinate transformations the $y$ coordinate value does not change, while $x$ and $z$ coordinates change. As shown in Figure 2.3, before the coordinate system transformations, on the plane parallel to the $y z$ plane and containing $\mathrm{P}_{0}$, the tangent to $\mathrm{P}_{0}$ is at an angle $\phi$ with the $y$ axis. The corresponding angle in the transformed coordinate system $x^{\prime \prime} y^{\prime \prime} z^{\prime \prime}$ is no longer equal to $\phi$ and denoted as $\eta$. $\eta$ can be formulated as

$$
\eta=\cos ^{-1} \frac{\sqrt{R^{2}-y_{0}^{2}}}{R}
$$

Figure 3.3(b) depicts the determination of the step size. In the transformed coordinate system $x^{\prime \prime} y^{\prime \prime} z^{\prime \prime}$, when the ball part center of the cutter moves from B to A, the distance between these two centers in the $y^{\prime \prime}$ direction is the step size $s . h$ represents the scallop height in the plane normal direction, while $\mathrm{P}_{0}$ is the cutter contact point with the surface. The step size can be expressed as

$$
s=2 \cos \eta \sqrt{2 R h-h^{2}}
$$

The detailed derivation of step size $s$ is described in Appendix B. 


\subsubsection{Feedrate}

In machining operations, feedrate represents the speed of the cutter moving in the feed direction relative to the workpiece. Feedrate selection directly affects the efficiency of the machining process and the part quality. It is obvious that faster feedrate results in higher efficiency. On the other hand, faster feedrate leads to poorer part quality due to the large cutting system deflections caused by excessive cutting forces. Constrained by the surface tolerance requirements, cutting forces can not exceed the limiting values. Since feedrate is directly related to cutting forces, there are upper limitations for the allowable feedrate during the machining process. For an end mill with $N$ cutting edges, the feedrate, $\nu$, can be calculated by:

$$
v=f N S
$$

where $f$ is the chip load (feed per tooth) and $S$ is the spindle speed. $N$ is fixed for a given cutter. $S$ is optimized with respect to cutting speed and tool life. As a result, feedrate optimization is in fact a procedure of optimizing the chip load. Chip load $f$ is an essential parameter to cutting forces. Its optimal value is obtained from cutting force and machining error calculations using an iterative procedure. Cutter feed direction and maximum step size determined previously are required to calculate the cutting forces. The cutting forces used to determine the resulting machining errors are those when the cutter is generating $\mathrm{P}_{0}$ on the plane surface. As the ith cutting edge is generating $\mathrm{P}_{0}$, the angular orientation of the ball-end mill is denoted as $\theta_{i}$ :

$$
\theta_{i}=\sin ^{-1} \frac{x_{0}}{\sqrt{x_{0}{ }^{2}+y_{0}^{2}}}+\frac{z_{0}}{R} \tan \beta+(i-1) \frac{2 \pi}{N}
$$


Among the $N$ cutting edges, only the cutting edge that produces the largest cutter force when generating $\mathrm{P}_{0}$ is considered. Cutting forces of this cutter orientation are calculated which are used to iteratively determine the maximum feedrate. It is evident from Eq. (3.9) that $\theta_{i}$ is related to the cutter contact point with the $3 \mathrm{D}$ plane surface. As has been shown in Eq. (3.1), when $\alpha$ changes, the values of $x_{0}$ and $y_{0}$ change. This results in the change of $\theta_{i}$ according to Eq. (3.9). More importantly, cutting force components calculated at $\theta_{i}$ change accordingly.

The surface tolerance which is defined in the surface normal direction is an important criterion in the calculation of the maximum feedrate. Machining errors mainly result from cutting system deflections in ball-end milling and are measured in the surface normal directions. The machining error is the component of the cutting system deflection in the surface normal direction. In other words, the machining error is the inner product of cutting system deflection $\delta_{k y}$ and the unit vector $\hat{n}$ of the surface normal. The resulting machining error $e$ is then given by:

$$
e=\delta_{x \gamma} \cdot \hat{n}
$$

This machining error is to be evaluated against surface tolerance requirements. To assure product quality, $e$ must be less than the surface tolerance.

Iterative procedure is applied to determine the maximum chip load $f$. First, a preset initial value of $f$ is used. Cutting forces and the resulting deflections in the $x$ and the $y$ directions are calculated based on this $f$ using the cutting force model described in the previous chapter. The machining error is calculated from the inner product of the 
cutting system deflection and the surface normal vector. Whenever the difference between the surface tolerance and the calculated machining error is larger than the specified convergence criterion, $f$ is updated according to this difference. Cutting forces and cutting system deflections are re-calculated with the updated $f$. This iterative procedure continues until the calculated machining error is very close to the specified surface tolerance requirement. In other words, the converged $f$ is found when the projection of the cutting system deflection in the surface normal direction of the $3 \mathrm{D}$ plane surface is equal to the specified tolerance.

It should be noted that often the chip load $f$ can reach a relatively large value without resulting in significant machining errors. This happens when cutting forces are sma!l as the cutter is generating $P_{\bar{u}}$ and'or the normal vector of the plane surface is almost perpendicular to the cutter $x y$ plane. A typical example is that the machining error of a horizontal plane is practically zero because the projected error of the cutting system deflection is zero. Under these situations, the calculated feedrate can be very large or even infinite. Using these calculated maximum feedrate in practice is not realistic. Even though the resulting machining errors are small at the cutter contact point, cutting forces in other cutter orientations may be very large. In these cases, the maximum chip load value recommended by machining handbooks (e.g., Tool and Manufacturing Engineers Handbook, 1983), $f_{\max }$, is used to avoid tool breakage or chatter. In the current work, whenever the converged $f$ exceeds the maximum value recommended by machining handbooks, $f_{\max }$ is used as the feed per tooth in the calculation of feedrate. 


\section{2.+ Machining Time}

The machining time for one particular feed direction is readily available from the total tool path length and feedrate. The approach to calculate the total tool path length is depicted in Figure 3.4. Cutter feed direction and maximum step size are used to define the parallel tool paths on the $3 \mathrm{D}$ plane surface. The basic idea is to calculate the projected tool path length on the $x y$ plane first, and then calculate the tool path length on the $3 \mathrm{D}$ plane surface. The tool path determination procedure is as follows. First, a series of lines parallel to the $x$ axis in the cutter coordinate system are used to intersect the projected area of the part in the $x y$ plane. The distance between any two adjacent parallel lines is equal to the maximum step size $s$. Second, determine the lengths of these intersected lines within the projected arca. Third, determine the tool path lengths on the $3 D$ plane surface.

Several factors need to be considered in the determination of the tool path lengths. The first one is the machined scallop heights in the beginning and the end of the machining process. It should be clear from Figure 3.3 that at the beginning or the end of machining, when the distance between the cutter contact (CC) tool path and the plane surface edges in the $y$ direction is less than $s / 2$, the resulting scallop height is less than the maximum scallop height. On the other hand, if this distance is larger than $s / 2$, the resulting scallop height is larger than the maximum scallop height. Therefore, to eliminate unnecessary cutter movements, the first intersecting line begins at a distance of $s / 2$ in the $y$ axis direction with respect to the plane surface edge. At the end of machining, if the distance between the plane surface and the last intersecting line is larger than $s / 2$, an additional tool path is needed to make the scallop height less than the maximum scallop height. Otherwise no additional path is needed. 

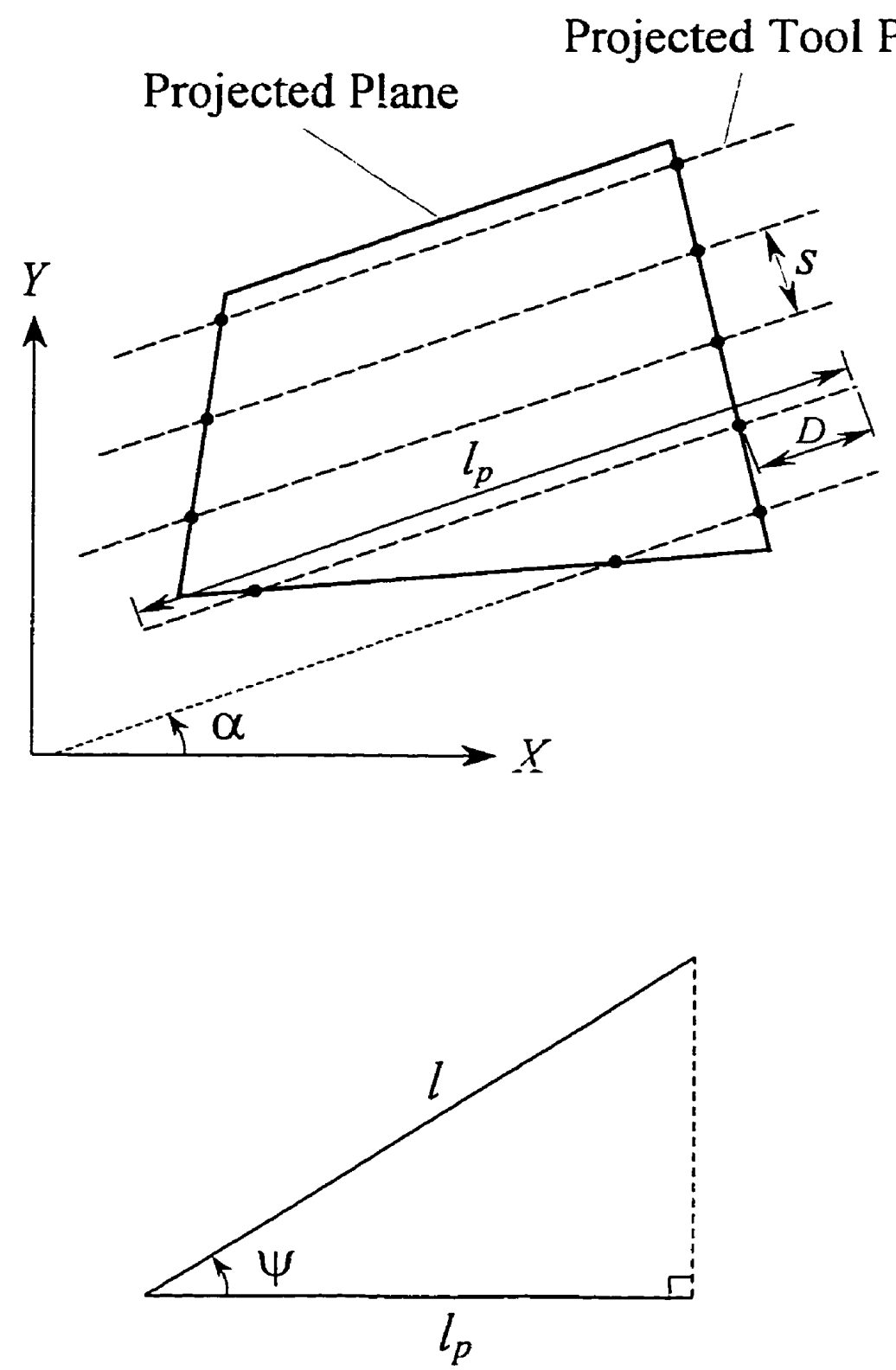

Figure 3.4 Tool path length calculation approach. 
Another factor that should be taken into account is the entry and the exit extension distances from the plane surface. In practice, the cutter starts and ends cutting at recommended extension distances away from the part to provide clearance to the machined surface. Entry and exit distances are in fact part of each individual tool path. The entry and the exit extension distance used in the present work is the cutter diameter $D$. Therefore, a distance of $2 D$ should be added to each projected tool path length.

In this work, lace (zigzag) or non-lace cut patterns can be used. In non-lace machining, the cutter moves in one direction only. After the cutter finishes machining one path, it moves rapidly to the start position of the next path. This rapid tool movement is ignored in the calculation of machining time because of the rapid feedrate. In other words, time required to rapidly position the cutter to the starting location of each too! path is not considered in the calculation of the machining time.

So far, by considering all the factors discussed above, the projected tool path length $l_{p}$ in the $x y$ plane can be calculated. By projecting $l_{p}$ onto the $3 \mathrm{D}$ plane surface by the feed angle $\psi$, the individual tool path length, $l$, can be determined:

$$
l=\frac{l_{p}}{\cos \psi}
$$

Summing up all the individual tool path lengths yields the total tool path length $L$.

Once the total tool path length $L$ and the maximum feedrate $v$ for one particular cutter feed direction are available, the machining time, $t$, for this feed direction can easily be determined: 


$$
t=\frac{L}{v}
$$

\subsection{Simulation Results and Discussions}

A simulated machining operation is used to demonstrate the feasibility of the current process planning method. The geometry of the $3 \mathrm{D}$ plane surface is described by a general plane expression: $A x+B y+C z+D=0 .(A, B, C)$ is the plane normal vector. The 3D plane normal vector used in the simulated study is $(0.5,0.5,1.0)$. The projected area of the plane surface on the $X Y$ plane is a $100 \mathrm{~mm} \times 100 \mathrm{~mm}$ square. A ball-end mill with $12.7 \mathrm{~mm}$ diameter, $35^{\circ}$ helix angle, and two cutting edges is used. Cutting conditions for the simulated down milling cuts are: depth of cut $d=6.35 \mathrm{~mm}$ and spindle speed $S=600 \mathrm{rpm}$. The machined surface requirements are: maximum scallop height $h=0.1 \mathrm{~mm}$ and surface tolerance $= \pm 0.025 \mathrm{~mm}$. The empirical parameters of the cutting force model have been described in the previous work by Feng and Menq (1996). $K_{T \cdot \psi}(\psi)$ and $K_{R . \psi}(\psi)$, used to characterize non-horizontal cutting mechanics, are approximated by

$$
\begin{array}{ll}
K_{T . \psi}(\psi)=0.97, K_{R . \psi}(\psi)=1.16 & \left(\psi>30^{\circ}\right) \\
K_{T . \psi}(\psi)=1.0-0.001 \psi, K_{R . \psi}(\psi)=1.0+0.0053 \psi & \left(30^{\circ} \geq \psi \geq 0^{\circ}\right) \\
K_{T . \psi}(\psi)=1.0-0.003 \psi, K_{R . \psi}(\psi)=1.0-0.002 \psi & \left(0^{\circ} \geq \psi \geq-30^{\circ}\right) \\
K_{T . \psi}(\psi)=1.09, K_{R . \psi}(\psi)=1.06 & \left(\psi<-30^{\circ}\right)
\end{array}
$$


To simplify the calculations, the origin of the part coordinate system is set at the left bottom corner of the projected square area in the $X Y$ plane. One edge of the square is set as the $X$ axis of the part coordinate system and the perpendicular edge on the left is the $Y$ axis.

Figure 3.5 shows the variation of step size and total tool path length with respect to $\alpha$. From Figure 3.5(a), it can be seen that the variation of step size is relatively small and around $20 \%$. The step size changes within the range of $1.82 \mathrm{~mm}-2.25 \mathrm{~mm}$. A period of $\pi$ is observed for both parameters in Figure 3.5. This periodicity is due to the same tool paths followed by the ball-end mill at $\alpha$ and $\alpha+\pi$ in reverse directions. It can be seen from Eq. (3.7) that as the absolute value of $\eta$ increases, the step size $s$ decreases. As described in Section 3.2.2, $\eta$ is closely related to $\phi$. From Eqs. (3.3) and (3.6), it is clear that as the absolute value of $\phi$ increases, the step size decreases. In Figure 3.5(a) the values of step size at $135^{\circ}$ and $315^{\circ}$ are the smallest because the absolute values of $\eta$ and $\phi$ are the largest at these positions. While at $\alpha=45^{\circ}$ and $\alpha=225^{\circ}, s$ becomes the largest due to the smallest $\eta$ and $\phi$ (both equal to 0 ).

Figure 3.5 (b) shows the variation of total tool path length, $L$, with respect to $\alpha$. It can be seen that the variation of $L$ is within $6.84 \mathrm{~m} \sim 7.42 \mathrm{~m}$ and less than $10 \%$. One observation made is that even though the step sizes at $\alpha=45^{\circ}$ and $225^{\circ}$ are the largest, the total tool lengths at these feed directions are still very large. This is because the total tool path length not only depends on the step size $s$ but also the feed angle $\psi$ (Eq. (3.11)). $\psi$ is the largest at these feed directions as can be seen from Eqs. (3.1) and (3.2). The 


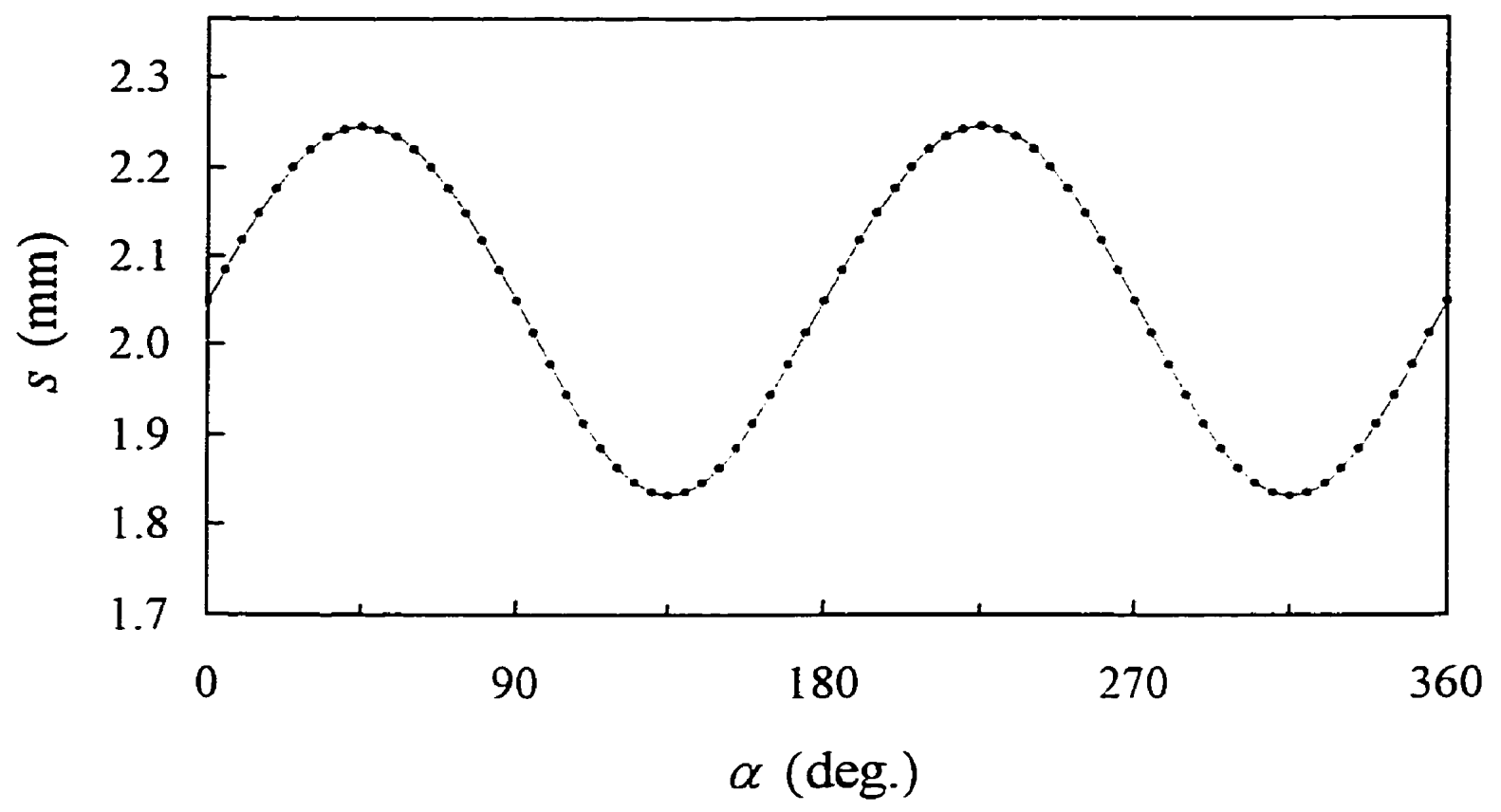

(a)

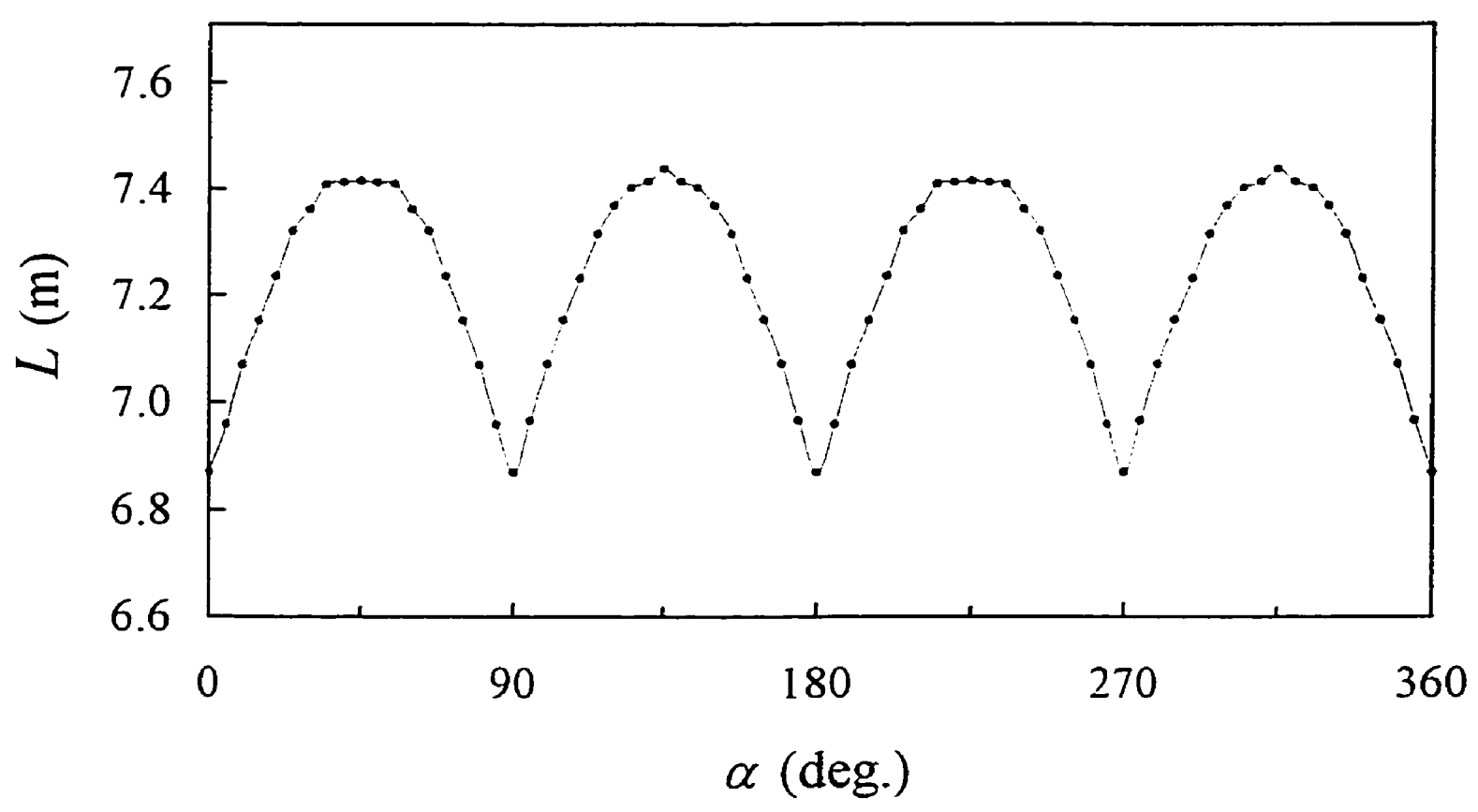

(b)

Figure 3.5 Variation of (a) step size and (b) total tool path length with $\alpha$. 
combination of the largest step size and the largest $\psi$ results in the very large total tool path length at these feed directions. Another observation made is the small peaks of the total tool path length at $\alpha=135^{\circ}$ and $315^{\circ}$. It can be explained by the entry and exit extension distance $2 D$ added to each individual tool path. Since the size of the plane surface is relatively small with respect to the cutter diameter, the total tool path length is sensitive to the additional entry and exit extensions. When the plane surface is relatively large, the total tool path length becomes less sensitive to the entry and exit extensions, and it is expected that the tool path length curve will become smother.

Figure 3.6(a) shows the variation of the maximum feed per tooth $f$ at different $\alpha$. The maximum feed per tooth $f_{\max }$, recommended by machining handbooks for similar cutring conditions and tooi/work materiais, is equal to $0.08 \mathrm{~mm} /$ tooth. There are two pocket areas in the figure in which the converged feed per tooth $f$ is less than $f_{\max }$. At $\alpha=95^{\circ} \sim 120^{\circ}$ and $\alpha=240^{\circ}-345^{\circ}$ the maximum feed per tooth $f$ is less than $f_{\max }$, while at other feed directions the feed per tooth is $f_{\max }$. This is because cutting system deflection varies at different feed directions. It results in variations in the allowable maximum $f$ with $\alpha$. As mentioned before, the machining errors are the inner product of the cutting system deflection and the plane surface normal. In fact, when the plane inclination is very small (i.e., when the plane surface normal is almost parallel to the cutter axis), the component of cutting system deflection projected in the plane surface normal direction is very small.

Once $f$ is obtained, the machining error at different $\alpha$ can be determined. Figure 3.6(b) shows the resulting machining errors at different $\alpha$. It is noted that when the 


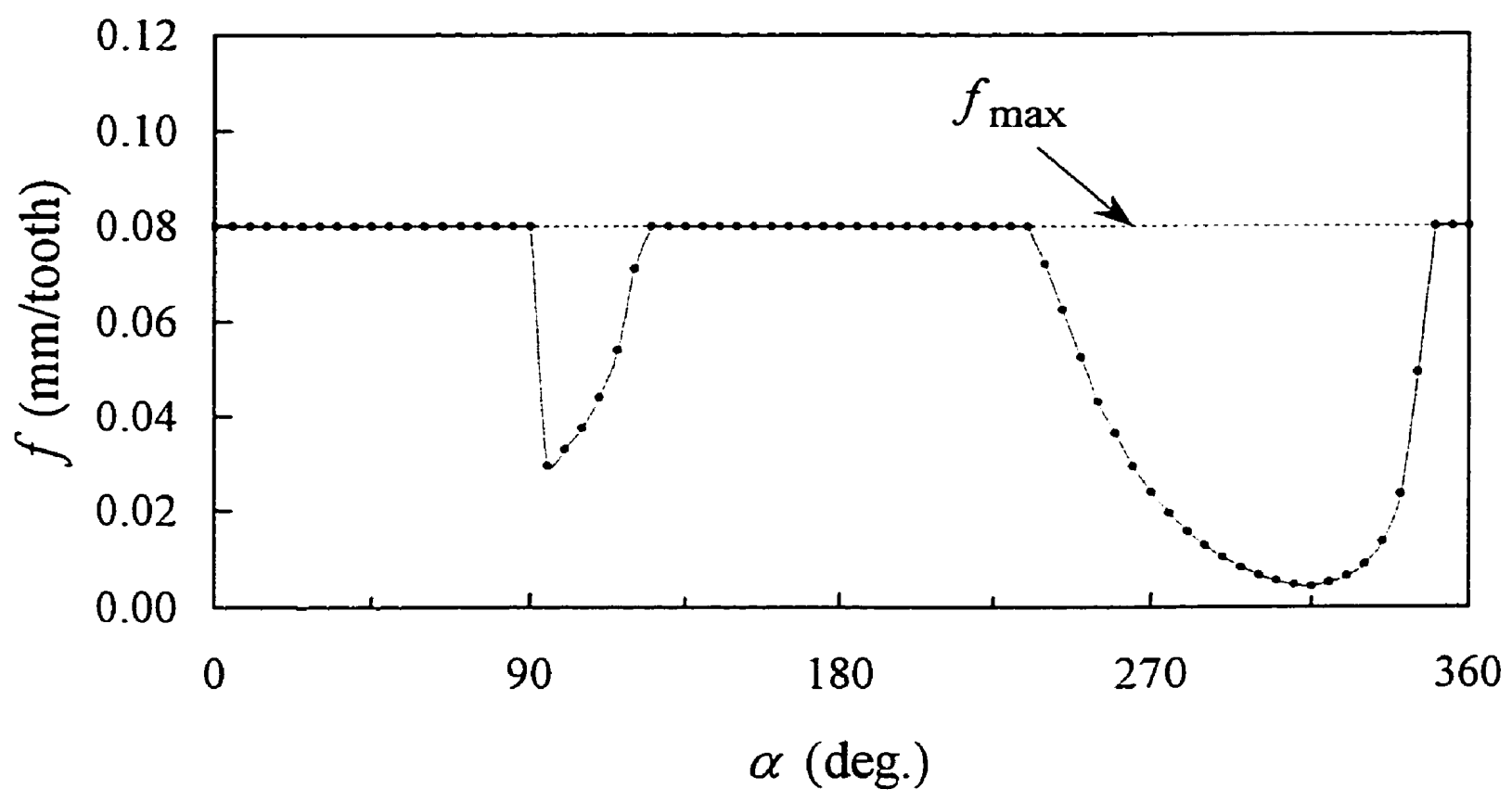

(a)

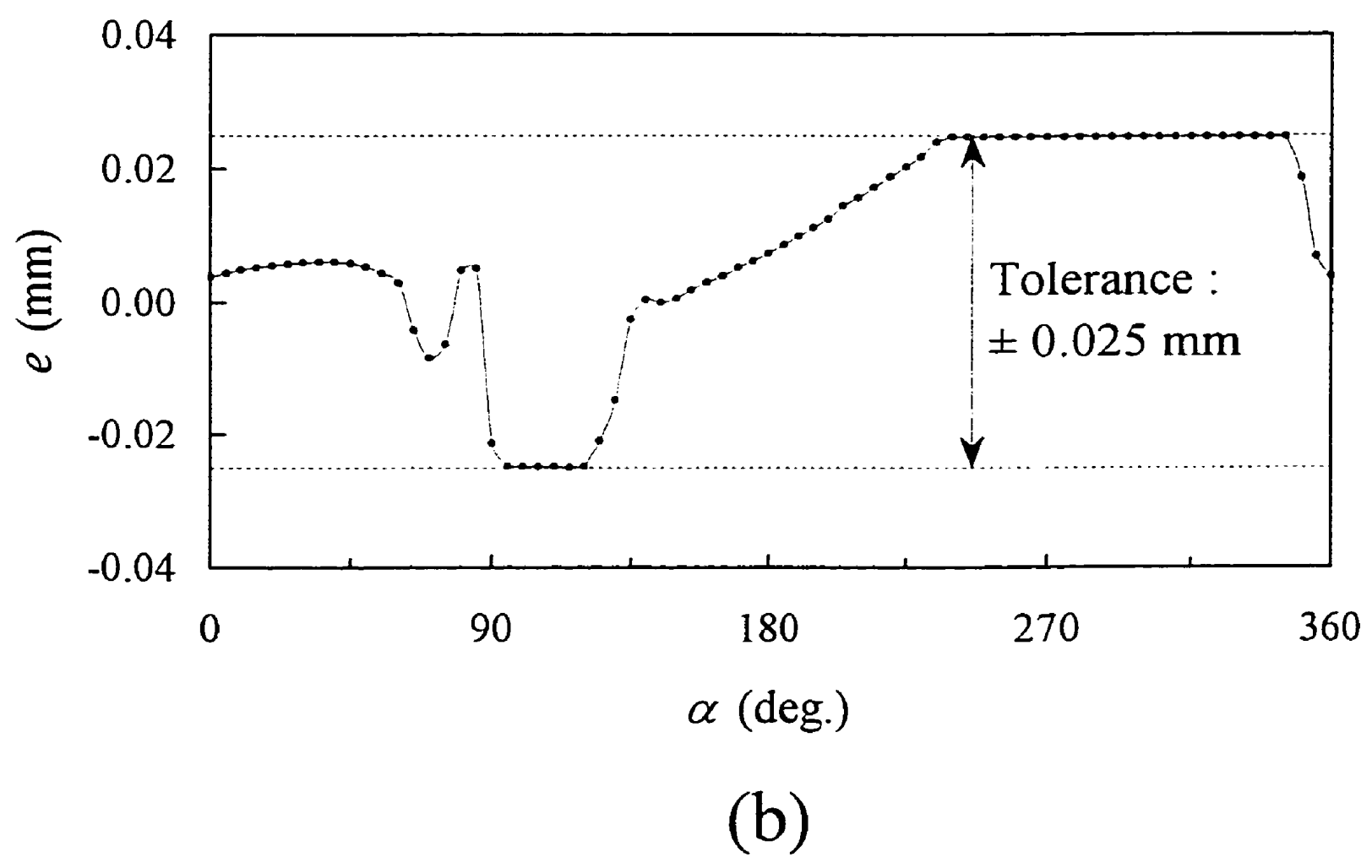

Figure 3.6 Variation of (a) feed per tooth and (b) machining error with $\alpha$. 
converged $f$ is smaller than $f_{\max }$ (i.e., in the pocket areas), the machining errors are almost equal to the tolerance value $( \pm 0.025 \mathrm{~mm})$. When $f_{\max }(0.08 \mathrm{~mm} /$ tooth $)$ is used, the machining errors are smaller than the tolerance. At $\alpha=0^{\circ} \sim 90^{\circ}, 125^{\circ} \sim 235^{\circ}$ and $350^{\circ}-360^{\circ}$, the machining errors caused by cutting system deflections are smaller than the tolerance. At some cutter feed directions the machining errors are close to zero, while at others the machining errors are bigger. This figure can be used to select the optimum cutter feed direction to produce the smallest machining error.

Figure 3.7 shows the trajectories of cutting system deflections at different cutter feed directions in the $X Y$ plane of the part coordinate system. The two thicker dashed lines represent the boundaries of the maximum cutting system deflection in the $X Y$ plane in order to meet the ivierance requirement. These two iimits are estabiished using the specified tolerance value, $\pm 0.025 \mathrm{~mm}$. It is expected that if the cutting system deflection falls within the two dashed lines: $\delta Y=-\delta X+0.0612$ and $\delta Y=-\delta X-0.0612$ (detailed derivations are described in Appendix C), the machining errors caused by cutting system deflections are within tolerance. These two limit lines are established from the surface tolerance requirement. They form the boundary of allowable cutter deflections in the $X Y$ plane. At the cutter feed directions in which a converged $f$ can be found, the cutting system deflection always reach the limit at the converged value. It can be seen that at $\alpha=110^{\circ}, 250^{\circ}$, and $330^{\circ}$, the converged $f$ can be found and is smaller than $f_{\max }$. Therefore the cutting system deflections reach the limit lines. Theoretically, except the horizontal plane, at any feed direction there exists one cutting system deflection that will result in an inner product with the surface normal equal to the tolerance. Sometimes at this feed direction the converged $f$ may be larger than $f_{\max }$ and the corresponding 


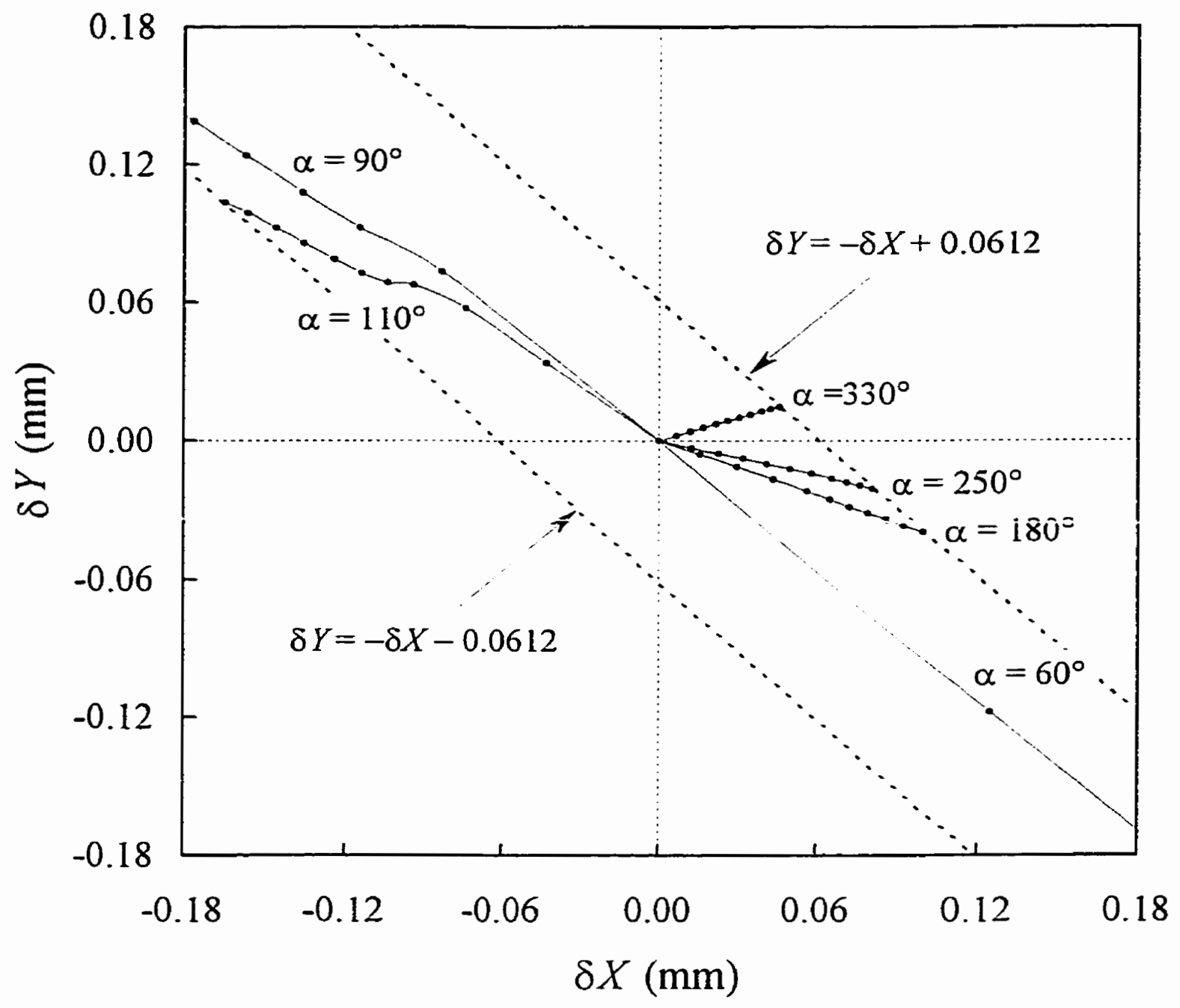

Figure 3.7 Trajectories of cutting system deflections at different $\alpha$. 
excessive cutting system deflections will result in cutter breakage. For example, at $\alpha=60^{\circ}$ the deflection is almost parallel to the limit lines, and it will intersect the upper limit line somewhere in the far position where the cutting forces are very large. This can be the optimum cutter feed direction for maximum efficiency and least machining error. The direction change of the cutting system deflection trajectory with respect to $\alpha$ can also be seen from Figure 3.7. For the first pocket in Figure 3.6(a), the cutting system deflections are seen at the second quadrant of the $X Y$ plane and restricted by the lower limit. While the cutting system deflections for the second pocket in Figure 3.6(a) are restricted by the upper limit line.

Machining time for different feed directions is shown in Figure 3.8. For those fécú directions in which the converged $f$ is less than $f_{\max }$, the machining time incteases dramatically. The two peaks in Figure 3.8 correspond to the two pockets in Figure 3.6(a). At feed direction in which $f_{\max }$ is used, due to the small variation of the total tool path lengths (less than 10\%), the variation of machining time at these directions is very small. Because of the small variation of machining time, in choosing the optimum cutter feed direction, the machining error should be considered. It is found that at $\alpha=0^{\circ} \sim 60^{\circ}, f_{\max }$ is used and the machining error is around zero. So, these feed directions can be considered as the optimum machining directions. From the figure it can be seen that the optimum feed direction is not unique but within an optimum range.

Comparison is made for machining a plane surface at different inclinations. The plane is a $100 \mathrm{~mm} \times 75 \mathrm{~mm}$ rectangle. The different plane inclinations are created by rotating the horizontal plane about the $Y$ axis by an angle $(\gamma)$ of $10^{\circ}, 20^{\circ}$, and $30^{\circ}$ in the 


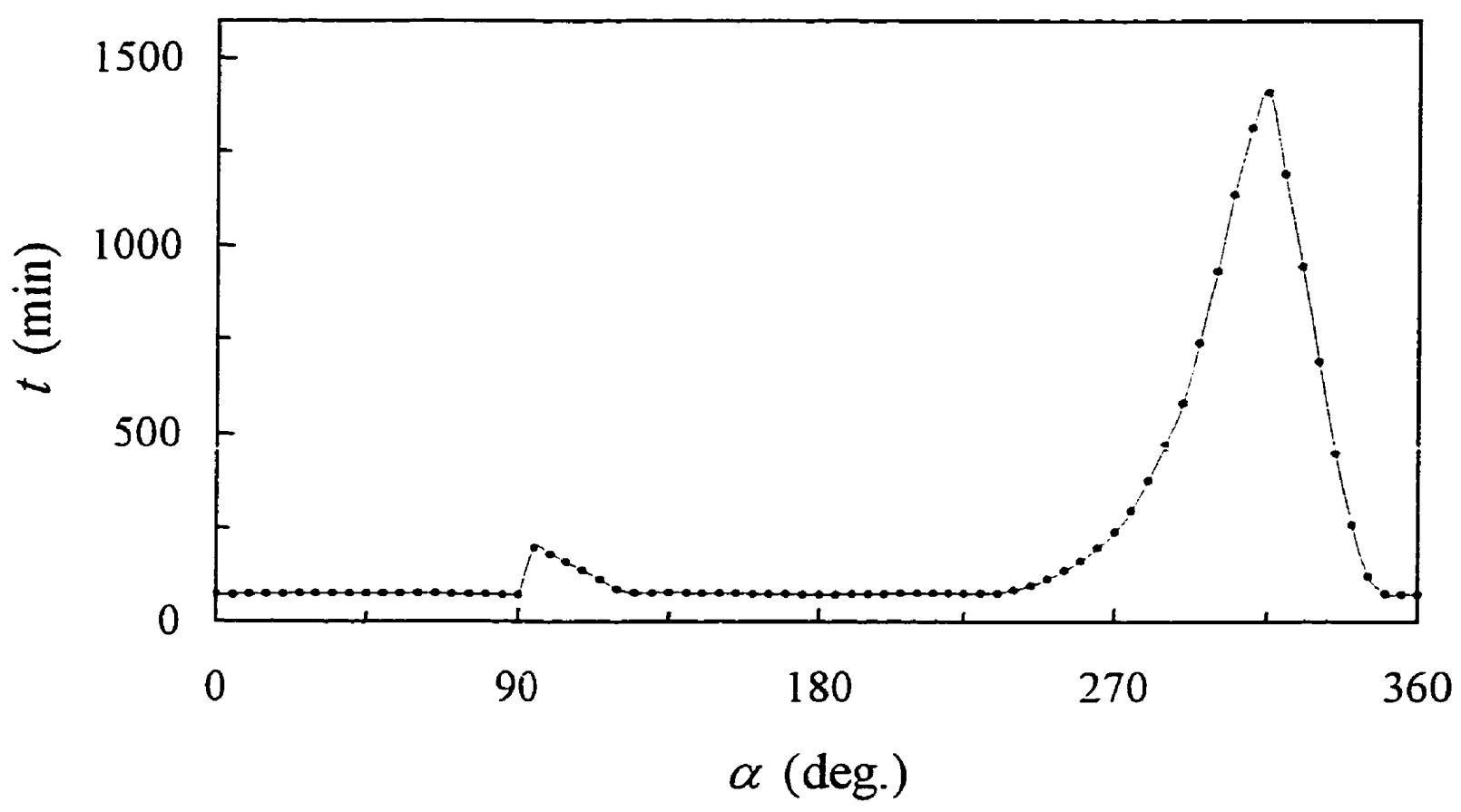

Figure 3.8 Machining time at different $\alpha$. 
$X Y$ plane of the part coordinate system. Figure 3.9 shows the machining time at these different inclination angles. At $\gamma=0^{\circ}$ the machining error is practically zero, so $f_{\max }$ is always used. Also, variation of the total tool path length at different feed directions is very small. As a result, variation of the machining time at different feed directions is negligible and is almost a straight line. As $\gamma$ increases, the component of cutting system deflection projected in the surface normal direction increases. This means the converged $f$ at some feed directions decrease such that the cutting forces and the cutting system deflection decrease and the resulting machining errors can be kept within tolerance. The larger the plane tilts (i.e., the larger the value of $\gamma$ ), the larger the value of $f$ has to decrease and the more the machining time is required. This can be seen in Figure 3.9. In this figure, at cutter feed directions in which $f_{\max }$ can not be used, the required machining time for $\gamma=30^{\circ}$ is the most, $\gamma=20^{\circ}$ the second most, and $\gamma=0^{\circ}$ is the least. 


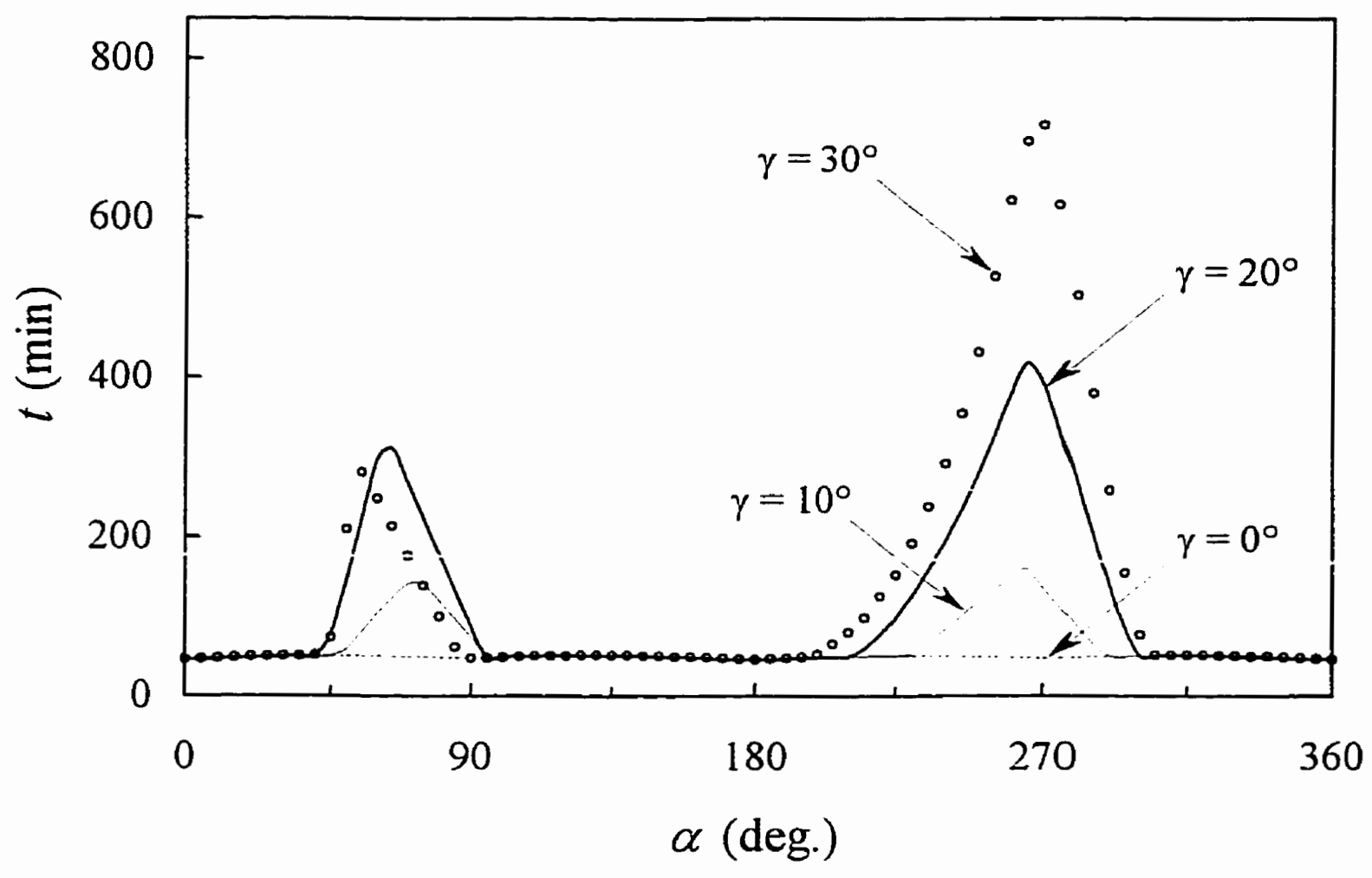

Figure 3.9 Machining time of plane surfaces at different inclinations. 


\section{CHAPTER 4}

\section{CONCLUSIONS}

In the finishing machining of $3 \mathrm{D}$ sculptured surfaces using ball-end milling, the machined surface is generated by non-horizontal and cross-feed cutter movements. These cutter movements result in much more complicated cut geometry, undeformed chip thickness distribution, and empirical chip-force relationships than horizontal cutter movements. An improved mechanistic cutting force model is presented in this work to deal with these complexities. Cut geometry is used to identify engaged area on the ballend mil!. It is established by boundary limits resulted from the semi-finished part surface, the slot surface left by the adjacent finishing tool path, and the non-horizontal cutter feed direction. Undeformed chip thickness for each engaged cutting element is obtained by identifying the radial difference between the trajectory of the cutting element and the surface left by the immediate previous revolution of the cutter. A comprehensive empirical chip-force relationship is employed to characterize non-horizontal cutting mechanics in $3 \mathrm{D}$ ball-end milling. The empirical model parameters are determined from measured average cutting forces of both horizontal and non-horizontal slot cuts. The present model together with the empirical parameters has been validated by the excellent correspondence between the predicted and the measured instantaneous cutting forces in $3 \mathrm{D}$ ball-erid milling.

From the simulation results of the integrated process planning method based on cutting force optimization, the following conclusions can be drawn. First, this method 
enables process planners to choose the most economical process to make the product. The combined consideration of maximum efficiency and minimum machining errors successfully determines the optimum feed direction. It has been shown that for a given $3 \mathrm{D}$ plane the total tool path length variation at different feed directions is very small. This shows that the tool path length should not be considered as the only criterion in process planning. On the other hand, the variation of maximum feed per tooth with respect to feed direction is obvious. The maximum feed per tooth $f_{\max }$ obtained from the machining handbook is not appropriate for every feed direction. At some feed directions, smaller chip load should be used to assure machining quality. These machining directions should be avoided in practice due to the low machining efficiency. Machining error is another consideration in process planning and should be as small as possible. Maximum step size interrelates tool path determination and maximum feedrate selection because it affects the total tool path length as well as cutting system deflections caused by cutting forces. Because tool path related step size and maximum feedrate are important components in determining cutting forces, concurrent optimization of tool path and feedrate is in fact optimization of cutting forces.

Another conclusion can be drawn from the simulated results is that the optimum cutter feed direction is not unique. For a given $3 \mathrm{D}$ surface, there often exist more than one optimum feed direction in which the feedrate is maximum and the machining error is minimum. Under this situation, in practice the feed direction should be chosen considering the convenience of tool access. Using this process planning method, the optimum feed direction can be selected on a scientific basis. High machining efficiency and machining quality can be achieved at the same time. 
The present work on 3D plane surface machining represents an important step toward true optimization of the finishing machining of sculptured surfaces using ball-end mills. Sculptured surfaces can be considered to be composed of numerous small 3D plane surfaces due to linear interpolation of tool paths of current Computer Numerical Control machine tools. It has been discovered that the optimum feed direction in $3 \mathrm{D}$ plane surface machining is often not unique but falls within an optimum range. This property greatly facilitates the linking of the linear tool paths for these small plane surface patches into a complicated tool path for a sculptured surface. Integrated process planning based on cutting force optimization for sculptured surface machining is the further work based on the present study. 


\section{APPENDIX}

\section{A. Determination of Cutter Contact Point $P_{0}\left(X_{0}, Y_{0}, Z_{0}\right)$}

The part coordinate system is defined first. With this part coordinate system, the expression of the 3D plane surface is available:

$$
A X+B Y+C Z+D=0
$$

where $\bar{n}=(A, B, C)$ is the normal vector of the $3 \mathrm{D}$ plane surface. The cutter contact point $\mathrm{P}_{0}\left(X_{0}, Y_{0}, Z_{0}\right)$ in the cutter coordinate system when $\alpha=0^{\circ}$ can be determined from the surface normal vector. As shown in Fig. A. 1, the cutter coordinate system is in the same orientation as the part coordinate system. $\varphi$ is the angle between the $z$ axis and the surface normal vector.

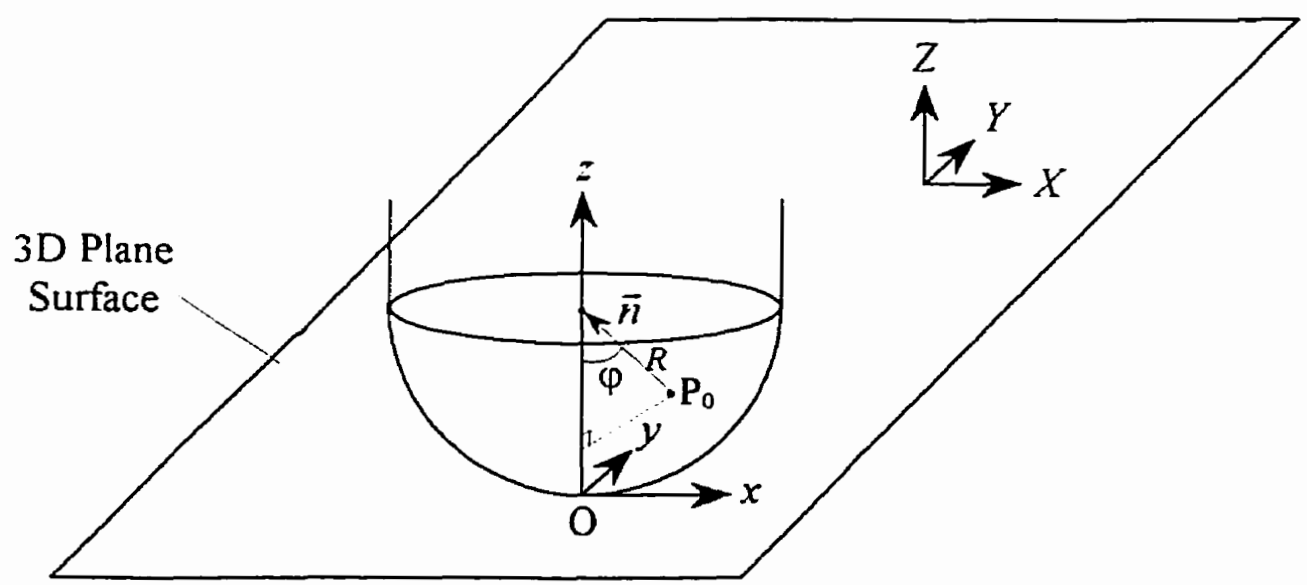

Figure A.1 Determination of cutter contact point in the cutter coordinate system. 
Then,

$$
\cos \varphi=\frac{\vec{n} \times \vec{e}_{z}}{|\vec{n}|\left|\vec{e}_{=}\right|}=\frac{C}{\sqrt{A^{2}+B^{2}+C^{2}}}
$$

where $\bar{e}_{z}$ is the unit vector in the $z$ direction.

It can be seen from Fig. A. 1 that

$$
Z_{0}=R-R \cos \varphi
$$

The 3D line that passes through the cutter contact point $\mathrm{P}_{0}$ and the ball centre $(0,0, R)$ of the cutter can be expressed as

$$
\frac{x}{A}=\frac{y}{B}=\frac{z-R}{C}
$$

As a result, the coordinates of the cutter contact point $\mathrm{P}_{0}$ in the cutter coordinate system when $\alpha=0^{\circ}$ are

$$
\begin{aligned}
& X_{0}=\frac{A}{C}\left(Z_{0}-R\right) \\
& Y_{0}=\frac{B}{C}\left(Z_{0}-R\right) \\
& Z_{0}=R-R \cos \varphi
\end{aligned}
$$




\section{B. Step Size Determination}

As mentioned in Section 3.2.2, after the coordinate system transformations, the $y$ coordinate dose not change. Therefore in $\triangle \mathrm{BP}_{0} \mathrm{E}$ in Fig. A.2, there exists:

$$
\cos \eta=\frac{\sqrt{R^{2}-y_{0}^{2}}}{R}
$$

Also,

$$
\begin{aligned}
& A D^{2}+C D^{2}=R^{2} \\
& h=R-C D \\
& A D=\frac{A B}{2}=\frac{s}{2 \cos \eta}
\end{aligned}
$$

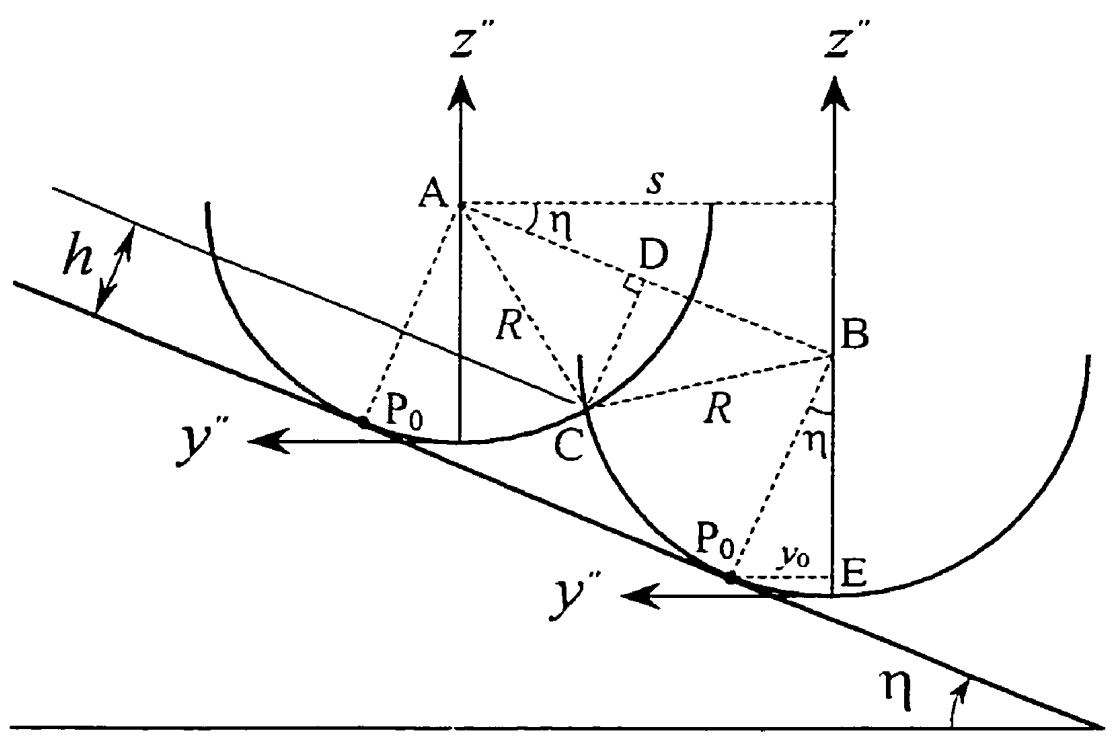

Figure A.2 Step size determination geometry. 
Substituting Eqs. (A.8) and (A.9) into Eq. (A.7), the expression for step size can be obtained:

$$
s=2 \cos \eta \sqrt{2 R h-h^{2}}
$$

\section{Limit Lines for Cutting System Deflections}

Given the surface tolerance value $\pm E$ and the $3 D$ plane surface normal vector $(A, B, C)$, the allowable cutting system deflections in the $X Y$ plane of the part coordinate system, $(\delta X, \delta Y, 0)$, can be obtained by using Eq. (3.10)

$$
\begin{aligned}
& \pm E=(\delta X, \delta Y, 0) \cdot\left(\frac{A}{\sqrt{A^{2}+B^{2}+C^{2}}}, \frac{B}{\sqrt{A^{2}+B^{2}+C^{2}}}, \frac{C}{\sqrt{A^{2}+B^{2}+C^{2}}}\right) \\
& A \delta X+B \delta Y \mp E \sqrt{A^{2}+B^{2}+C^{2}}=0
\end{aligned}
$$

Given surface tolerance value, $\pm 0.025 \mathrm{~mm}$, and the surface normal vector $(0.5,0.5,1)$, the upper and lower limit lines for the cutting system deflections can be established using Eq. (A.11)

$$
\begin{array}{ll}
\delta Y=-\delta X+0.0612 & \text { (the upper limit line) } \\
\delta Y=-\delta X-0.0612 & \text { (the lower limit line) }
\end{array}
$$




\section{REFERENCES}

Abrari, F., and Elbestawi, M. A., 1997, "Closed Form Formulation of Cutting Forces for Ball and Flat End Mills," International Journal of Machine Tools and Mamufacture, Vol. 37, pp. 17-27.

Bayoumi, A. E., Yucesan, G., and Kendall, L. A., 1994a, "An Analytic Mechanistic Cutting Force Model for Milling Operations: A Theory and Methodology," ASME Journal of Engineering for Industry, Vol. 116, pp. 324-330.

Bayoumi, A. E., Yucesan, G., and Kendall, L. A., 1994b, "An Analytic Mechanistic Cutting Force Model for Milling Operations: A Case Study of Helical Milling Operation," ASME Journal of Engineering for Industry, Vol. 1 16, pp. 331-339.

Boogert, R. ìi., Kais, H. j. j., and Van Hiouten, F. j. A. ìi., i 9990 , "Tooi Faths and Cutting Technology in Computer-Aided Process Planning," The International Journal of Advanced Mamufacturing Technology, Vol. I 1, pp. 186-197.

Budak, E., Altintas, Y., and Armarego, E. J. A., 1996, "Prediction of Milling Force Coefficients from Orthogonal Cutting Data," ASME Journal of Manufacturing Science and Engineering, Vol. 118, pp. 216-224.

DeVor, R. E., Kline, W. A., and Zdeblick, W. J., 1980, "A Mechanistic Model for the Force System in End Milling with Application to Machining Airframe Structures," Proceedings of the 8th North American Manufacturing Research Conference, pp. 297303, Rolla, Mossouri.

Dong, Z., Li, H., and Vickers, G.W., 1993, "Optimal Rough Machining of Sculptured Parts on a CNC Milling Machine," Journal of Engineering for Industry, Vol. 115, pp. $424-431$. 
Dragomatz, D., and Mann, S., 1997, “A Classified Bibliography of Literature on NC Milling Path Generation," Computer-Aided Design, Vol. 29, No. 3, pp. 239-247.

Ehmann, K. F., Kapoor, S. G., DeVor, R. E., and Lazoglu, I., 1997, "Machining Process Modeling: A Review," ASME Journal of Mamufacturing Science and Engineering, Vol. 119, pp. 655-663.

El Mounayri, H., Spence, A. D., and Elbestawi, M. A., 1998, "Milling Process Simulation - A General Solid Modeller Based Paradigm," ASME Journal of Manufacturing Science and Engineering, Vol. 120, pp. 213-221.

Feng, H. Y., and Menq, C. H., 1994a, "The Prediction of Cutting Forces in the BallEnd Milling Process - I. Model Formulation and Model Building Procedure," International Journal of Machine Tools and Mamufacture, Vol. 34, pp. 697-710.

Feng, H. Y., and Menq, C. H., 1994b, "The Prediction of Cutting Forces in the BallEnd Milling Process - II. Cut Geometry Analysis and Model Verification," International Journal of Machine Tools and Mamufacture, Vol. 34, pp. 711-720.

Feng, H. Y., and Menq, C. H., I996, “A Flexible Ball-End Milling System Model for Cutting Force and Machining Error Prediction," ASME Journal of Mamufacturing Science and Engineering, Vol. 118, pp. 46l-469.

Groover, M.P., 1996, Fundamentals of Modern Mamufacturing, Prentice-Hall, Upper Saddle River, New Jersey.

Huang, Y. and Oliver, J. H., 1994, "Non-Constant Parameter NC Tool Path Generation on Sculptured Surfaces," The International Journal of Advanced Manufacturing Technology, Vol. 9, 28 1-290.

Hwang, J. S., 1992, "Interference-free Tool-Path Generation in the NC Machining of Parametric Compound Surfaces," Computer-Aided Design, Vol. 24, No. 12, pp. 667-676. 
Hwang, J. S. and Chang, Tien-Chien, 1998, "Three-axis Machining of Compound Surfaces Using Flat and Filleted Endmills," Computer-Aided Design, Vol. 30, No. 8, pp. 641-647.

Kline, W. A., DeVor, R. E., and Lindberg, J. R, 1982a, "The Prediction of Cutting Forces in End Milling with Application to Cornering Cuts," International Journal of Machine Tool Design and Research, Vol. 22, pp. 7-22.

Kline, W. A., DeVor, R. E., and Shareef, I. A., 1982b, "The Prediction of Surface Accuracy in End Milling," ASME Journal of Engineering for Industry, Vol. 104, pp. 272-278.

Kline, W. A., and DeVor, R. E., 1983, "The Effect of Runout on Cutting Geometry and Forces in End Milling," International Journal of Machine Tool Design and Research, Vol 23, nn 123-140

Lim, E. M. and Menq, C. H., 1997, "Error Compensation for Sculptured Surface Productions by the Application of Control-Surface Strategy Using Predicted Machining Errors," ASME Journal of Manufacturing Science and Engineering, Vol. 119, pp. 402409.

Lim, E. M., Menq, C. H., 1997, "Integrated Planning for Precision Machining of Complex Surfaces. Part 1: Cutting-Path and Feedrate Optimization," International Journal of Machine Tools and Marnifacture, Vol. 37, No. 1, pp. 61-75.

Lim, E. M., Menq, C. H., and Yen, D. W., 1997, "Integrated Planning for Precision Machining of Complex Surfaces. Part 2: Application to the Machining of a Turbine Blade Die," International Journal of Machine Tools and Mamufacture, Vol. 37, No. 1, pp. 7791.

Lin, R. S. and Koren, Y., 1996, "Efficient Tool-Path Planning for Machining FreeForm Surfaces," Journal of Engineering for Industry, Vol. I 18, pp. 20-28. 
Marshall, S. and Griffiths, J. G., 1994, "A New Cutter-Path Topology for Milling Machines," Computer-Aided Design, Vol. 26, No. 3, pp. 204-2 14.

Melkote, S. N., and Endres, W. J., 1998, "The Importance of Including Size Effect When Modeling Slot Milling," ASME Journal of Mamufacturing Science and Engineering, Vol. 120, pp. 68-75.

Nakayama, K., and Tamura, K., 1968, "Size Effect in Metal-Cutting Force," ASME Journal of Engineering for Industry, Vol. 90, pp. 119-126.

Park, S., Jun, Y. T., Lee, C. W., and Yang, M. Y., 1993, "Determining the Cutting Conditions for Sculptured Surface Machining," The International Journal of Advanced Mamufacturing Technology, Vol. 8, pp. 61-70.

Sim. C.. and Yang. M., 1993. "The Prediction of the Cutting Force in Ball-End Milling with a Flexible Cutter," International Journal of Machine Tools and Manufacture, Vol. 33, pp. 267-284.

Smith, S., and Tlusty, J., 1991, "An Overview of Modeling and Simulation of the Milling Process," ASME Journal of Engineering for Industry, Vol. 113, pp. 169-175.

Society of Manufacturing Engineers, 1983, Tool and Mamufacturing Engineers Handbook, Vol. I: Machining, Fourth Edition, Dearborn, Michigan.

Suh, Y. S., and Lee, K., 1990, "NC Milling Tool Path Generation for Arbitrary Pockets Defined by Sculptured Surfaces," Computer-Aided Design, Vol. 22, No. 5, pp. 273-284.

Suresh, K. and Yang, D. C. H., 1994, "Constant Scallop-height Machining of Freeform Surfaces," Journal of Engineering for Industry, Vol. 1 16, pp. 253-259. 
Sutherland, J. W., and DeVor, R. E., 1986, “ An improved Method for Cutting Force and Surface Error Prediction in Flexible End Milling Systems," ASME Journal of Engineering for Industry, Vol. 108, pp. 269-279.

Veeramani, D., and Gau, Y. -S., 1998, "Models for Tool-Path Plan Optimization in Patch-by-Patch Machining," International Joumal of Production Research, Vol. 36, No. 6, pp. 1633-1651.

Wang, J.-J. J., and Liang, S. Y., 1996, "Chip Load Kinematics in Milling with Radial Cutter Runout," ASME Journal of Engineering for Industry, Vol. 118, pp. $111-116$.

Yang, M., and Park, H., 199 I, "The Prediction of Cutting Force in Ball-End Milling," International Journal of Machine Tools and Mamufacture, Vol. 31, pp. 45-54.

Yellowley. I., 1985, "Observations on the Mean Values of Forces, Torque and Specific Power in the Peripheral Milling Process," International Journal of Machine Tool Design and Research, Vol. 25, pp. 337-346.

Yucesan, G., and Altintas, Y., 1996, "Prediction of Ball End Milling Forces," ASME Journal of Engineering for Industry, Vol. 118, pp. 95-103.

Zheng, L., and Liang, S. Y., 1997, "Identification of Cutter Axis Tilt in End Milling," ASME Journal of Mamufacturing Science and Engineering, Vol. 119, pp. 178-185.

Zheng, L., Liang, S. Y., and Melkote, S. N., I998, "Angle Domain Analytical Model for End Milling Forces," ASME Journal of Mamufacturing Science and Engineering, Vol. 120, pp. 252-258. 